University of Louisville

ThinkIR: The University of Louisville's Institutional Repository

Electronic Theses and Dissertations

8-2013

\title{
An historical perspective on labor productivity in the modern era.
}

Peter Brem 1979-

University of Louisville

Follow this and additional works at: https://ir.library.louisville.edu/etd

\section{Recommended Citation}

Brem, Peter 1979-, "An historical perspective on labor productivity in the modern era." (2013). Electronic Theses and Dissertations. Paper 147.

https://doi.org/10.18297/etd/147

This Doctoral Dissertation is brought to you for free and open access by ThinkIR: The University of Louisville's Institutional Repository. It has been accepted for inclusion in Electronic Theses and Dissertations by an authorized administrator of ThinkIR: The University of Louisville's Institutional Repository. This title appears here courtesy of the author, who has retained all other copyrights. For more information, please contact thinkir@louisville.edu. 


\title{
AN HISTORICAL PERSPECTIVE ON LABOR PRODUCTIVITY IN THE MODERN ERA
}

\author{
By \\ Peter Brem \\ Diplom Kaufmann, HFH Hamburg, 2007 \\ Master of Science Industrial Engineering, University of Louisville, 2010
}

\begin{abstract}
A Dissertation
Submitted to the Faculty of the

J.B. Speed School of Engineering of the University of Louisville in partial fulfillment of the requirements for the degree of

Doctor of Philosophy

Department of Industrial Engineering

University of Louisville

Louisville, Kentucky, USA
\end{abstract}

August 2013 
Copyright 2013 by Peter Brem

All rights reserved 



\title{
AN HISTORICAL PERSPECTIVE ON LABOR PRODUCTIVITY IN THE MODERN ERA
}

\author{
By \\ Peter Brem \\ Diplom Kaufmann, HFH Hamburg, 2007 \\ Master of Science Industrial Engineering, University of Louisville, 2010
}

A Dissertation Approved on

July 23, 2013

by the following Dissertation Committee:

Dr. William E. Biles (Dissertation Director)

Dr. Gail W. DePuy

Dr. Gerald W. Evans

Dr. Rammohan K. Ragade

- ii - 
ACKNOWLEDGMENTS

Professor Dr. William E. Biles 


\title{
ABSTRACT \\ AN HISTORICAL PERSPECTIVE ON LABOR PRODUCTIVITY IN THE MODERN ERA
}

\author{
Peter Brem
}

July 23,2013

Changing framework conditions and constantly changing influences complicate the existence of the companies that are in competition with one another. To be able to guarantee the sustainable success of a company, it is decisive for the market participant to react to the prevailing challenges in a productive and efficient way. Despite various individual approaches currently there is no uniform master plan that represents the topic of the labor productivity in the context of modern requirements.

It is the aim of this dissertation to analyze the approaches on labor productivity on the most important protagonists which in the history. The historic description is done based on the pioneers of labor productivity and includes Adam Smith, Karl Marx, Frederick W. Taylor, Henri Fayol, Chester I. Barnard and Henry Ford. By analyzing the Post-Fordism Era, the biggest influence factors on labor productivity - Toyota Production System and Information and Communication Technic - will be also taken into account. 
Special emphasis will be placed on the key factors of labor productivity. This dissertation provides a literature review of the above mentioned pioneers and their approaches an ideas on labor productivity. Based on the literature review and the additional research work the dissertation will provide a comparison of the key factors to detect common and different approaches.

After identifying all important key factors of labor productivity from the selected pioneers, the thesis will investigate about the effects on labor wages. A necessary analyze of the development of labor wages and the development of labor productivity will be done. The analyze should compare these two developments. Depending on the result potential reasons for the effect of the development should be investigate. Considering this comparison and the result possible suggestions for the feature development will arise.

Key words:

Labor Productivity, Labor wages, Adam Smith, Karl Marx, Frederick W. Taylor, Henri Fayol, Chester I. Barnard, Henry Ford, Fordism, Post-Fordism, Toyota Production System, Information and Communication Technic, 


\section{TABLE OF CONTENTS}

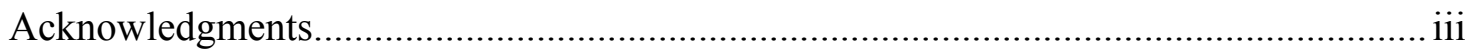

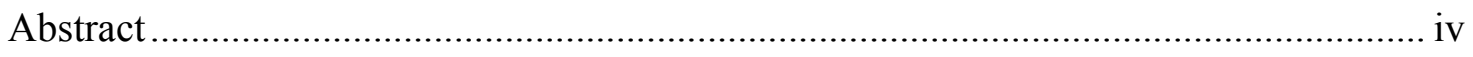

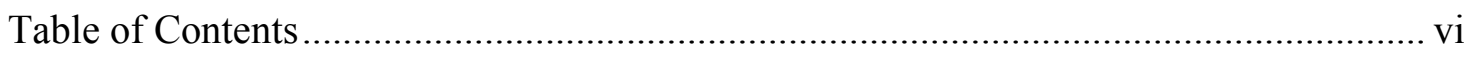

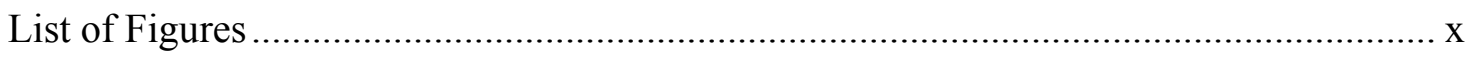

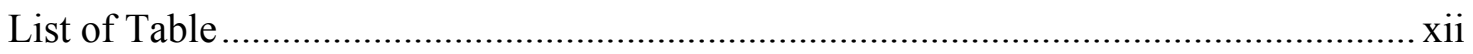

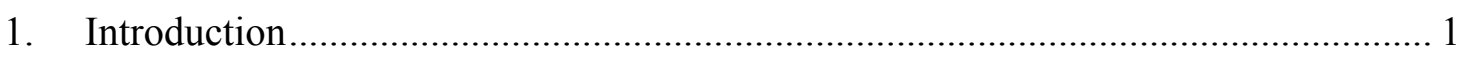

$1.1 \quad$ Productivity as Modern Challenge ............................................................. 1

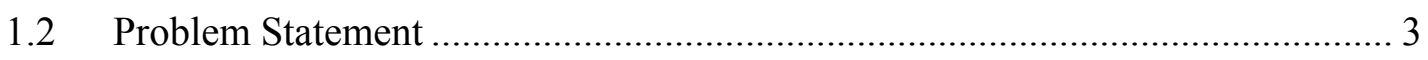

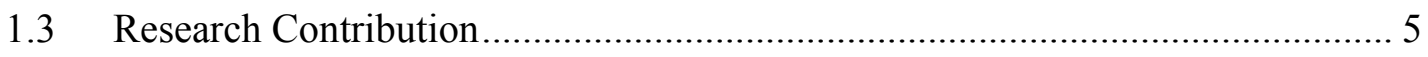

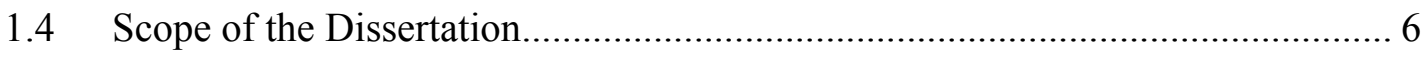

2. literatur Review - Evaluation of Historical Developments ....................................... 7

$2.1 \quad$ Adam Smith - Wealth of a Nation (1776) ….................................................... 7

2.1.1 Theory of Smith`s Labor Productivity .................................................. 7

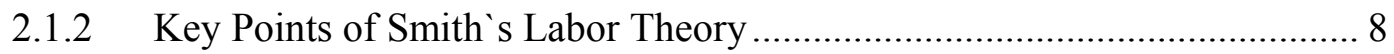

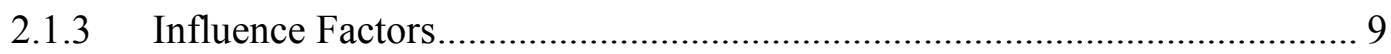

2.1.4 Critical consideration of Smiths Labor Productivity ............................... 10

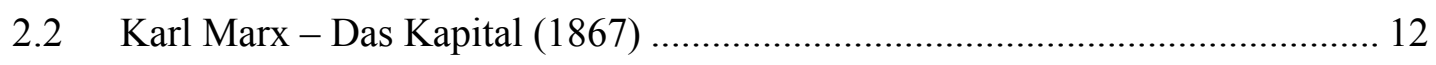

2.2.1 Theory of Marx`s Labor Productivity.................................................. 12

2.2.2 Key Points of Marx`s Labor Theory .................................................... 13

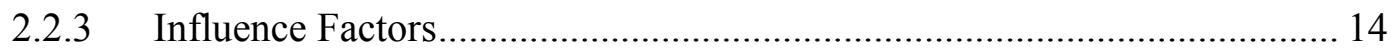

2.2.4 Critical consideration of Marx`s Labor Productivity ............................... 15

2.3 Frederick W. Taylor - The Principles of Scientific Management (1911) .......... 17 
2.3.1 Theory of Taylor`s Labor Productivity ................................................... 17

2.3.2 Key Points of Taylor`s Labor Theory ….................................................... 18

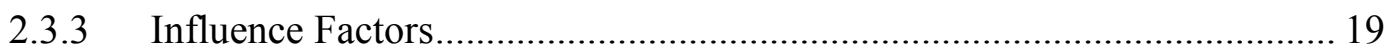

2.3.4 Critical consideration of Taylor`s Labor Productivity ................................ 20

2.4 Henri Fayol - General and Industrial Management (1916) ............................... 23

2.4.1 Theory of Fayol `s Labor Productivity .................................................... 23

2.4.2 Key Points of Fayol `s Labor Theory ....................................................... 24

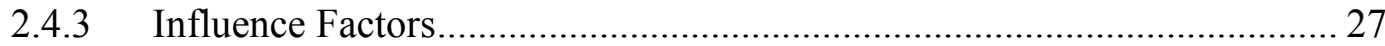

2.4.4 Critical consideration of Taylor `s Labor Productivity .............................. 28

2.5 Chester I Barnard - Functions of the Executive (1938) …................................. 30

2.5.1 Theory of Barnard `s Labor Productivity.................................................. 30

2.5.2 Key Points of Barnard `s Labor Theory ................................................... 30

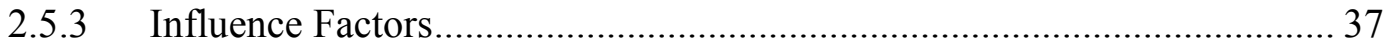

2.5.4 Critical consideration of Barnard `s Labor Productivity............................. 38

2.6 Fordism - Henry Ford - My Life and Work (1922) ........................................ 40

2.6.1 Fordism Formation and Development ...................................................... 40

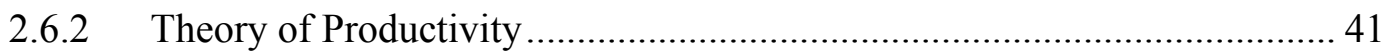

2.6.3 Key Points of Ford's Labor Productivity ................................................ 42

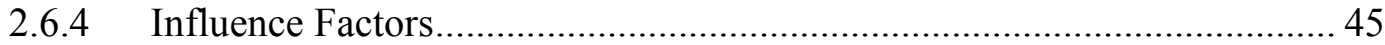

2.6.5 Critical consideration of Fordism in Relation of Labor Productivity ......... 46

3. Modern Productivity Systems in the Post Fordism................................................... 49

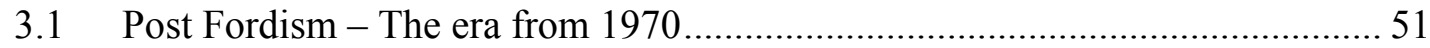

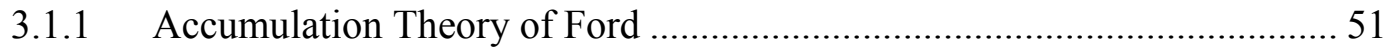

3.1.2 Formation and Development of the Prost - Fordism................................ 52 
3.2 Implementation of New Productivity Systems in the modern Era 55

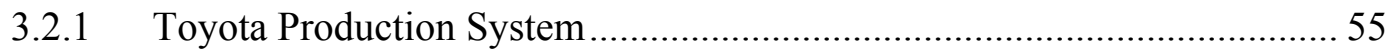

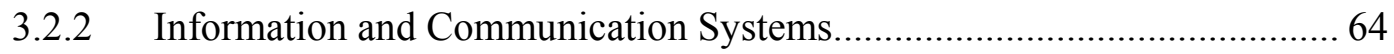

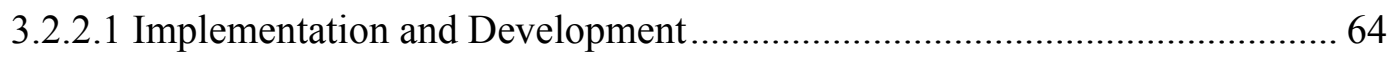

3.2.2.2 Effects on the Modern Labor Productivity ................................................... 65

3.2.2.3 Implementation of Information and Communication Technology .............. 66

3.2.2.4 The Paradox of Productivity of the ICT …….............................................. 70

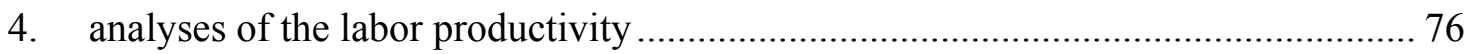

4.1 The approaches of the different pioneers ..................................................... 76

4.2 The development of productivity in comparison with labor wages ................... 82

5. Investigation of causes for this asymmetrical development ................................. 91

5.1 Selected example of a potential internal cause ............................................... 92

5.2 Selected example of an potential external cause ............................................... 93

5.3 Impacts on consequences for development of the wealth ............................... 94

6. A Prescriptive Model for Productivity Allocation........................................................... 95

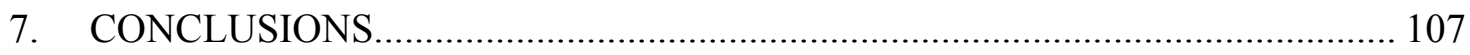

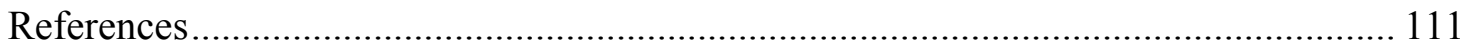

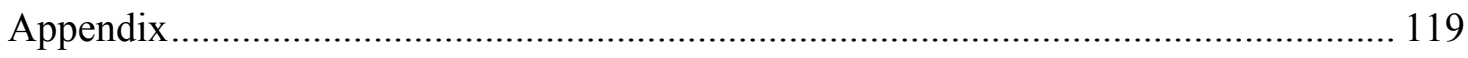

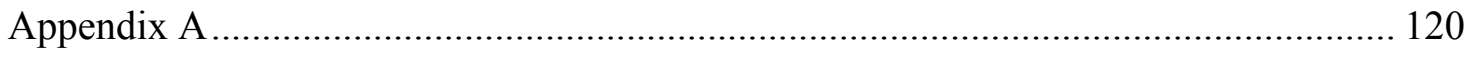

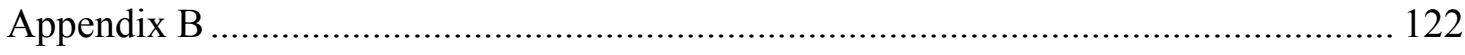

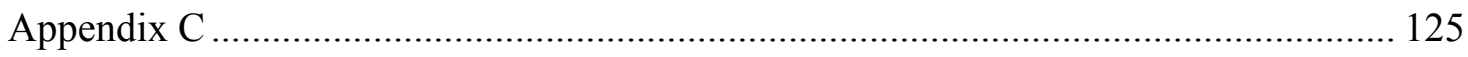

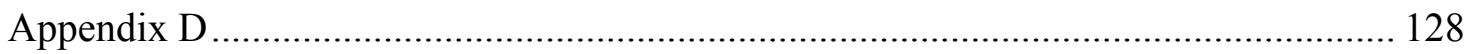

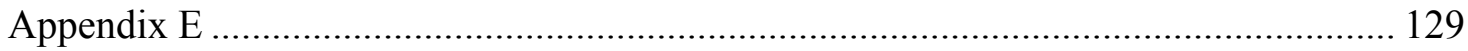

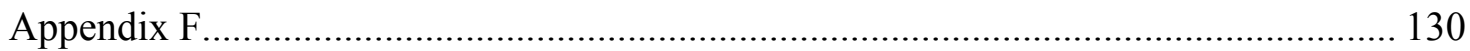




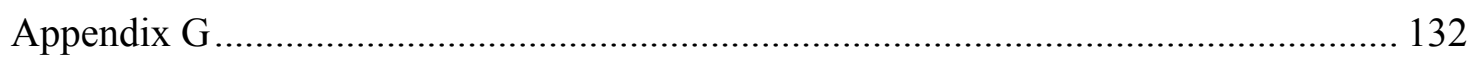

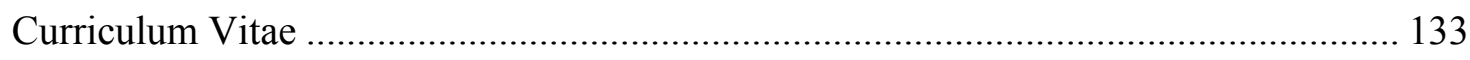




\section{LIST OF FIGURES}

Figure 1 Mutual Relation in Taylor's Labor-Productivity-Theory ................................ 17

Figure 2 Structure of Barnard `s Labor-Productivity-Theory ....................................... 31

Figure 3 Fluctuation and Discharge Rate after Introduction of the Ford's \$5-Day.......... 47

Figure 4 Output per Hour Employed Person 1950-2010 (Index: 1950=100) ................... 54

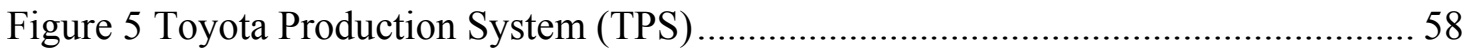

Figure 6 Main Goal of Toyota Production System .............................................................5

Figure 7 Integrated Elements of the Information and Communication Technology 66

Figure 8 Labor Productivity per Hour Worked Converted to 2011 Price Level

(Index: 1991=100)

Figure 9 ICT capital services per hour worked, total Industries 1980-2007 68

Figure 10 ICT Capital Share in Total Capital 1980 - 2007. 69

Figure 11 ICT Capital Services per Hour Worked, 1995 Reference 1980 - 2007. 73

Figure 12 The $\Delta$-Scissor $1980-2007$ 74

Figure 13 The Influence Giants of Modern Labor Productivity 76

Figure 14 Comparison rOPH and rAAC 1950 - 2011 85

.Figure $15 \Delta$ between Comparison rOPH and rAAC 1950 - 2011 86

Figure 16 First 20 Years Results rOPH and rAAC 1950 - 1969 88

Figure 17 Results rOPH and rAAC $1970-2011$ 90

Figure 18 Comparison original rOPH, rAAC and CPI 1970-2011. 96

Figure 19 Development rAAC (1/3 allocation) 1970-2011 100

Figure 20 Development CPI (1/3 allocation) 1970-2011 100 
Figure 21 Comparison Original and Allocated Data rAAC 1970-2011,

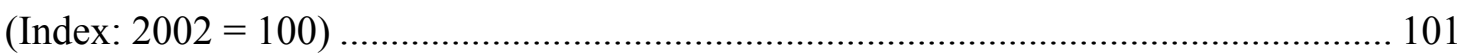

Figure 22 Comparison Original and Allocated Data CPI 1970-2011,

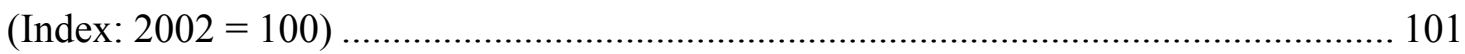

Figure 23 Development rAAC (1/4 allocation) 1970-2011 ........................................... 104

Figure 24 Development CPI (1/4 allocation) 1970-2011 ............................................. 104

Figure 25 Comparison Original, 1/3 Allocated and 1/4 Allocated rAAC 1970 - 2011 .. 105

Figure 26 Comparison Original, 1/3 Allocated and 1/4 Allocated CPI 1970 - 2011 _... 105 


\section{LIST OF TABLE}

Table 1 Abbreviations Explanation of selected industries USA ...................................... 73

Table 2 Key factors on labor productivity - Selected pioneers........................................ 77

Table 3 Analyze of the approaches in labor productivity - Selected pioneers ................. 78

Table 4 Analyze rOPH with rAAC 1950 - 2011 Part I (Index 2002) ............................... 83

Table 5 Analyze rOPH with rAAC 1950 - 2011 Part II (Index 2002)............................... 84

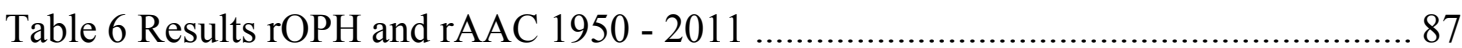

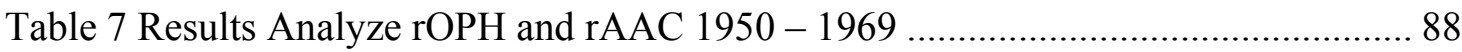

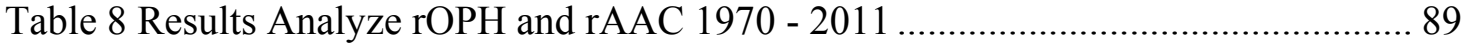

Table 9 Results Analyze rOPH and rAAC 2000 -2009 .................................................... 89

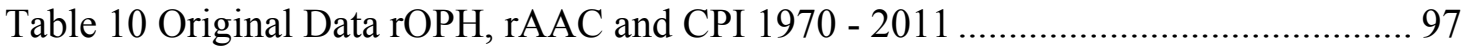

Table 11 Allocated Data 1/3 Participation: OPH, rAAC and CPI $1970-2011 \ldots \ldots \ldots \ldots \ldots . . .99$

Table 12 Allocated Data 1/4 Participation: OPH, rAAC and CPI 1970 - 2011 _............ 103 


\section{INTRODUCTION}

\subsection{Productivity as Modern Challenge}

The Massachusetts Institute of Technology Commission on Industrial Productivity declared in its study "Made in America" already at the end of the 1990s that there is a looming problem with respect to productivity in America and that this is not only due to high costs of capital and organizational weaknesses. (Mehta 1989) Above all, this becomes obvious according to the studies of the U.S. Bureau of Labor Statistics when comparing the development of productivity of various countries. (U.S. Bureau of Labor Statistics)

Each company both on the national and international market must face competition. To be sustainably successful it is decisive to be efficient and productive with respect to the manufacturing process, the administration, in all the operative and nonoperative business units and as a whole in the entire organization. The key element is sustainability. Any long-term success of a company can only be achieved by implementing sustainable productivity and efficiency in each of the individual steps. There is no particular relevance, if the company works in the area of the manufacturing or the service industry.

Deviations do only exist in the consumer segment in the area of lifestyle or in tactical management decisions. In these cases, productive processes are abandoned for 
short periods of time to achieve special results and competitive advantages. Such a deviation is the absolute exemption for the following reason: as a basic rule, long-term success may only go along with strategic orientation and therefore with the optimum sustainable design of all the departments of the company.

For any company intending to adapt to future needs and intending to meet the modern challenges, there must be one simple question: Quo Vadis - Where are you going to? 


\subsection{Problem Statement}

The change of the - internal and external - influences is an inevitable cause for the further development of the approaches on productivity. It was in the two decades before and especially at the beginning of the 21 st century that most of the changes of the market environment necessitated a strategic orientation in the competitive context.

Globally operating companies like Ford or Volkswagen are subject to certain conditions and must permanently compete with the competition for market shares and sales markets. The companies are forced to permanently optimize and improve the manufacturing processes and structures to be able to succeed in the prevailing competitive struggle.

However, this competitive pressure not only affects the large corporations. Productive manufacturing processes and optimized procedures are a big advantage for all companies, regardless of size or market position. Additionally, the economic sector or environment of the company is not decisive. All business entities are affected - service, industry and even governmental institutions. All economic parties are forced to act in the market environment in an efficient and productive way.

The foundation of any business success and sustainable development of an enterprise is not least but especially due to the employee. Labor productivity is next to the productivity mainly from work or work force, the basis of every single employee in the 
company. Here wages and the projected salary play a crucial role. The question arises why then $1 \%$ of the American population has nearly about $50 \%$ of U.S. assets. (Norton and Ariely 2011) But this is not solely an American phenomenon. According to various studies it can be seen a similar asymmetric distribution of wealth in Germany. 


\subsection{Research Contribution}

The dissertation is supposed to represent the historical development of labor productivity. It is the aim of this dissertation is to identify the key factors of several selected pioneers in the area of labor productivity.

Out of these results similar approaches should be identified. In a second step it will be important to analyze the development of the labor productivity in comparison with the development of the real labor wages in the same time frame. Considering the result of the analyze impact factors for the specific development shell be recognized. According to this information there could be information and suggestion for the development of labor wages and labor productivity in the future. 


\subsection{Scope of the Dissertation}

This dissertation is structured to start with the introduction and the description of the necessity of productivity and to include the literature research in chapter 2 . This part of the dissertation shall include an analyze of the approaches on labor productivity of the individual eras on the basis of the great pioneers. The individual eras result from Adam Smith, Karl Marx, Frederick W. Taylor, Henri Fayol, Chester I. Barnard, Henry Ford and the period after Ford during Post-Fordism. The main focus is on the individual approaches that were implemented in the past.

On this basis, chapter 3 will investigate the productivity approaches in the era of Post-Fordism because of the prevailing changes and/or the changes that have already taken place since the year 1970.

Chapter 4 will use the knowledge that was gained in the previous chapters to compare the key factors and realize if there are similar approaches over the last 250 years. Out of this result it will be important to compare the development of the labor wages considering the labor productivity since the era of Post-Fordism. 


\section{LITERATUR REVIEW - EVALUATION OF HISTORICAL DEVELOPMENTS}

\subsection{Adam Smith - Wealth of a Nation (1776)}

\subsubsection{Theory of Smith`s Labor Productivity}

Smith`s basic module of labor productivity is largely based on labor division. Therefore, there is his basic definition of An Inquiry into the Nature and Causes of the Wealth of Nations of his first book titled: Of the causes of improvement in the productive powers of labour, and of the order according to which its produce is naturally distributed among the different ranks of the people:
(1) Labor Division
(3) Expertise
(2) Skill
(4) Experience

This is the basis for a basic and positive productiveness. (Smith 2009)

Adam Smith emphasizes his theory on productivity by giving the example of manufacturing pins. If a worker would start to manufacture pins on his own - under the condition that he would do it for the first time and that there would not yet be any learning curve - and he additionally would do all working steps on his own, this single 
worker would - according to Smith - not be able to manufacture 20 complete pins a day. On the other hand, if there is a technical separation or even a specialization of the different work steps, it can be seen that a small staff of approximately 10 workers can manage to manufacture up to 48.000 pins a day. (Smith 2009) This observation alone emphasizes Smith's theory on the increased productivity by the labor division that was publicized by him.

Smith writes and explains that as soon as a separation of the individual work steps of the production flow is possible in an industry, it results in an increased productivity and this on the other hand results in a diversification and the development of different professions and industries, since separate processing steps result in a professional specialization. (Smith 2009)

\subsubsection{Key Points of Smith`s Labor Theory}

According to Smith, the improvement of the labor productivity while using the same manpower is based solely on the division of labor. It is based on three different factors: (Smith 2009)

(1) The skill of the individual worker completing the task

(2) The avoidance of waste of time when changing the individual tasks

(3) The use of machines that are facilitating the individual work steps, shortening the working hours and additionally enabling the workers to complete the work of many workers alone 
These key points of Smith's theory of labor productivity can easily be seen as a basic approach of the first economic rationalization. His factors basically represent the modern approach of process optimization.

\section{(1) Specialization \\ (2) Economy of Time / Avoidance of Waste of Time}

(3) Using Technological Progress

\subsubsection{Influence Factors}

In addition to the key factors and key points that are able to control the productivity of work there is another influencing factor that is controlling - and sometimes even limiting - the productivity. Smith identified the particular geographical location / the geographical environment to be of influence. Smith talks in his third chapter The size of the market - a limit to the division of labour about a decisive influence with respect to the geographical environment: a natural limitation of the growth of productivity. Bartering is identified as the cause of the labor division. This growth of productivity may be limited - or even prevented - automatically because of the market size. (Smith 2009)

According to Smith's theory the increase in productivity is based on labor division while simultaneously taking into account the key factors and it is triggered by the natural bartering of individual people. Therefore, the increase in productivity leads to the natural 
situation of supply and demand. But influencing it is possible, if the supply side or the demand side is disrupted by influencing factors, e.g. the geographical location.

Smith mentions an example of a village located in the Scottish Highlands. In the 18th century, the inhabitants of remote settlements and towns were responsible for all their bread and butter. The necessity to be farmer, baker and brewer at the same time is based on the fact that due to missing structures and the limited size of settlements the complete self-sufficiency had to be guaranteed. (Smith 2009)

Therefore Smith states that it was not possible to accomplish labor division to increase productivity. The balance of supply and demand cannot be achieved, because both factors are not present to such an extent in such a geographical environment. The exchange of goods and the - according to Smith - resulting increase in productivity due to labor division is not possible in a geographically limited area.

\subsubsection{Critical consideration of Smiths Labor Productivity}

Without a doubt, Adam Smith's approaches to the productivity of work may be considered to be trend-setting, especially if the circumstances and situation of labor and production procedures of his time are made evident. Additionally it may be assumed that Smith's theory is an important contribution to the start of the industrial revolution since the middle of the 18th and the beginning of the 19th century.

Despite the aspects resulting from the realization of Smith's approach for the industrial revolution and possibly for the increased wealth of individuals the important 
aspect of labor division can and must be critically observed. Smith's idea that the specialization of the individual results in an improvement of the individual and a simultaneous personal development in the daily workday may have a moral justification. (Smith 2009) Nevertheless, there is great danger that it is precisely because of this specialization and the respective labor division and the repetitive tasks that the occurring monotony and the lack of intellectual demand are causes for the dissatisfaction and the unhappiness of the working population. Without a doubt, Smith plays a leading role for the consideration of productive elements in the working process and each and every modern criticism must be considered in terms of the productive circumstances. Smith's contribution can be compared with Darwin's contributions in the field of biology or Newton's contributions in the field of physics. (Butler 2001) It can be clearly seen that Smith's insights and methods - despite all critical aspects of his theory - could very well have positive effects and consequences for all economic parties concerned. 


\subsection{Karl Marx - Das Kapital (1867)}

\subsubsection{Theory of Marx`s Labor Productivity}

Marx defined the labor productivity as:

The increase of labor productivity is said to be a change of the working process that reduces the working time of the society necessary for the production of a product. Therefore, less work is needed to produce a bigger amount of practical value. (Marx 1867)

Furthermore, he limits his statement by adding the added value he had developed:

Only such a worker is productive that creates added value for the capitalist or that is used for the self-exploitation of the assets.(Marx 1867)

Additionally, Marx states that with regard to productive work not only the relation of work and efficiency, but also the social integration and the conditions of the integration of the production processes must be considered. Therefore, Marx concludes:

To be a productive worker is not luck, but bad luck (Marx 1867)

Marx equates the natural value of work with the necessity to produce the amount of provisions the worker needs to survive. (Marx 1867) Marx says that all work that exceeds this equilibrium is the so-called added value and this added value must be 
divided into the absolute added value and the relative added value.(Marx 1867) The absolute added value basically is the work of the workers to earn their wages. The worker is not using his manpower to work for himself, but he makes his manpower available for an employer. Marx calls it the formal submission of work under the assets. The submission of the worker (absolute added value) is a necessity for the development / production of the added value and this is complemented by the rationalization of the actual working steps (relative added value). According to Marx, a revolution of the working processes is taking place. (Marx 1867)

According to Marx, the labor productivity is achieved in two different ways. On the one hand, there is the absolute added value, and on the other hand, there is the relative added value. Therefore, the productivity of the work would be the worker himself as well as the production conditions and the working conditions that are created by the employer.

\subsubsection{Key Points of Marx`s Labor Theory}

Marx defines the added value by using three different influencing factors having a direct impact, depending on their respective situation-specific characteristics that are either constant or variable. Important influencing factors are:
(1) Duration of the Working Day
(2) Quantity of Work
(3) The Normal Intensity of the Work 
These key points are decisive factors for a specific workload in a specific time. (Marx 1867) Therefore, a change of the productivity of the work can only be achieved by optimizing the work processes. Only this ensures reduced working hours for the production of a certain amount of products. This means that using a reduced amount of input can result in an increased output. (Marx 1867)

\subsubsection{Influence Factors}

Marx mentions a number of influencing factors having direct impact on the productivity of the work in general.

The productivity of work is determined by various factors, amongst others there is the average skill of the worker, the level of development of science, and the technological applicability, the social combination of the production process, the extent and the capacity of the means of production and the natural conditions. (Marx 1867)

Marx emphasizes the existing natural conditions to be one of the most influential factors on the manifestation of labor productivity. Additionally, he identifies two classes: the first class is based on the natural wealth like soil fertility and waters rich in fish; the second class is based on the natural resources and raw materials. A fundamental factor for the development of society and the resulting labor productivity always is the availability of soil fertility. (Marx 1867)

In advanced cultures, the additional need for natural resources is decisive. With respect to this topic, Marx writes that there is low labor productivity mainly in the first 
stages of society. However, the needs that are arising out of the increased labor productivity are similarly less developed, and this is partially due to the fact that there is no strong mutual interdependence. In this context, Marx mentions the added value that turns into a condition of existence for the fellow human beings. (Marx 1867)

According to Marx, besides the classic influencing factors for the labor productivity - e.g. skill and technical change by using machines - first and foremost it is the natural prevailing circumstances and social developments that do influence the productivity of the work.

\subsubsection{Critical consideration of Marx`s Labor Productivity}

The analyze of Marx's labor productivity should only refer to the aspects of work and productivity. The objective of this part of the paper is not to evaluate the complete works.

To be able to treat and discuss this aspect of Marx's "Capital" it is necessary to understand the criteria that were used by Marx to distinguish work that is productive from work that is not productive. Marx declares that all work creating added value is productive. Any work that is creating no added value is not productive.

It is no longer sufficient only to produce. Added value must be produced. Only such a worker is productive that creates added value for the capitalist or that is used for the selfexploitation of the assets.(Marx 1867) 
On the other hand, the added value is such a kind of work done by the worker that is achieved beyond the work that is necessary for securing his livelihood. (Marx 1867) Therefore, Marx simply equals the absolute added value to be the basis of the prolonged working hours, because this added value exceeds the work that is necessary for securing one's livelihood. (Marx 1867) From this perspective, Marx derives the theory that each and every added value is a capitalization of the worker and therefore he is effectively bowing down to the assets.

Since according to Marx the absolute added value always is a prerequisite for the development of the relative added value, it is automatically assumed that there is a bowing down to the productive work. (Marx 1867) Marx calls this the voluntary slave labor (Marx 1867) Since each and every worker gives his working time and therefore his value to the product. This is always done in terms of the personal and productive working method. (Marx 1867)

According to Marx, basically an increase in productivity only can be achieved in two ways:

- Change of the production process to generate a higher output; e.g. by using machines

- Each and every work is done beyond the scope that is necessary for securing one's livelihood.

Therefore, Marx concludes: With each additional cooperative character of the working process it is necessary that the concept of productive work and its supporter the productive worker - is extended. (Marx 1867) 


\subsection{Frederick W. Taylor - The Principles of Scientific Management}

(1911)

\subsubsection{Theory of Taylor`s Labor Productivity}

The principal object of management should be to secure the maximum prosperity for the employer, coupled with the maximum prosperity for each employee. (Taylor 1998)

This quotation represents the work of Frederick Winslow Taylor. At this point the aspects and perspective of Taylor's theories and thoughts are negligible. The aim of his activities and analyses was the added value and the benefit of the whole system that was resulting from the completeness of the work process consisting of various factors.

Taylor's theory of labor productivity was based on both involved parties - the employees and the employers - both of which are somehow interconnected in a mutual relationship with one another. (Taylor 2004)

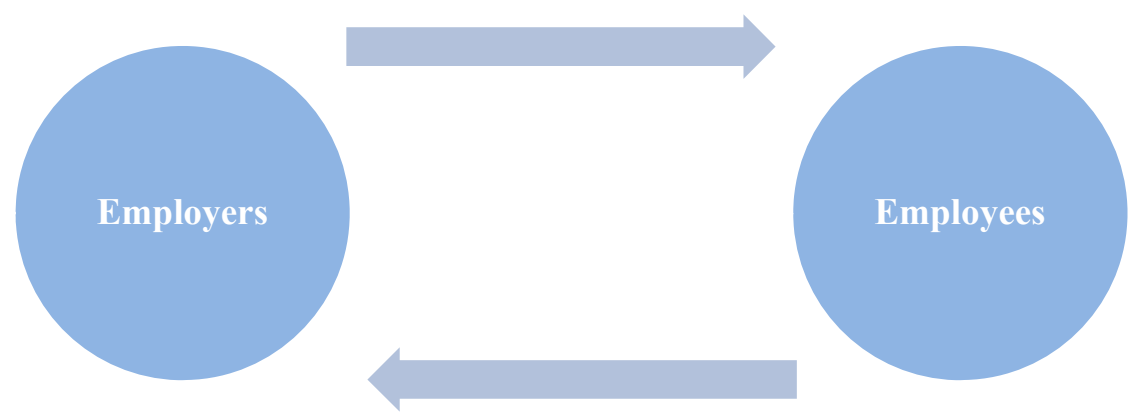

Figure 1 Mutual Relation in Taylor's Labor-Productivity-Theory 
Besides taking into account the employers and employees that can only mutually have a positive influence on labor productivity Taylor attempted as one of the first persons ever to scientifically analyze the work process to create optimum output on behalf of the whole organization. (Taylor 2004) This also resulted in the term of Scientific Management. Frederick W. Taylor worked on his approaches to achieve process optimization and not to further the management. That was why he used the term "Task Systems". (Schachter 1989) The movement of Scientific Management originally was characterized by Louis Brandeis who used this term for Taylor's theory already in 1910. (Hebeisen 1999)

\subsubsection{Key Points of Taylor`s Labor Theory}

Taylor's approach of his new system is based on key elements necessary for the optimum functioning in the organization and the resulting labor productivity. His analyze and observations result in the following key factors: (Taylor 2004)

(1) A clear definition of the individual work steps and a differentiation between executed work and managed work

(2) The choice of a suitable workforce and its further training and instruction

(3) The co-operation of workers and management

(4) The reasonable distribution and joint responsibility of workers and management 
Frederick W. Taylor developed the key points of his theory on the basis of his time studies and used them to derive detailed work processes. The most famous example is his observation of shovel works. (Taylor 2004)

Based on these key elements, Taylor talks of four main groups of the administrative body of the new system. (Taylor 2004) However, it is possible that the performance-based compensation that is propagated by Taylor can be seen to be the fifth element and principle of his theory. If the workload based on the four elements is completed, this involves the respective performance-based compensation with an increase of $30 \%$ and $70 \%$ compared to the traditional system. Another effect would be the avoidance of the "shirking" that is inevitably connected with the traditional system. (Taylor 2004)

Taylor defines the performance-based compensation not to be a single element of his system. Due to the linking with his four factors it should nevertheless be seen as another principle.

\subsubsection{Influence Factors}

In his time Taylor's concept was revolutionary and radical and at the same time various elements had a strong influence on his concept. In addition to that, the industrial change starting in the middle of the 19th century paved the way for the industrial mass production. This industrial change made it absolutely necessary to analyze the work processes and the resulting optimization of the labor productivity. Besides the basic influencing factors of the industrial change society plays the biggest role. Before Taylor, 
there was a clear distinction between bourgeoisie (assets) and proletariat (workers). Taylor recognized this fact and his elements demanded a close relationship between the parties of the whole work process. Furthermore, the behavior and the methods of the individual worker have a great influence according to Taylor's theory. Taylor starts from the assumption that there is a low basic attitude towards working and as such he mentions shirking. (Taylor 2004) According to Taylor, the influence of this basic attitude of the worker can be opposed by introducing a performance-based compensation that is linked with the respective definition and specification of the individual work steps and a clear allocation of the workload.

It becomes clear that besides the individual influencing factors it is the situation and the socio-economic change that have a special influence on Frederick W. Taylor's approaches to the labor productivity. Taylor was one of the first persons to base his studies and results on personal practical experiences in the industrial environment and not only on observations with respect to social science and philosophy.

\subsubsection{Critical consideration of Taylor`s Labor Productivity}

The implemented methods that are based on Taylor's theories resulted in a great increase in productivity on the basis of an increase of productivity of the individual worker - mainly in the USA. As a second step, due to the proven success, Taylorism even prevailed in Europe very fast. (Znoj 2007) Despite the big success and the resulting potential it is especially important to view Taylor's approaches in a heterogeneous way. 
Along with the strict implementation and application of Taylor's elements there are various effects that are partly contrary to Taylor's intentions.

The separation of the working processes in as many small parts as possible (that were described in the papers of Adam Smith as well) may result in an optimization of the workflow and a minimization of the loss of time when changing tasks when observed initially. As a first step, this promoted the productivity of the individual and the rationalization and the productivity of the overall process. On second thought, this approach results in monotony when performing the tasks, since the processes are repetitive. There is an additional alienation with respect to the "product as a whole" and this is contrary to the division of the responsibility between workers and managers, as it is propagated by Taylor. (Taylor 2004) Therefore, there is the question with regard to the quality consciousness of the individual. Without any responsibility for the "product as a whole" the requirement of the individual may suffer and this could result in the need for additional resources for quality assurance in the first steps. (Taylor 2004)

Generally speaking, it is very easy to contradict the individual elements of Taylor's approaches. When there is any analyze of his approaches, it is important not to lose sight of the context of his theory. The starting point for Taylor always was the philanthropic idea of the fair wealth for all persons involved in the work processes. To satisfy Taylor's theory it is necessary to take into account the circumstances of its origin and the then happening change of the economic and social prevailing circumstances. It is reasonable and possible to further develop the approaches of Taylor. For example, in his paper The limits of labour division of 1959 Georges Friedmann discusses the question to 
what extent the division of labor is reasonable with respect to the productivity and when it starts to become a disadvantage. (Friedmann 1959) 


\subsection{Henri Fayol - General and Industrial Management (1916)}

\subsubsection{Theory of Fayol `s Labor Productivity}

Because of the historical development it was obligatory to have the aim to minimize the requirements with respect to the individual employee to increase the productivity of the individual and as a result to achieve a process that is more productive as a whole. The goal of the classical organizational theory was to use the individual employee in a way that would create a productivity as great as possible and simultaneously to maintain a high quality standard. This is universally applicable. As a basic principle it is correct that the person in charge for creating competitiveness must have a great understanding and feeling for the organization and the management processes in itself and this person must not only have the technical know-how with respect to the product. (Wren, Bedeian et al. 2002)

Henri Fayol's approaches are based on this organizational nature and that is why Fayol - next to Max Weber - is one of the co-founders of the organization theory in the field of science. Fayol, too, has a principle aim of increasing productivity as a whole that is achieved by optimizing the administration and organization.

Fayol's approach was based on the need - created because of the technological change of the industrial age and the resulting growth - to supplement the purely technical 
part of the manufacturing process with a management theory to satisfy the requirements of the change. (Kosak 2006)

\subsubsection{Key Points of Fayol `s Labor Theory}

Henri Fayol's theory was based on five key elements of the industrial administration / management. (Fayol 1969)

(1) Outlook and Planning

(3) Organization

(5) Instructions
(2) Coordination and Governance

(4) Control

These five modules go hand in hand with 14 general management principles that were derived by Fayol while working as head of an industrial enterprise. Fayol suspected that productive work can only be achieved, if the management has certain leadership qualities and managerial skills. (Fayol 1969)
(1) Labor Division
(2) Authority
(3) Discipline
(4) Unity of Placing of Orders
(5) Scalar Principle
(6) Organization
(7) Equality
(8) Unified Orientation
(9) Subordination
(10) Just Payment 
(11) Centralization

(13) Initiative

1. Labor Division

Segmentation of the complete work process and the individual work tasks in small steps to facilitate the potential for optimization

\section{Authority}

Authority in connection with responsibility. Creating the possibility to give orders and to get obedience. At the same time, this creates the necessary responsibility

\section{Discipline}

Success can only be achieved together and therefore a certain discipline must prevail in the organizational structure. Accordingly, it is possible to punish a lack of discipline

4. Unity of Placing of Orders/Commanding

There is only one superior that is allowed to give orders. This creates certainty and clarity in the structure

\section{Unified Orientation}

The aim of the whole organization should be a movement in one direction as a collective unity. Doing this, losses caused by friction and waste can be avoided 


\section{Subordination}

The aim of the collective unity is important. Thus individual interests are less important and are subordinated

\section{Just Payment}

The payment is done in terms of motivation. The circumstances and the situation of the workers must be taken into account

\section{Centralization}

The centralization is company-dependent and is connected with the subordination of the worker. The degree of centralization must be determined by the management with respect to the conditions of production

\section{Scalar Principle}

There must a hierarchical structure, but there must not be too many levels. A communication between the levels is desirable, but the orders are given only top down

10. Organization

The organization of physical and social concerns must be present to facilitate resource-saving management without any waste

\section{Equality}

All workers must be treated fair and equal 
12. Low Labor Turnover

A high labor turnover disrupts the production process and the organization and this must be avoided. Optimum results are only possible when there are stable conditions

\section{Initiative}

Support of the workers to show initiative. This strengthens the organization

14. Esprit de Corps

Companionship, solidarity, and team spirit must be supported to create a strong "feeling of belonging together" in the organization.

\subsubsection{Influence Factors}

The basics of his theory were the practical observations and experiences he made while working at the Compagnie de Commentry-Fourchambeau-Decazeville as chief mining engineer. The fact that the development of his theory was achieved by using practical approaches indicates the reference and the importance of Fayol's work with respect to the then prevailing situation in the industrial environment. Like Taylor's "Principles of Scientific Management" Fayol's theory should satisfy the industrial change that was happening during that time and it should initiate the associated rationalization in the manufacturing sector. It was the aim of his principles to create optimization and improvement in the organizational structure to increase the necessary labor productivity. 
Besides the industrial change, Fayol's position in the company and the associated daily challenges in the company should also have had a great influence on his works. Henri Fayol could implement his principles in the organization of the company to observe the direct consequences of this implementation of his principles.

\subsubsection{Critical consideration of Taylor `s Labor Productivity}

Like Taylor, Fayol had direct insights in the then prevailing and existing method of production in the industrial area because of his everyday professional life and he based his theory on observations. This raises the question, to what extent this administrative and organizational approach is applicable to other industrial enterprises and industries. Contrary to Taylor's experimental approach and the implementation of practical experiments in the direct production process, Fayol considers only the organizational environment and the structure of the organizational processes and the related hierarchy levels. Without a doubt, Fayol had understood at an early point in time the importance of a safe and ordered structure in a process and that it is necessary to sustainably increase the labor productivity and to contribute to the success of the company. It is not sufficient to focus only on one individual aspect of the whole production process.

Additionally, there may be a risk that individual elements of his 14 management principles could result in an increase of labor productivity only because of the interaction with the other factors, since all 14 management principles are analyzed as a whole. It would be very interesting to independently analyze the individual elements and the involved effects on the productivity of the work in the work process as a whole. The 
individual elements surely may be able to have counterproductive effects when there is any correlation or symbiosis. This could become obvious on the basis of the two elements Subordination and Initiative. The subordination of the individual has the aim to subordinate the individual interests to the collective interests. In such a system the development and the resulting initiative of the individual may be critically questioned, since a healthy and optimum environment is necessary for the development of people's initiative. Additionally, the interaction of labor division and low labor turnover is in a mutual relationship. A detailed labor division of very small work steps is used to achieve a corresponding learning effect of the own task, but at the same time this bears the risk of a very monotonous task that could later result in dissatisfaction and the associated change in the company, i.e. a high labor turnover.

It is certainly correct, that considered as a whole the effect supports labor productivity. However, it must be questioned to what extent the individual elements are counteracting and therefore might decrease the labor productivity. 


\subsection{Chester I Barnard - Functions of the Executive (1938)}

\subsubsection{Theory of Barnard `s Labor Productivity}

Chester I. Barnard based his theory on labor productivity on his practical work and experience at American Telephone and Telegraph (AT\&T) and published it in 1938 in his book The Functions of the Executive. He was one of the first to analyze the relationship between formal and informal groups and the resulting decision-making process. (Kennedy 1998) His theory always observes the role of the management of the company. His primary target most certainly was not the increase of labor productivity, but rather to make meaningful use of the efficiency of an organization as a whole to increase the productivity of the organization of the company. In the end, this additionally results in an increase of the labor productivity.

Due to his approaches and starting with the formal organization as a central element of his theory, Barnard's theory on labor productivity is much more sophisticated than the approaches with respect to rationalization that are only based on the production process.

\subsubsection{Key Points of Barnard `s Labor Theory}

Barnard assumes that there are interrelated elements that form a functioning and efficient structure because of their inherent interaction. Therefore, efficient labor productivity can only be achieved, if the formal organization and the management are basic elements and are interacting with the various key elements. Consequently, two 
basic elements of Barnard's theory can be noticed that are based on the individual key elements.

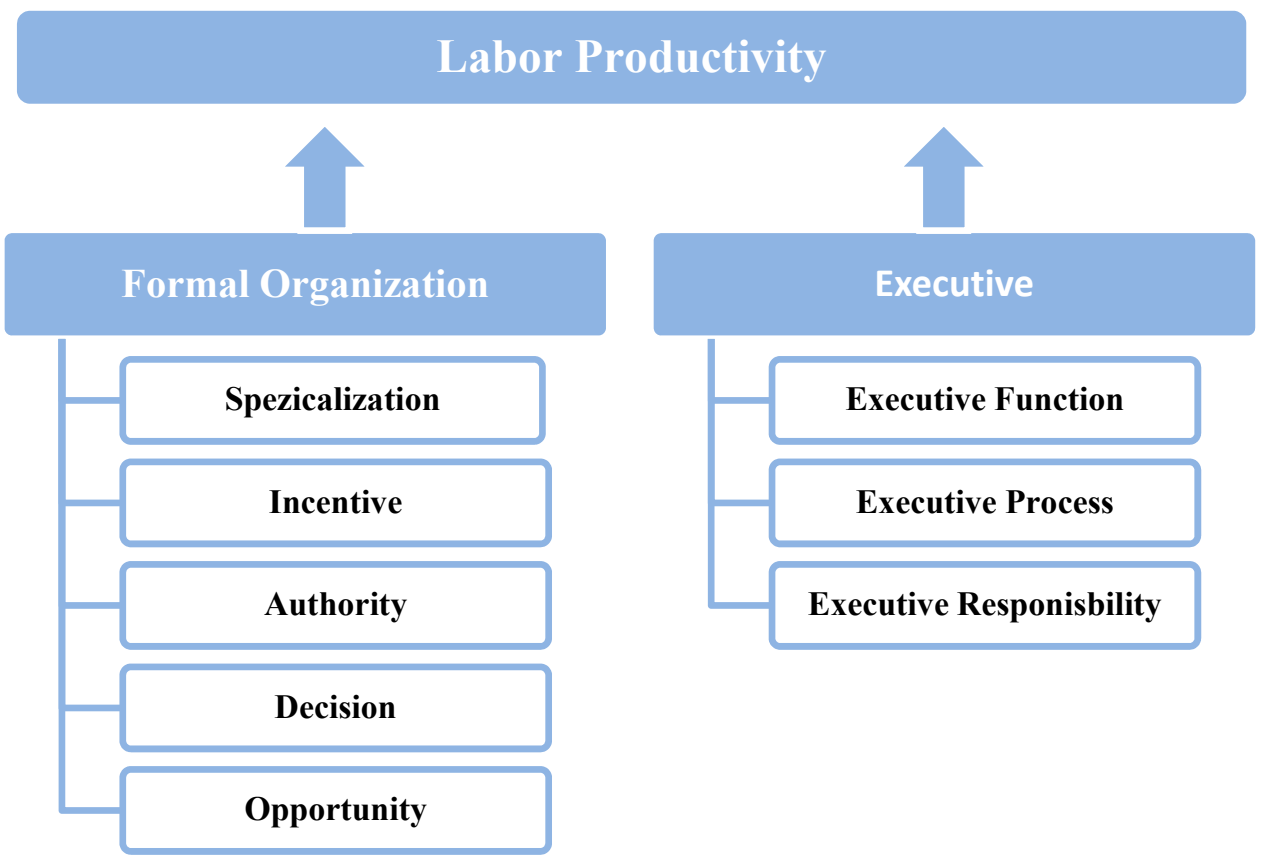

Figure 2 Structure of Barnard `s Labor-Productivity-Theory

The Formal Organization consists of five key elements that must be considered more closely.

Barnard clearly describes how the Specialization in the formal organization must look like. It must be clearly defined where the works are done. In addition to that, there must be a clear communication about the timespan that is available to complete the work and who is doing the work. Barnard defines the specialization of the workers in view of the person as an "associative specialization". Every stable and lasting Organization is after Barnard therefore a thing of associative specialization. (Barnard 1968) 
According to Barnard, other parts of the specialization are the purpose why the work is done as well as the method or the process itself.

First and foremost, it is the Incentives that Barnard considers to be the motivator of the individual person in the organization and that becomes obvious, since the individual person balances the possible pros and the possible cons. Therefore, the main tasks and main challenges of the organization / management are to control the interaction of positive and negative "incentives" and to further the positive incentives and to prevent the occurrence of negative incentives, if possible. Additionally there is the possibility of a classification with respect to the furthering of the targets. Barnard calls this The Method of the Incentive and the subjective setting The Method of the Conviction. (Barnard 1968)

Barnard considers the Authority to be ineffective, if there are no consequences for not obeying the rules and instructions. At the same time, Barnard considers this as a sign of communication. The contact and the cooperation in the organization and the various stages are considered. If misbehavior is tolerated or if it is not punished, this permits conclusions with respect to the leadership know-how and the communication, since the individual persons in the organization must adhere to certain rules. The management must consider two different aspects. In the organization, the management must consider both the personal subjective perceptions and the objective aspects of the own actions and these may not be disregarded. For this reason, it is fundamental for the management to be willing and able to understand the needs of the organization. Therefore, the management responsibility depends both on the development of the individual and the technical and social environment in the organization. (Barnard 1968) 
With respect to the key element Decision it is important for Barnard to create a balance in those areas where decisions are made.

Distinguished are three areas:

\section{Authoritarian Arrangement of Superiors \\ 2. $\quad$ Pressure of Subordinates to Make a Decision.}

\section{Initiatives of Executives}

The balance of these three areas is decisive and fundamental, since as a basic rule the human actions are determined by two aspects. Barnard writes in his papers that the workers act because of intentional conditions. Taking a closer look at this fact, this means that workers act due to specified conditions and intentional deliberations in the secure environment - or they complete tasks unconsciously because of internal and external influences, motivated because of past experiences or actual situations. Barnard is of the opinion that positive decision making can result in active actions of the worker. If there is a negative decision making or if no decisions are made at all, this results in passive action. A passive action in this context means, that either wrong actions are done or no actions at all are done by the worker and both of these possibilities result in negative consequences for the organization. (Barnard 1968)

The fifth key element of the basic factor Formal Organization is called according to Barnard - the Opportunity. The theory of opportunity consists of the fact that a reaction is only possible, if there are set conditions and available means. The process is supposed to be completed in small steps / it must be divided into small decision making 
steps. According to Barnard, each and every step or working process is considered to be a task that has its own aims and it is supposed to be a process of its own. The reason for this is to achieve an advanced distinction due to an analyze with the individual situation and the environment. The purpose is to have aims that can be achieved and that are practical. The physical, biological, social, moral, and emotional values of each individual employee can influence the opportunistic actions. These opportunistic actions are always governing the employee differently according to the purpose to be achieved and the respective varying degree of significance that the purpose has for the respective employee. (Barnard 1968)

Barnard defines Executive to be the second basic element of the three key elements that make it necessary to be considered more closely.

The Executive Function is based on three other tasks.

- Maintenance of the Communication of the Organization

Barnard considers the Executive Function mainly to have the task to create interfaces and means of communications and to staff them with suitable employees. The creation, usage, and adjustment of suitable means of communications is the basic task of the management, since it permits the existence of suitable processes. (Barnard 1968)

\section{- $\quad$ Securing of Essential Services of Individuals}

The second task of the management is defined by Barnard to be the creation of an environment in which the employee can be part or member of the cooperative teamwork 
in the organization. (Barnard 1968) Only in such an environment can a successful task be accomplished and the full potential can be exploited.

- The Formulation of Purpose and Objectives

According to Barnard, the third task of the executive is the definition of aims and purposes. It is decisive that the defined purpose is defined in such a way that it can be accepted by the workforce. The third part for executives is the formulation of purposes and objectives. To achieve the aims it is beneficial to divide both the tasks and the purpose in small steps and parts, since this helps to achieve efficiency and rational production. (Barnard 1968) The process division is another component of the Opportunism of the formal organization and it is connected / interconnected with the leadership role.

The Executive Process makes a distinction between Effectiveness and Efficiency.

- $\quad$ Effectiveness

The effectiveness observes the correct choosing of instruments and means that are used in the respective situation to achieve the goal that was set beforehand. These are the techniques that are used as well as certain procedures, behavior pattern and methods of applied science. (Barnard 1968)

\section{- Efficiency}

Barnard identifies / defines the Efficiency with respect to the organization and its capability of the management to create satisfied employees. The organization itself consists of individuals, creates actions, cooperates, and aims for individual advantages. 
The efficiency of the management demands the creation of equalization / balance between the various benefits to be used immediately. At the same time, this efficiency of the management is used as a control tool and management tool. Therefore it can be concluded, that the efficiency of the organization is a function of the various means of control. On the one hand there is the detailed control of expenses and profits at the time of the exchange and on the other hand there is the control about the internal coordination of the productive factors in the organization. (Barnard 1968)

According to Barnard, the third key element is the Executive Responsibility. $\mathrm{He}$ thinks that the main function of the management is to be productive with respect to its management task and management function. It must be able to convince others of the own concerns. This makes it possible to draw conclusions about the fact how a member of the management deals with responsibility. The responsibility of the management is a decisive element of each organization. The organization itself can only be successful and productive, if the management in charge has the respective abilities for motivation and persuasiveness. (Barnard 1968) A weak management will never be able to make any contribution to a successful business. 


\subsubsection{Influence Factors}

Barnard formulates in his conclusion 16 main statements which looked as especially important and will influence the organization and therefore in view of labor productivity according the outcome and results of the organization. (Barnard 1968)

1) Physical and biological factors are the basis of all cooperation

2) The organization recognizes all things as capital

3) All complex formal organizations originate and exist on the basic organizations

4) The qualities of the formal basic organizations are determined by physical, biological and social circumstances

5) The basic structure of every bigger organization is determined by the totality of the formal organizations

6) In all formal organizations exists informal organizations

7) Disturbances of the balance in cooperative systems originate from wrong ideologies

8) According to no. 7 there are three fundamental mistakes: Simplification; Disregard; Mistakes

9) Adaptation follows through consolidation of physical, biological, personal and social factors

10) Wrong decisions on account of wrong perception 


\section{1) Systems of benefit}

12) Determined social concepts expressed by language and symbolic systems

13) More cooperation flows in more moral complexity

14) The strategical factor of the cooperation is the leadership

15) The strategical factor of the dynamic side of the leadership is determined by the moral productiveness

16) The strategical factor of the social integration is the development and choice of executives

\subsubsection{Critical consideration of Barnard `s Labor Productivity}

Generally speaking, Barnard understood the strength of the cooperation of human beings that have a free will. Any personal development results from cooperative actions. Additionally, each person must accept responsibility for the decisions that he/she made. The resulting balance that is the basis of productivity and success derives from the inside of the organization and the interaction of the necessary pre-requirements and the human well-being.

A basic element for Barnard's theory is the existence of a formal organization with set basic conditions provided that the free will of the individual always is the strategic factor of the organization. (Kieser 2006) (Barnard 1968) It is this free will inside the system that is double-edged, since the system can restrict this free will. Besides this, 
Barnard starts from the assumption that the system is absolutely complete. This academic-theoretical approach cannot be reflected in the daily production environment that consists of various different influencing factors.

Nevertheless, Barnard's paper The Functions of the Executive is without a doubt one of the most influential works on the operational organization theory. Barnard considers the successful organizations to be efficient instruments of social progress.(Kennedy 1998) His management concept and the operations in the organization are clearly contrary to the management concept of many management personnel having a management concept that is only based on short-tem success. (Kennedy 1998) Barnard`s biggest success may well be to have developed an approach to a theory that mainly bases on long-tem sustainability and rational and productive considerations. 


\subsection{Fordism - Henry Ford - My Life and Work (1922)}

\subsubsection{Fordism Formation and Development}

The period at the beginning of the 20th century is called Fordism and it was named after the founder of Ford Motor Company: Henry Ford. This was due to the revolutionary social and technical considerations of Henry Ford with respect to the production methods. Therefore, Ford's name is irrevocably connected with mass production and conveyor-belt production. (Burt 2001)

Because of the introduction of the conveyor-belt production it was possible to optimize the processes of the production. This resulted in a higher output of manufactured products and simultaneously it resulted in lower productions costs. This, on the other hand, had positive influences for the customers due to a lower retail price. Furthermore, Ford not only optimized the conveyor-belt production, but he also optimized the individual working steps by introducing standardized working steps with the associated tools. This resulted in lower costs and a lower price for the Ford T Model that was a cornerstone for the conveyor-belt production.

Besides the technical optimization of the working and production processes, Ford was the first person to implement not only rationalization and optimization methods, but also socio-economic changes in his company. For his company, he implemented the 8hours-working-day and paid his workers wages way above average. (Ford 2006) 


\subsubsection{Theory of Productivity}

Ford's practical approach to increase labor productivity basically based on his experiments and experiments in his career and at the Ford Motor Company. These experiments can be described by mentioning key factors - which is done in the next chapter. Ford did everything possible to optimize the continuous progress of his manufacturing techniques and to implement the potential to save money.

Henry Ford's theory of labor productivity mainly bases on three decisive elements while simultaneously considering the key factors to guarantee an optimum production efficiency. (Ford 2006)

(1) The Optimization of the Manufacturing Processes

(2) The Avoidance of Waste

a. Lean Production

b. Lean Organization and Management

c. Lean Hierarchy

(3) Development of Basic Manufacturing Rules

a. Arrangement of Tools and Workers according to the Production Sequence

b. Implementation of Means of Transport

c. Implementation of Assembly Lines 
These basic rules are based on extensive time studies and analyses that Ford had carried out in his company. For example, he investigated the potential for improvement with respect to the production of piston rods to achieve a higher output. Upon closer consideration of the nine hour working day it was discovered that four hours alone were spent on changing tools and fetching and placing material. Back then, the initial daily production of 28 workers was 175 piston rods. At that time, all working steps were completed by one worker alone. The manufacturing process was then split to be carried out by specific workers. This resulted in a reduction of employees down to seven workers and simultaneously it resulted in an increased daily production of 2,600 piston rods. (Ford 2006) Such time studies were conducted in all areas of the production process. To achieve an optimum production process, Ford not only conducted time studies but also enhanced the existing production machinery. For this purpose, he sometimes had carried out several months of test runs to increase the efficiency of individual equipment and machines. (Ford 2006)

\subsubsection{Key Points of Ford's Labor Productivity}

Based on these basic rules, Ford derived nine key factors that fundamentally contributed to the increase of labor productivity and therefore to the success of his company. These key elements of Ford's labor productivity were developed on the basis of the above mentioned methods like the examination and analyze of workflows, time studies, and time measurements as well as on the basis of a working atmosphere that not only admitted but boosted optimization. (Ford 2006) Ford himself strived for 
performance improvement and was not satisfied with the results he had already achieved. (Ford 2006)

\section{(1) Smaller Working Steps and Labor Division}

The existing working steps are split into smaller working steps to avoid unnecessary binding of resources

\section{(2) The Implementation of Batch Production}

Corresponding to the manufacturing processes, working steps are arranged in groups and the necessary machines are allocated in the best possible way

\section{(3) Standardization}

Products as well as production processes are standardized in detail. This results in a great learning experience and higher quality and faster processes

\section{(4) Utilization of Conveyor-Belt Production}

Using and implementing conveyor-belt production, slipways and transport, the product to be manufactured is moved to the worker - the worker is not moving to the product. The ideal tuning of speed and timing saves resources and avoids physical overload

\section{(5) Training of the Workers}

All workers are trained and qualified according to their tasks in order to be able to manage the respective tasks in the best possible way 
The personal responsibility of each individual worker results in quality assurance and increases the personal commitment with respect to the product and the work itself

\section{(7) Equity and Equal Opportunities}

Each worker is treated equally, regardless of the hierarchy.

(8)

Motivation

Each employee has the chance to make a career in the company, if they show and possess the necessary commitment and skills and this is not based on background knowledge or education. Furthermore, the task and the commitment are compensated by paying higher wages

\section{(9) Fair Working Conditions}

As a general rule, all methods are implemented by using tools and machinery that avoid any physical overload. Doing this, the workforce should be permanently maintained and fluctuations in the daily production should be avoided

These nine key elements of Ford's labor productivity can be derived from his paper My Life and Work and they provide information about the fact that next to the technical optimization procedures Ford first and foremost had in mind the increase of labor productivity of the working conditions of the workers. (Ford 2006) 


\subsubsection{Influence Factors}

Frederick Taylor is said to have had great influence - maybe the greatest influence at all - on Ford and the derived Fordism. Ford used the approaches of F. W. Taylor to further develop these approaches in the production processes of the Ford Motor Company. (Steinkühler 1995) The separation of the individual working steps was combined with the optimum arrangement of machines and the batch production and this immediately resulted in a success with respect to the labor productivity and the rationalization of the manufacturing processes that were derived from this labor productivity.

Equally important certainly was the fact that Henry Ford entered the market at a time when a sophisticated derivation of the industrial revolution was taking place. It was Ford's aim to realize a daily production of 1,000 cars a day and these cars had to be bought by the customers. (Ford 2006) At the beginning of the production, horses and carts would be in the majority, but Ford realized the influence of change and time and reorganized his production accordingly. The influence of the change resulted in automobiles being an asset instead of being an object of luxury and this was picked up by Ford and could only be implemented in his company by significantly increasing the labor productivity.

Besides the historical influences and pioneers like Taylor and the then happening change in the field of manufacturing methods and the simultaneous necessary alignment of the labor productivity it certainly was Ford himself that had a great influence on the development of the labor productivity. Because of his natural approach, his attitude, and his nature to observe all things, Ford was capable of creating a sustainable working 
process and also a sustainable labor productivity. Ford always saw the possibility for optimization even when previous attempts and observations proved to be negative or ineffective. (Ford 2006) He had a strong will and did not lose sight of his goals even when facing defeat. This characteristic most certainly had a great influence on the success of Ford's labor productivity.

\subsubsection{Critical consideration of Fordism in Relation of Labor Productivity}

As a basic rule it must be observed that besides the merely rationalizing actions in the production processes Ford implemented a series of methods to avoid disruption by the absence of workers. It was for this reason that Ford Motor Company was one of the first companies in the world that implemented occupational-safety measures to increase the safety at work. (Ford 2006) Of course, this was not only done to protect the workers. On the contrary, Ford was a strategic-thinking entrepreneur that considered accidents at work to be a failure resulting in financial losses. However this might be considered by the reader, these methods increased productivity and contributed to the ongoing success of the company.

Another novelty of that time was the implementation of the daily wage of the socalled \$5-Day. These wages were almost twice as high compared to other manufacturing companies. (Ford 2006) Due to Ford's comprehensive observations and time studies he was able to exactly calculate the speed of the assembly line and the respective cycle time. Thereby he was able to pay daily wages and he could quit paying wages that were only based on the individual efficiency of the respective worker. (Héron 1976) Additionally, 
bonus payments based on the period of employment and the annual profit were added to the daily wages. (Ford 2006)

This type of payment was not previously known back then. Ford was a businessman and wanted to achieve two effects: On the one hand he wanted to increase the individual productivity of the respective worker by motivating him using higher wages - and on the other hand he wanted to minimize the level of labor turnover in the company and the respective costs of fresh engagements and the resulting training time. (Ford 2006) (Raff and Summers 1987) (Blanchard and Illing 2009)

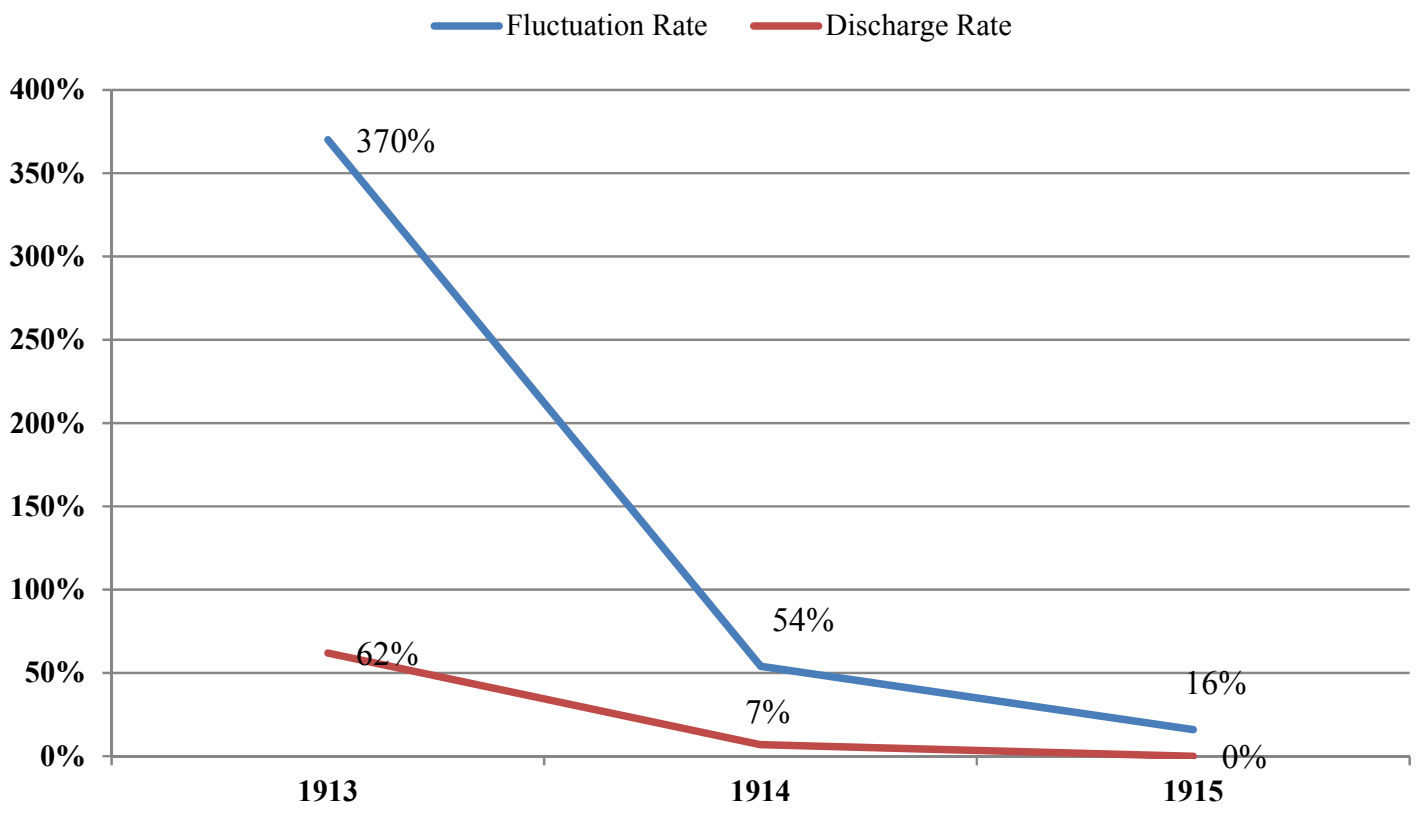

Figure 3 Fluctuation and Discharge Rate after Introduction of the Ford's \$5-Day

(Blanchard and Illing 2009) 
Ford implemented a lot of methods to increase the productivity of labor and the productivity of the whole company. At first glance, the occupational safety measures and the high daily wages seem to be the result of the hard as nails businessman Ford. But it should also be mentioned that Ford paved the way for better working conditions of the future. In retrospect it becomes obvious that the increase of labor productivity due to the measures that had positive effects for the workers were always decided at the worker's expense. Higher wages were the by-product when perfecting the labor division and the standardization. At the present point in time we can ask the question to what extent these higher wages in combination with all the positive developments did lead to a degradation of the motivation, the work performance, the labor productivity of the individual worker, and the labor turnover in the long run.

An interesting proof for this conclusion is a letter that was sent to the board of directors of Ford Motor Company.

The chain system is slave labor. My God! Mr. Ford, my husband came home from work and went to bed immediately. He did not eat anything - he was so exhausted! Isn't there anything that can be changed? ... The $\$ 5$ a day are a blessing - a greater blessing you can ever imagine, but the workers deserve every cent of it. (Hughes 1991) 


\section{MODERN PRODUCTIVITY SYSTEMS IN THE POST}

\section{FORDISM}

Since the existence of modern industries and modern manufacturing methods there is a constant process of change. New developments in all areas take place. Just like in each and every other sector of the world, but especially in the working environment, idleness is the cause for a loss of efficiency and market shares. And these efficiency and market shares are basic requirements for long-term success.

With respect to the area of labor productivity, the era of Post-Fordism was characterized by two fundamental innovations of the labor and productions methods of economy and industry. On the one hand, it was necessary to continue the logical chain of the great pioneers and masterminds that started with Adam Smith, Karl Marx and continued with Taylor and Ford - this was done by Ohno Taiichi. He was the founding father of the Toyota Production System (TPS). Today, TPS is called Lean Manufacturing and it is introduced to various branches and industries. This lead to a fundamental change of the manufacturing processes.

Almost at the same time, another innovation was initiated in the middle of the 20th century - more specifically it was in the 1960s and 1970s. In the history of the industrialization and the respective labor productivity, this was the time of one of the most essential changes since the invention of the steam engine or the light bulb. 
With the introduction of information and communication technology in economy and industry alike, the working environment was completely changed - this is both true for the whole industry and the individual working steps and processes. The digital technology initiated a change that is basically still happening today; and the end of this change cannot be estimated at the moment. Today, the digital technology is present in all areas of working and living. This is true for all consumer applications, but the most important transition takes place in the working environment, causing drastic changes.

If both of these innovations are considered individually, each one of them introduces great positive changes on its own and each one of them characterizes the possibilities to increase labor productivity fundamentally. The combination of both these methods together with the optimized usage of the Toyota Production System (TPS) and modern Information and Communication Technology (ICT) causes a multiplication of the possibilities to increase labor productivity, if coordinated in an effective way. 


\subsection{Post Fordism - The era from 1970}

\subsubsection{Accumulation Theory of Ford}

If the working and production model of Ford is broken down into its key aspects, the basis is the approach to increase the output and the production by using strict labor division and the segmentation into the smallest units of work possible. Along with the associated reduced per-unit-costs Ford could pay corresponding wages and lower the prices for his products. This paved the way for an increase in the number of clients. This feedback effect - reduced per-unit-costs, lower sales prices - and the associated increase in the number of clients allowed Ford to make use of the "produced added value" according to the classic ways of the accumulation model.

The accumulation of Ford was realized both with the constant capital (machines and equipment) and the variable capital (number of employees and wages).

The limits of Ford's accumulation process are the general framework of the model that cannot be influenced. As long as the internal and external conditions remain the same, this model bases on the accumulation of the capital. Ford realized the accumulation up to the absolute increase of the creation of value. But in the middle of the 20th century he reached the limits of his classic model. At that time the Ford production model of the mass production and the respective mass consumption was mainly influenced by external changes. For almost half a century, Ford's regulatory system was the basis of the 
accumulation of capital in the prevailing industrial environment of that time. Hirsch 2005 mentions that the viability of this system is only guaranteed as long as the accumulation process of the capital is the economic reproduction process. (Hirsch 2005)

\subsubsection{Formation and Development of the Prost - Fordism}

The era when pure mass production theory was changed and the socio-economic approaches happened according to Ford therefore is called Post-Fordism in literature. An exact date cannot be defined. Nevertheless, it can be concluded that the transition emerging in the 1970s has its basis in the changed framework conditions that separated itself from the mere and rigid mass production. (Hirsch 1995)

The basis was the increase in productivity of the beginning mass production together with the associated decreasing prices. This was satisfied by the respective consumption of Ford's production model. (Volker 1996)

Due to the change of the requirements and the framework conditions and starting from the assumption of the social transition (change of the demand for consumer goods) and the market globalization, any further efficient increase according to the model of Ford was no longer possible. The rigid and non-flexible production system was not futureoriented and this was additionally enhanced by various emerging crises (e.g. oil crises in 1973 ) and the resulting increase in prices for raw materials and the global actions of the economic operators. 
All in all, the crisis and the associated change can be said to be triggered by the following factors:

Internal Key Elements

- The traditional production system could not be adapted to the changed market environment.

- Potential reserves in productivity were exhausted.

- There was a changed attitude and behavior of the workers (trade unions).

\section{External Key Elements}

- Changed framework conditions caused by different consumption habits in society.

- The high unemployment rate resulted in decreasing demand.

- The external socio-economic change increased the pressure on the internal processes.

The impact of these factors had three direct influences on the productivity of the individual national economies. The below illustration is an accumulated description of the course of the productivity in the United Stated of America and Japan. 


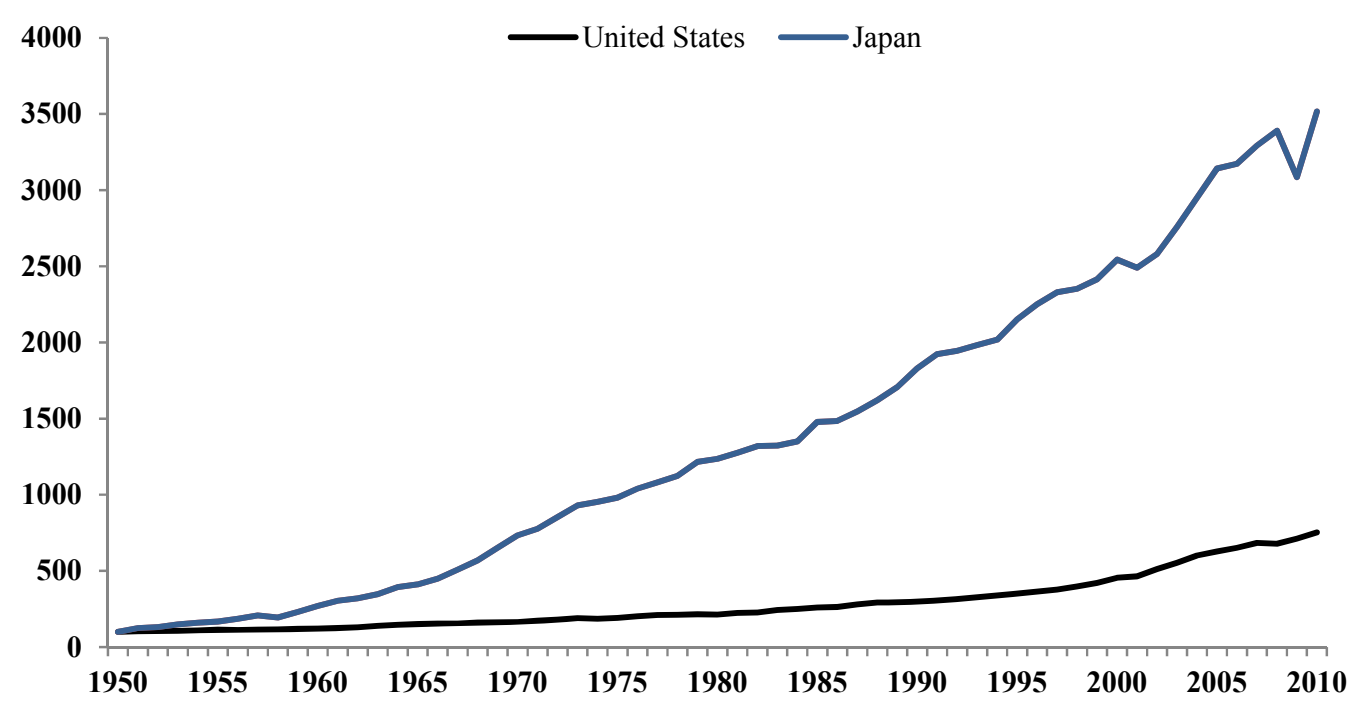

Figure 4 Output per Hour Employed Person 1950-2010 (Index: 1950=100)

(U.S. Bureau of Labor Statistics 2010)

In all of the G-7 countries there is an increase in labor productivity in the period of 1950-1973. However, the difference between the individual member states was significant. While the United States of America had a productivity rate of $2.6 \%$, it rose to $10.0 \%$ in Japan during the same period of time. In other member states it was between $3.3 \%$ and $6.9 \%$. (Cobet and Wilson 2002) 


\subsection{Implementation of New Productivity Systems in the modern Era}

\subsubsection{Toyota Production System}

Due to the changed framework conditions the limits of mass productions were reached and new production systems were necessary to be able to properly react to the new conditions and the changed challenges.

By doing this - the waste of resources was avoided and eliminated and a whole new form was created - the Toyotismus and the Toyota Production System emerged. The Toyota Production System is the next step in the development of efficient production processes since the implementation of mass production by Henry Ford. The TPS equally is known as Lean Production or Lean Manufacturing. (Liker 2004) Initially the term Lean Production was coined by James P. Womack, Daniel T. Jones and Daniel Roos in the publication The Machine That Changed the World which is based on the MIT study for the International Motor Vehicle Program they were managing. (Womack, Jones et al. 1991) 
Lean Production is defined as:

Lean production combines all functions starting from the top management and the workers to the suppliers. This result in an integrated whole that is able to react to customer requirements of the marked in a fast and efficient way. It can double the productivity, it can improve the quality, and it can keep the costs low. (Womack, Jones et al. 1997)

Ohno Taiichi was a Japanese engineer at Toyota and is said to be the founding father in the era of Post-Fordism. Ohno Taiichi was inspired by a visit of the premises of the Ford Motor Company in 1953. Back then he analyzed the classic production model of Ford and adapted it to efficiently increase the production by taking into account the requirements of modern times. (Toyota 2010) It became famous as the Toyota Production System.

One of the historical origins of the Toyota Production System can be found in the United States of America. During his visit in the United States of America Ohno was especially impressed by the efficiency the American supermarkets used to restock the goods that were taken out of the shelves by the customers. Watching this, Ohno developed the Kanban System that restocks taken goods as fast as possible without any occurrence of idle time. At the same time there is no large stock. In combination with the Just in Time Principle of the Toyota founder's son Kiichiro Toyoda the Toyota Productions System was created. (Toyota 2010) Another great influence on the basic concept of the TPS was the American scholar Dr. William Edwards Deming who additionally was a pioneer in quality control. A key principle of Deming based on the idea to consider each new production section to be a client of the previous production 
process and to adapt this internal client-supplier-relationship to the external client. (Walton 1988) Ohno combined this stage-to-stage client concept with the Just in Time Principle and used this combination for the development of the TPS. Ohno's aim was to create a production system that was able to satisfy client requirements and that efficiently made use of the productivity of the production processes despite the occurrence of limited resources. This he managed by further developing Ford's production model and adapting it to modern requirements by taking into account the prevailing limits and client-based elements. The TPS is a system that combines the productivity and the efficiency of the series production with the advantages and the quality components of the contract manufacturing.

A basic differentiation of the modern Toyota Production System and the Fordism characterized by Taylor is the produced amount of output. While the model of Ford bases on mere mass output, the TPS refers to the principle of the best possible satisfaction of the consumer demand. (Gienke and Kämpf 2007) The company produces only such an amount of goods that is demanded by the customers. At the same time the production process is capable of manufacturing large quantities.

The Toyota Production System puts the workers in a position to optimize the quality by constantly improving processes and avoiding waste of natural, human and company resources. The TPS influences every aspect of the organization and includes a common basis of values, knowledge and procedures. The workers are entrusted with well defined responsibilities in each of the production steps and each team member is encouraged to strive for improvements. (Toyota 2010) 
This definition of TPS points out how extensive and comprehensive it is applied to the production process and thereby on the whole productive, organizational and administrative instruments of a company. There are no areas that are excluded. Therefore, in the entirety of its systems TPS is only effective, if each individual unit is included.

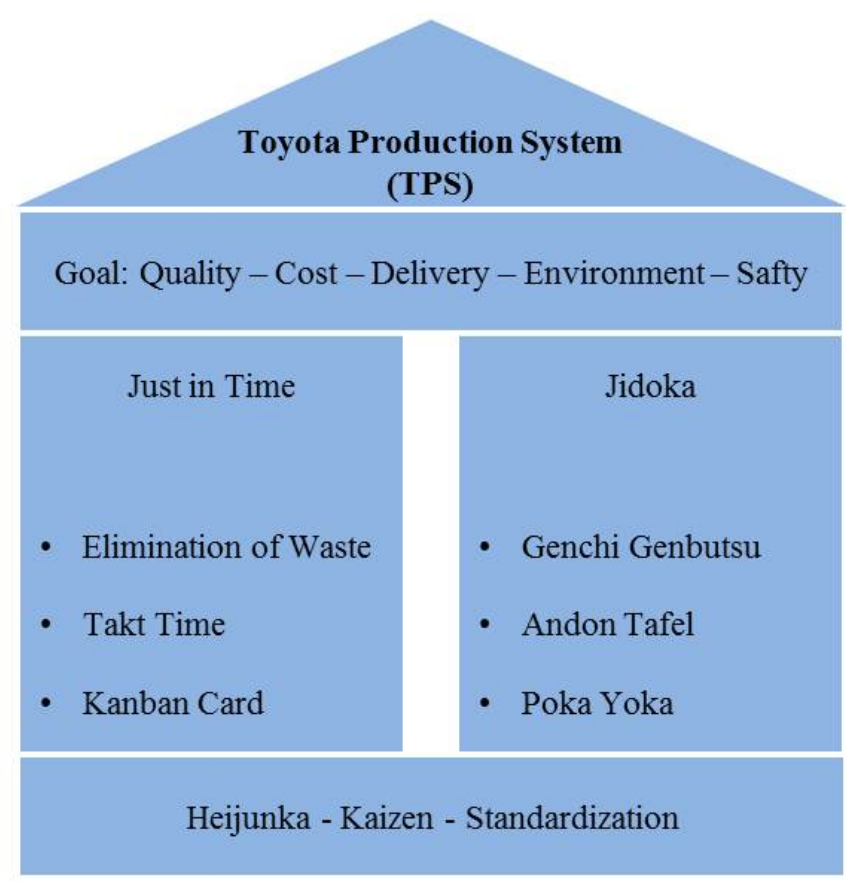

Figure 5 Toyota Production System (TPS)

(Toyota 2010)

In the Toyota Production System, the main priority is this aim: highest quality at lowest costs with minimum cycle times. This shall mainly be achieved by a consistent effort to avoid Muda - waste, Mura - irregularities, and Muri - excessive workload. (Ohno 1998) The TPS principle is based on two key pillars - Just in Time and Jidoka, that can be translated as automation with a human touch. (Drew, McCallum et al. 2005) 
The foundation of the whole model is achieved by equalizing the production flow (Heijunka), the standardization and the consistent striving for improvements (Kaizen). (Drew, McCallum et al. 2005) (Becker 2006) It is important to understand that the Toyota Production System is only functional and achieved in its complex architecture. The implementation of individual elements can increase the productivity partially and locally, but much potential is lost, if all of its structures are not interacting.

Taiichi Ohno summarized the complexity of the aims of TPS in one single statement. The concentration and the strategy of TPS is the elimination of all Non-Value Adding Wastes to minimize the duration of time between the incoming orders and the cash flow.

Time Line - Toyota Production System

(Reduce by removing non-value-added wastes)

Figure 6 Main Goal of Toyota Production System

(Ohno 1998)

For this purpose TPS uses various methods of the so-called Toyota Way to achieve the best possible result. (Toyota 2010) 


\section{(1) Challenge}

Each task is considered to be a challenge to achieve the intended result and to be able to realize long-term visions.

\section{(2) Kaizen}

Ongoing improvement - There are constant improvements and optimizations of all processes of the company. Never shall there be a state of idleness.

\section{(3) Genchi Genbutsu}

To get the necessary information it is important to go to the source of the information / the location of its origin and to consider this source or location to be the point of departure.

\section{(4) Respect}

Individual responsibility and mutual respect are the basis for creating long-term trust.

\section{(5) Teamwork}

Every aim and success can only be achieved together. Therefore, it is important to work as a team and simultaneously to encourage the development of the individual. These five key values are mainly targeted to create sustainable customer satisfaction and this is the final objective of the TPS. This shall be achieved by striving for and practicing a continuous improvement of all elements and methods. 
The key element of the Toyota Production Systems is waste. Therefore, waste must be avoided in the TPS as a basic rule. For this purpose, Taiichi Ōno defines seven different types of waste: (Ohno 1998)

\section{(1) Overproduction}

Each type of production that exceeds the degree that can be absorbed by consumption.

\section{(2) Unnecessary Movements}

Workplace layouts that are not optimized, long and possibly unnecessary distances, and material movements.

\section{(3) Waiting Times}

Each and every type of idleness because of missing or bad maintenance. Manufacturing processes that are unnecessary and not optimized.

(4) Transports

All transports that are not covered by reasonable planning

(5) Excessive Labor

Each and every extra work exceeding the necessary amount - often to be found in the area of quality assurance due to test sequences that are carried out two times or due to too many test sequences. 
Each and every storage of materials ties up capital and causes additional losses due to a lack of alternative use of the funds. The stock of materials must be adjusted to the production process.

\section{(7) Rework and Rejections}

Besides the additional control each type of rework causes additional efforts and ties up resources that could otherwise be used in a better way or that could be cut down completely. Moreover, there are high cost items due to rejections and therefore there are goods that cannot be used for sales and subsequently do not prove advantageous for the company.

Literature added another potential type of waste to these seven types of waste that were established by Taiichi Ohno. The neglecting of using the full potential / the skills of the employees is published by Mc Graw Hill in The Toyota Way and said to be another possible type of waste. (Liker 2004)

Without a doubt, the Toyota Production System has revolutionized the industrial production and the production process of the past. It is obvious that the TPS can not only considered to be a mere modification of the traditional research of the production model, but moreover it is an effective and productive further development that was adjusted to the prevailing circumstances and resources. This becomes apparent, since its individual elements are components of the TPS. For example, Ford introduced the conveyor-beltproduction and relied heavily on standardization. Both of these aspects are also addressed in the TPS and they are adapted to the new model. 
However, other elements and production processes are interpreted and integrated into the production sequence in a completely different way. Therefore, contrary to Ford the TPS backs on the optimum usage of well-trained staff that is responsible for each individual working step with respect to quality and quality control.

The TPS could be established because of its various advantages compared to the rational approaches. Nevertheless, individual aspects do have some disadvantages (as it is the case in every other model). The occurrence of these disadvantages is not compulsory, but they are present at all times. In particular, internal and external stimulation can turn advantages into disadvantages in no time. The Just-in-Time Process can be mentioned for this purpose. If it is not possible to realize the delivery of the needed materials and resources adjusted to the production process, the complete planning of the tuning is void. If there are no internal and external disruptions, there is an optimized and productive production cycle. But as soon as there are any influences prohibiting the optimized and productive production cycle, there might be massive costs. The TPS is liable to break down not only in the area of JiT, but in all of its areas. This especially includes the disruption of the communication of all the processes of the organization. It is important to understand that the success of the TPS is not based on the optimization of individual aspects. As a basic rule it must be noted that the TPS is an interconnected gearbox in which all processes are coordinated like toothed wheels.

Without a doubt, the Toyota Production System has coped with the requirements and the prevailing framework conditions at Toyota in an excellent way. Additionally, the fact that the TPS is no static system that is implemented and subsequently realized clearly demonstrates the advantages and the potential that are expressed by its efficiency and 
productivity. Nevertheless it is unclear, how this system can be implemented with respect to the modern challenges and the changed framework conditions as well as with respect to the new requirements of today's competition. It becomes obvious that the lean management is an integral part of the Toyota Production System and meanwhile it has been introduced to different extents in many companies.

\subsubsection{Information and Communication Systems}

\subsubsection{Implementation and Development}

The Information and Communication Technology (ICT) basically exists since the beginning of humanity. Cave paintings of the Stone Age, papyrus scrolls in Ancient Egypt, books in the Middle Ages - each and every culture was using Information and Communication Technology to preserve its knowledge and to pass on information. This technological culture was subject to a rapid development by introducing the digital technology in the middle of the 20th century. It was and still is the aim of this digital technology to preserve, pass on or duplicate information. (Picot 1986) It becomes obvious that Information and Communication Technology cannot be seen as a stable and limited instrument. In fact, there is a fast and ongoing development in the arising manufacturing branches. The end is in the far future. The change that is happening is characterized by its own individual quality and quantity. This becomes obvious when taking into account the development of computers. When only considering tools of production, work and productivity, this digital revolution is a historic continuity of the development of productive work. (Picot 1986) In this context, various sociologists even 
mention a third revolution - the digital revolution - in the historical development of productive work. (Balkhausen 1984)

That is why the ICT is introduced into the everyday working life for many years and it forms the different processes and procedures of widely varying working steps. This results in tremendous influences and consequences.

\subsubsection{Effects on the Modern Labor Productivity}

The always increasing importance in the various areas becomes obvious when comparing the manufacturing companies of the different eras / the development of the respective production processes. In the past, the different processes had to be mapped individually. Modern ICT allows the integration of many working steps. This has major influences on the labor productivity. In this context, Balkhausen mentions the connection between the technological integration and the sectoral integration. (Picot 1986) Based on the same basic technology, both of these areas of application are merging into a new and individual area of application. The modern labor productivity is subject to a fundamental structural change. This theoretical approach can be proven to be true for the practical working process by comparing the historical production process of Henry Ford with the modern production lines in the area of automobile manufacturing. When considering manufacturing companies, a holistic integration of all elements of ICT has taken place. 


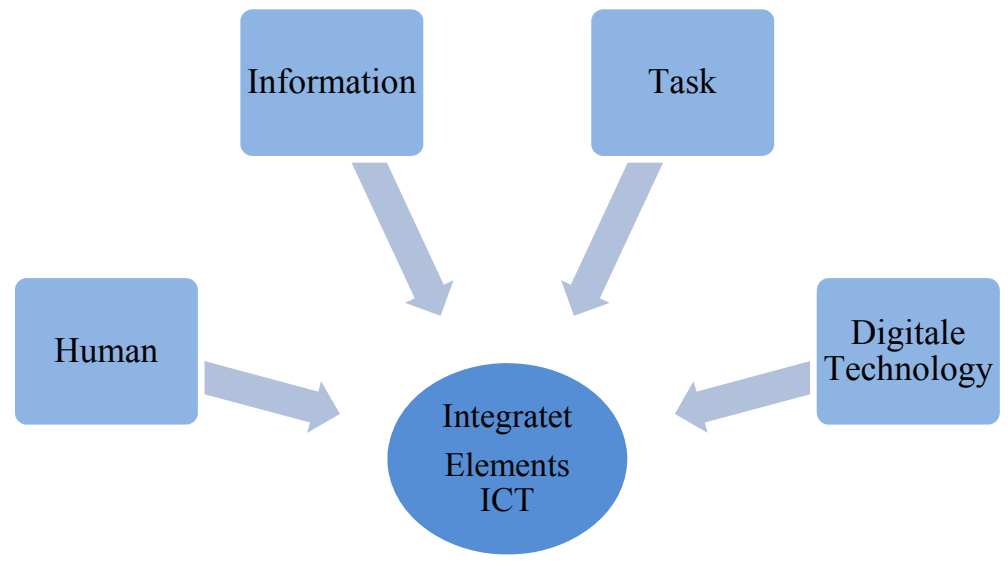

Figure 7 Integrated Elements of the Information and Communication Technology (ICT)

The implementation of modern ICT can be said to be the integration of the various elements, Human, Task, Digital Technology and Information as a whole new element. ICT takes a holistic approach and guarantees a productive way of working, when it is optimized.

\subsubsection{Implementation of Information and Communication Technology}

Besides the much-described change it can be speculated that information and communication technology offers a great deal of applications to sustainably improve labor productivity. Remembering the early stages of automobile industry - to continue the already mentioned example of Ford - and comparing it with the modern production lines consisting of the assembly line of modern automobile industry, the past technical and automated chance clearly becomes obvious. To give one example, this can be emphasized 
by considering modern painting lines. In the past, many workers were busy painting vehicles by hand. In the modern manufacturing plants of today, this is completely done by using automated painting robots - not a single human worker is needed for this working process. Therefore the following question arises: which influence does the ICT have on the economic growth and the productivity? Many studies have been conducted analyzing this topic and these studies prove the impact of ICT on the growth of productivity in the United States of America. (Kretschmer and Strobel 2012)

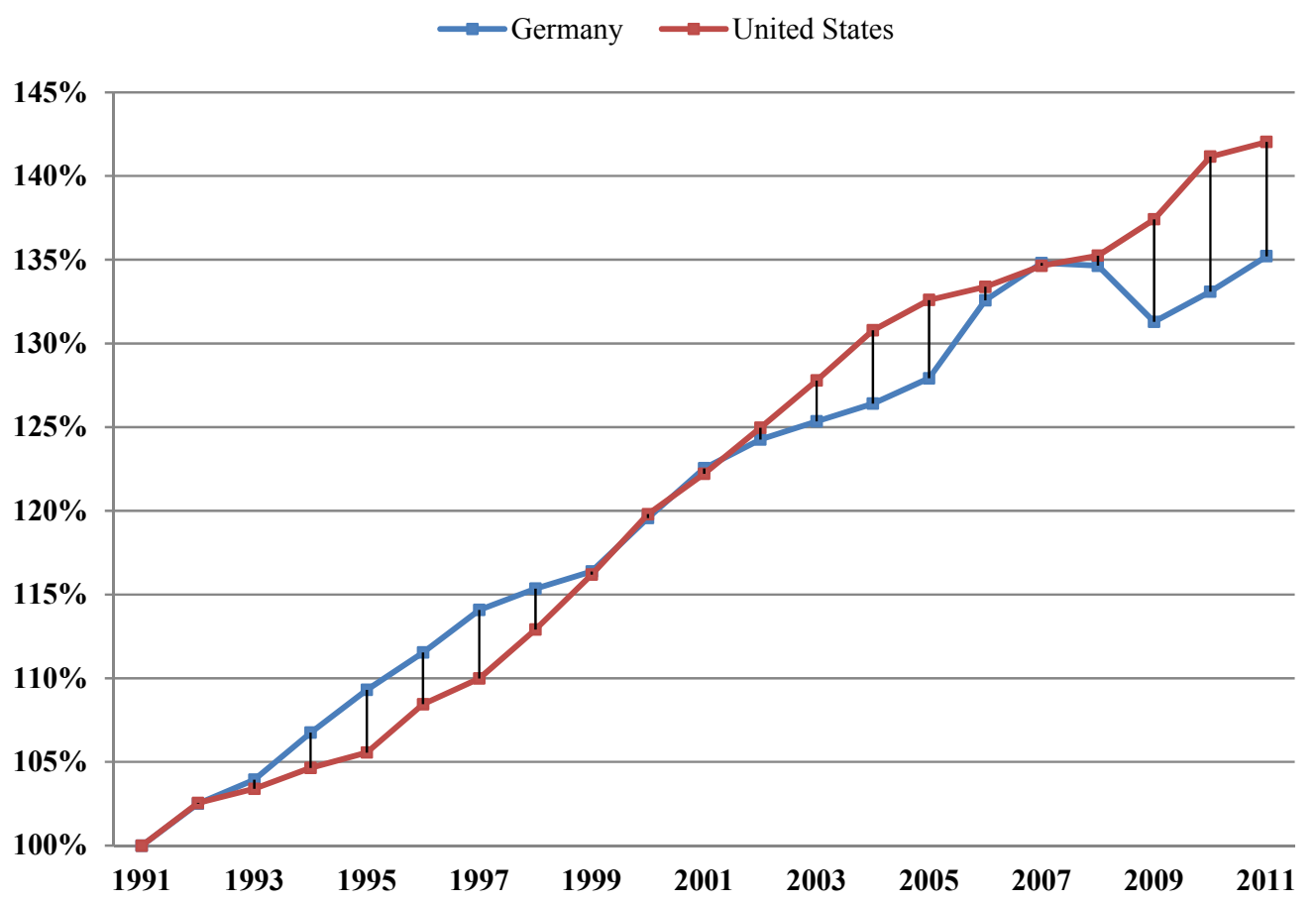

Figure 8 Labor Productivity per Hour Worked Converted to 2011 Price Level (Index: 1991=100)

(The Conference Board 2011)

Kretschmer and Strobel did a research work on IKT und Produktivität: Identifikation und Beitrag des IKT-Effekts in der empirischen Forschung in 2012 and pointed out the connection between the usage of ICT and productivity. Kretschmer states 
that there are various approaches that can be examined. Besides the Growth Accounting Approach there is another one called Output Elasticity Approach. (Kretschmer and Strobel 2012) However, due to the existing conclusions no clear statement can be made about the factual context of the increase in productivity and the increased use of ICT when using this method.

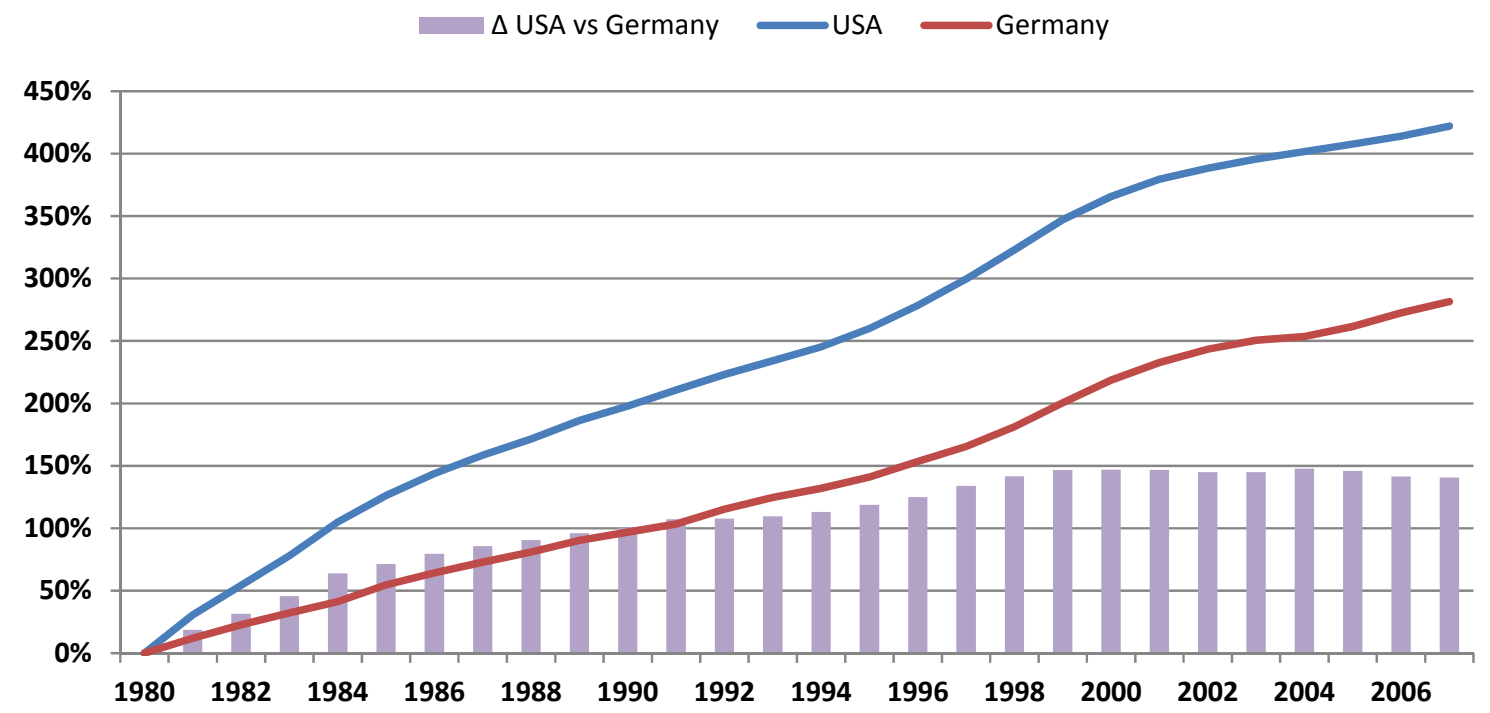

Figure 9 ICT capital services per hour worked, total Industries 1980-2007

(EUKLEMS 2011)

According to Kretschmer various researches in the field of growth accounting emphasize the various positive influences of the expenses that are spent on information and communication technology on the labor productivity. (Kretschmer, Cardona et al. 2012) It is particularly interesting to see the results when comparing the development of company investments in the United States of America and the Federal Republic of Germany. Until the beginning of the 1980s, the investments in ICT of both countries were roughly the same, but afterwards the investments in the United States of America 
increased considerably. The gap between these two countries particularly increased starting with the year 1992. This might be an answer to the question, why the European economy has been growing slower that the economy of the United States of America. In Economic Growth in Europe there is a detailed research. Bad investments in the field of information and communication technology are one of the mentioned causes, why Europe and the Federal Republic of Germany are lagging behind the United States of America since the 1990s. (Timmer, Inklaar et al. 2012)

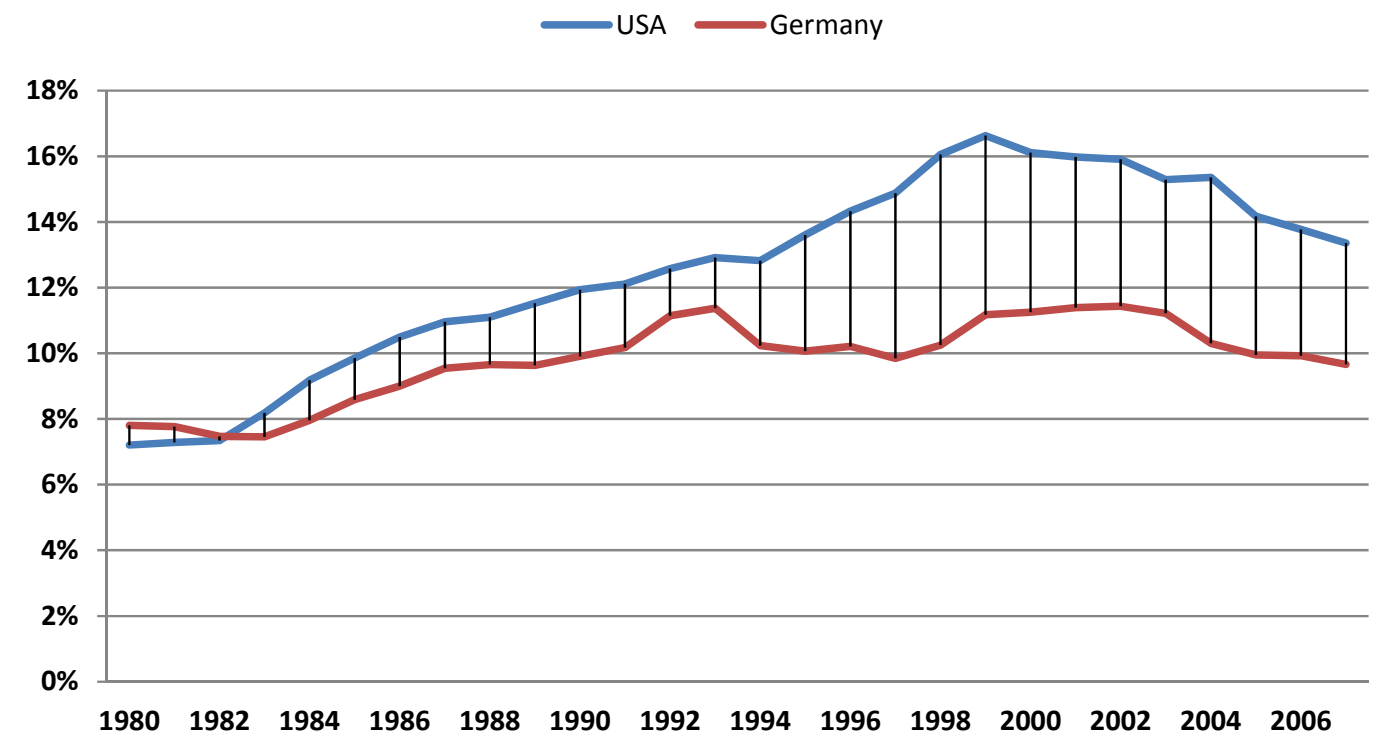

Figure 10 ICT Capital Share in Total Capital 1980 - 2007

(EUKLEMS 2011)

The progressive use of information and communications technologies (ICT) in modern business is beyond any question. Also thereby generated advantages for the communication within an organization are clear. Especially multinational companies have a great benefit out of modern ICTS. There is the chance - within in a short 
timeframe - to have an internal and external communication by the rapid exchange of information over all continents.

But already Fayol and Barnard who have had a more detailed view on the organizational structure of productive solution have likely participated in the great benefits of ICT. It must also be assumed that Henry Ford has benefited from the great advantages of ICT. Otherwise the development of his company wouldn't be so successful without an excellent use of ICT at this time.

\subsubsection{The Paradox of Productivity of the ICT}

By using information and communication technology, the working process has fundamentally changed in many areas. The great number of possibilities that could result from this fact may lead to the conclusion that the use of modern ICT in the modern working environment is causing a significant facilitation of the production sequences and processes. Therefore it can be concluded that ICT is eventually having positive influences on labor productivity. In order to ensure this, some factors must be taken into account, stating that the controlled use of ICT also has the expected effects in the working environment. The effect of the paradox of productivity must be avoided in this context. This effect proves that despite the increased use of modern ICT the desired increase in profitability and productivity is not achieved. (Piller 1998) Especially till the beginning of the 90 s of the 21 st century a great number of researches were conducted examining the influence of the use of modern information and communication technology with respect to the productivity resulting in many different findings (Gargallo-Castel and Galve- 
Górriz 2007) Already in the year 1996, Brynjolfsson and Yang (1996) gave various explanations with respect to the existence and the associated different results that are illustrating this fact.

(1) The difficulty of the quantitative measurement of the investment of ICT and its consequences

(2) The allocation of the temporal effects between use and consequence

(3) Overinvestment

(4) Mutual occurrence of the increase in productivity when considering different companies - Zero-Sum-Game. (Brynjolfsson and Yang 1996)

Independent of these perils that can lead to a paradox of productivity by using information and communication technology, it must be considered as a feasible option that there always is a temporal delay with respect to the effects and consequences of using the input and the effects of the output - irrespectively of the means that are used. An "as is" implementation at time zero is only possible by using a theoretical approach and by assuming that all other influencing factors are constant at point in time $\mathrm{t}+1$. This results in an equation for the growth of productivity based on the technical progress: 


$$
\begin{array}{ll}
Y_{0}=C_{0} L_{c} t P_{0} & Y_{1}=C_{0} L_{c} t P_{1} \\
Y_{0}=\text { Total Productivity Growth } & Y_{1}=\text { Total Productivity Growth } \\
C_{0}=\text { Capital } & C_{0}=C_{1} \\
L_{0}=\text { Labor } & L_{0}=L_{1} \\
t P_{0}=\text { Technical Progress } & t P_{1}=\text { Technical Progress }
\end{array}
$$

The growth rate of the technical progress is achieved by:

$$
\frac{t P_{1}}{t P_{0}}=\Delta t P
$$

This results in the growth rate for the total productivity growth

$$
\frac{Y_{1}}{Y_{0}}=\Delta Y
$$

It is interesting to study the effects of the usage of modern information and communication technology on the different branches. The below illustration explains this and it describes the use of capital for ICT for each hour of actual work of selected industries in the United States of America. It becomes obvious that - especially with the beginning of the 1990s - the use of information and communication technology is disproportionately increasing. Additionally the different use of ICT in different industries becomes obvious. Whereas the manufacturing branches like Pulp, Paper, Printing and Publishing (PPP), Construction (The Conference Board), Mining and Quarrying (MQ) and Food, Beverages and Tobacco (FBT) register only a moderate use, the use of ICT is substantially increased in industries like Electricity, Gas and Water Supply (EGWS), 
Transport and Storage and Communication (TSC) and Chemicals and Chemical Products (CCP).

$\begin{array}{llll}\text { TOTIND } & \text { TOTALINDUSTRIES } & \text { EOE } & \text { Electrical and Optical Equipment } \\ \text { MQ } & \text { Minning and Quarrying } & \text { EGWS } & \text { Electricity, Gas and Water Supply } \\ \text { FBT } & \text { Food, Beverages and Tabacco } & \text { CON } & \text { Construction } \\ \text { TLF } & \text { Textiles, Leather and Footwear } & \text { WRT } & \text { Wholesale and Retail Trade } \\ \text { WWC } & \text { Wood and of Wood and Cork } & \text { TSC } & \text { Transport and Stroage and Communication } \\ \text { PPPP } & \text { Pulp, Paper, Printing and Publishing } & \text { FIREBS } & \text { Finance, Insurance, Real Estate and Business Service } \\ \text { CRPF } & \text { Chemical, Rubber, Plastics and Fuel } & \text { EDU } & \text { Education } \\ \text { CCP } & \text { Chemicals and Chemical Products } & \text { HSW } & \text { Health and Social Work } \\ \text { MQ } & \text { Machinery } & & \end{array}$

Table 1 Abbreviations Explanation of selected industries USA

(EUKLEMS 2011)

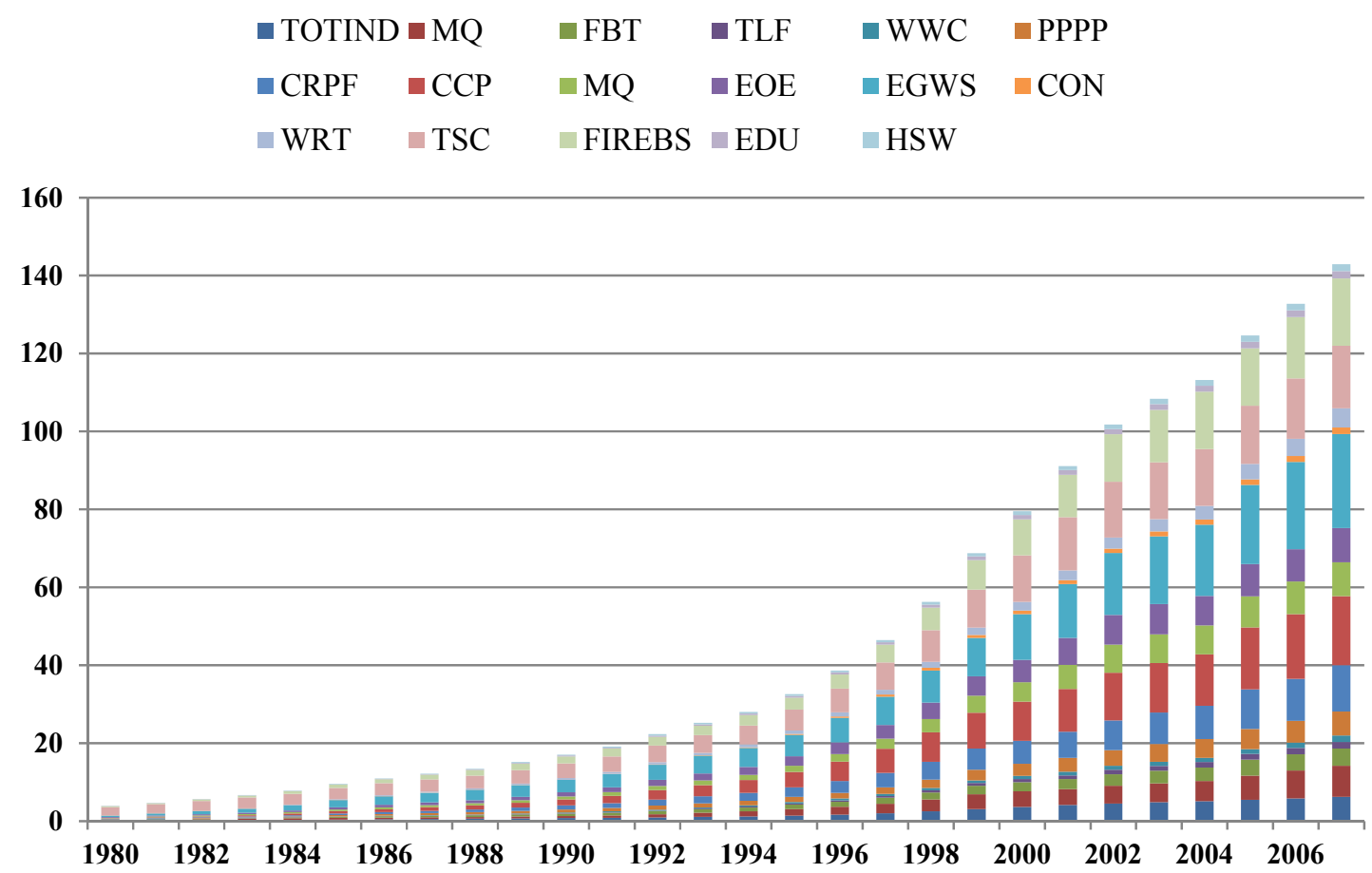

Figure 11 ICT Capital Services per Hour Worked, 1995 Reference 1980 - 2007

(EUKLEMS 2011) 
It is interesting to directly observe the development of the gross domestic product, the hourly productivity, the labor force and the volume of work of the United States of America. This shows that the increased strategic use of technical tools and the optimized use of machinery - respectively the continuously increasing use of ICT starting in the 1990 s - lead to a significant increase of the resiliency of the gross domestic product of the United States of America and this results in a continuous increase of the delta between input and output.

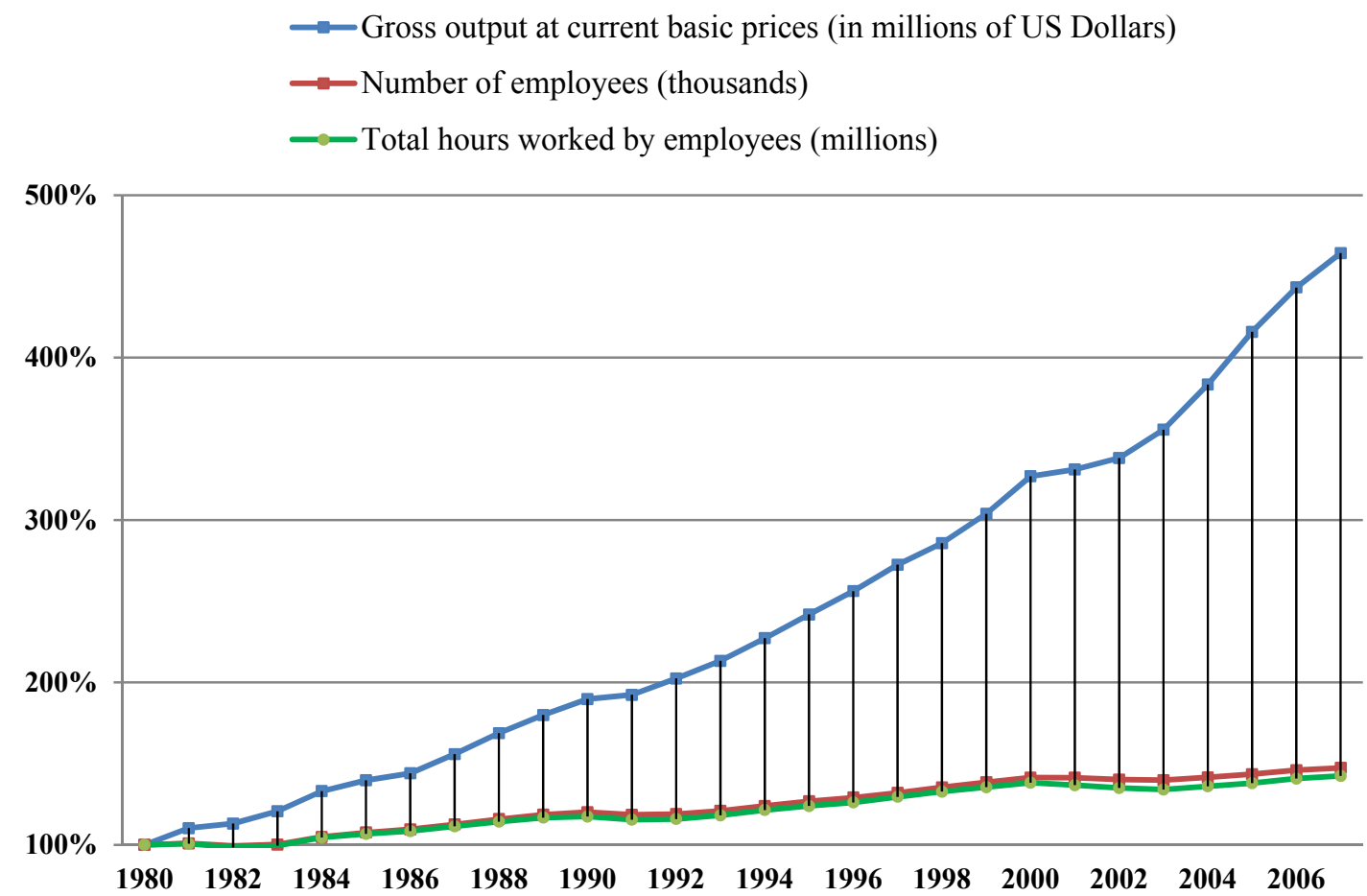

Figure 12 The $\Delta$-Scissor $1980-2007$

(The Conference Board 2011)

The results of various researches were able to prove that a target-oriented and rational use of information and communication technology can have positive influences on the labor productivity. It is not surprising that different industries use a varied amount or 
degree of ICT - this is due to the fact that there are different tasks that must be accomplished in each industry. Besides the purely technical applications in the area of ICT there is another influencing factor that has effects on the labor productivity of the different industries - the broadband technology. Broadband technology is only possible since the existence of modern ICT and therefore it is one of the key elements of labor productivity that is interesting for modern industrial companies. In this context, the research paper Broadband Infrastructure and Economic Growth analyzed the effects of broadband technology on the economic growth of different countries. Of course it must be taken into consideration that this technology is only one of the key elements of many influencing factors. Nevertheless it becomes clear that Gross Domestic Product (GDP) per capital has increased by 2.7 and 3.9 on average by introducing broadband technology. (Czernich, Falck et al. 2009) 


\section{ANALYSES OF THE LABOR PRODUCTIVITY}

\subsection{The approaches of the different pioneers}

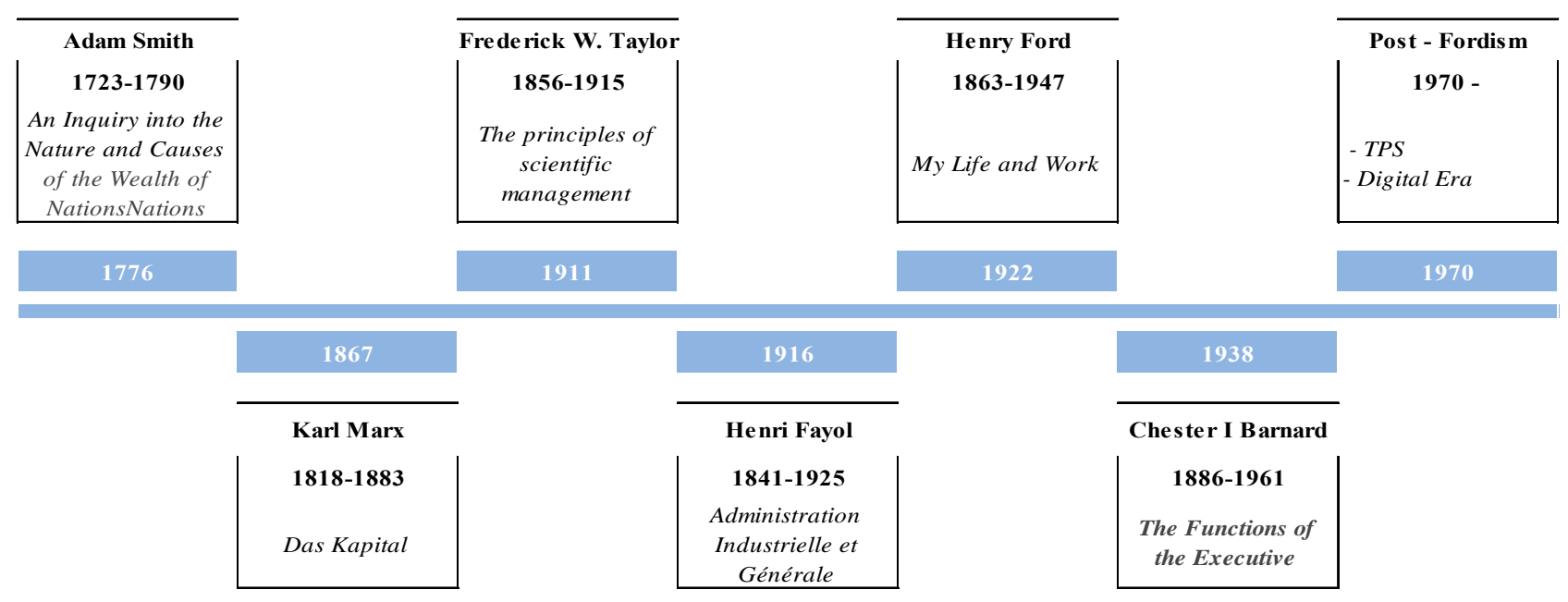

Figure 13 The Influence Giants of Modern Labor Productivity

Figure 12 shows the timeline over the last 250 years with the outstanding personalities who have made a significant contribution in labor productivity and therefor in the field of Industrial Engineering. In his publication in 1776 Adam Smith already began to investigate first steps for an optimized and targeted work. And this happened at a time when the industrial age was even more widely in the future, and the people were characterized by very different daily tasks. 
By identifying the key factors of labor productivity of each analyzed pioneer the following table come up.

\begin{tabular}{|c|c|c|c|c|c|c|c|}
\hline & $\begin{array}{l}\text { Adam Smith } \\
\text { 1723-1790 }\end{array}$ & $\begin{array}{l}\text { Karl Marx } \\
1818-1883\end{array}$ & \begin{tabular}{|c|} 
Frederick W. Taylor \\
$1856-1915$
\end{tabular} & $\begin{array}{l}\text { Henri Fayol } \\
\text { 1841-1925 }\end{array}$ & $\begin{array}{l}\text { Henry Ford } \\
1863-1947\end{array}$ & $\begin{array}{c}\text { Chester I. Barnard } \\
\text { 1886-1961 }\end{array}$ & $\begin{array}{l}\text { Post Fordism } \\
\text { 1960-Today } \\
\text { (TPS \& ICT) }\end{array}$ \\
\hline \begin{tabular}{|l} 
Skill \\
Avoidance of Waste \\
Usage of machines
\end{tabular} & $\begin{array}{l}x \\
x \\
x\end{array}$ & & & & & & \\
\hline \begin{tabular}{|l} 
Duration of Work \\
Quantity of Work \\
Intensity of Work
\end{tabular} & & $\begin{array}{l}x \\
x \\
x\end{array}$ & & & & & \\
\hline $\begin{array}{l}\text { Clear Work Definition } \\
\text { Workforce and Training } \\
\text { Cooperation } \\
\text { Joint Responisbility } \\
\end{array}$ & & & $\begin{array}{l}x \\
x \\
x \\
x \\
\end{array}$ & & & & \\
\hline \begin{tabular}{|l|} 
Outlook and Planning \\
Organization \\
Coordination \\
Control \\
Instructions \\
\end{tabular} & & & & $\begin{array}{l}x \\
x \\
x \\
x \\
x\end{array}$ & & & \\
\hline \begin{tabular}{|l|} 
Smaller Working Steps \\
Laber Division \\
Batch Production \\
Standartization \\
Conveyor-Belt Production \\
Training of the Workers \\
Responsibility \\
Equity and Equal Opportunities \\
Motivation \\
Fair Working Conditions \\
\end{tabular} & & & & & $\begin{array}{l}x \\
x \\
x \\
x \\
x \\
x \\
x \\
x \\
x \\
x\end{array}$ & & \\
\hline \begin{tabular}{|l|} 
Spezicalization \\
Incentive \\
Authority \\
Decisicin \\
Opportunity \\
\end{tabular} & & & & & & $\begin{array}{l}x \\
x \\
x \\
x \\
x\end{array}$ & \\
\hline $\begin{array}{l}\text { Technical Equipment } \\
\text { Task } \\
\text { Training } \\
\text { Standartization } \\
\text { Avoidance of Waste } \\
\text { Quality of Work } \\
\text { Respect and Teamwork } \\
\end{array}$ & & & & & & & $\begin{array}{l}x \\
x \\
x \\
x \\
x \\
x \\
x \\
\end{array}$ \\
\hline
\end{tabular}

Table 2 Key factors on labor productivity - Selected pioneers 


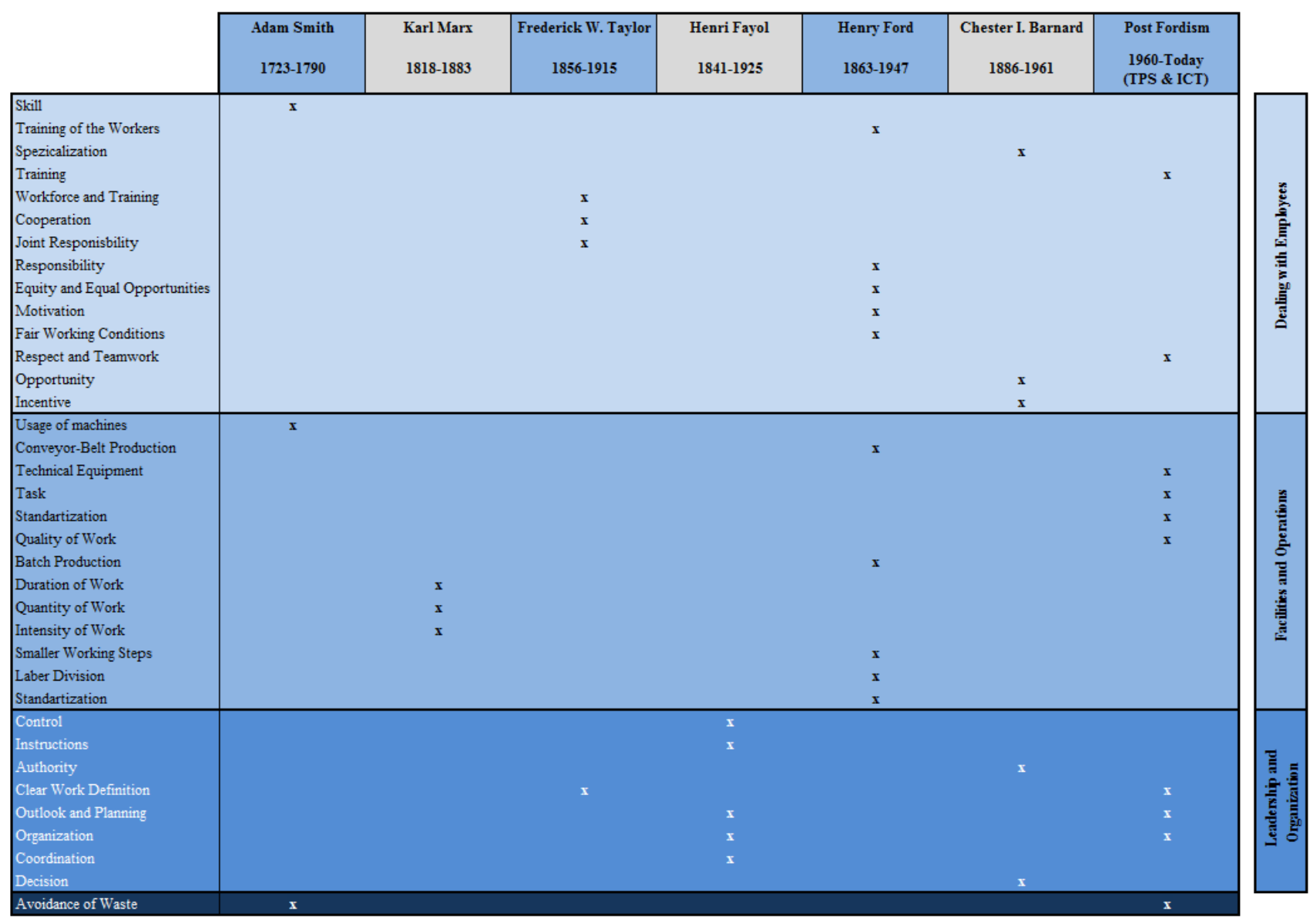

Table 3 Analyze of the approaches in labor productivity - Selected pioneers

Basically interesting that closer analyze of the various approaches reduces the variety of approaches to just a three groups.

(1) Dealing with Employees

(2) Facilities and Operations

(3) Leadership and Organization 
Likewise, it can be said that Karl Marx and Henri Fayol have dealt exclusively with one aspect of the productivity environment while the approaches of the other mastermind is not limited exclusively to only one aspect of the manufacturing process. Their approaches refer to cross sections of the single stages of production.

Also with interest may be noted that the elimination of waste - while at the very beginning with Adam Smith - as a fundamental aspect of the labor productivity, only again in modern times was crucial consideration. The elimination of waste is in the Toyota Production System an extremely important element of successful operation and represents thus for sustainable productivity.

It is also interesting to directly compare the individual pioneers of labor productivity.

It becomes clear that Chester I. Barnard and Henry Fayol have approaches to labor productivity that target organizational aspects of the company. Both of these pioneers try to achieve an optimization of the processes and the organizational structures of the company by implementing their respective key factors - and this directly results in an influence on the work and therefore an increase in efficiency. But in this respect Barnard goes the extra mile. Besides the purely organizational approach of Fayol, Barnard also wants to achieve positive effects for the labor productivity for the management of the company. Here, Barnard primarily focuses the executive function, the executive process and the executive responsibility. Nevertheless, both approaches take into account the importance of the formal organization in the company. The formal organization in a society - irrespective of the form, e.g. in working teams - plays a crucial role with respect to the success or the failure of a company that must not be 
underestimated. This importance was recognized by Barnard in a very early stage of his works and contrary to Fayol Barnard uses it as a key element for his labor productivity.

Therefore, the direct comparison of two pioneers is a very interesting one. A profound look on Marx and Taylor shows the contrasting approach to labor productivity. Whereas Marx primarily concentrates on the work itself, Frederick W. Taylor uses a holistic approach. The approach of Marx emphasizes the duration, the quantity of work and the intensity of labor. However, the key elements of Taylor for the productive work are based on the contact with the individual workers as well as the management and the organization of the company. The economical and sociological approaches of Taylor with respect to the labor productivity emphasize very clearly the holistic approach of Taylor. Whereas Taylor considers the employer and the employee to be in a mutual relation for the sustainable productive way of working, Marx wants to foster productive elements due to his research in the field of work.

Another comparison of two outstanding figures in the field of labor productivity is Frederick W. Taylor and Henry Ford. The two previous comparisons of the pioneers illustrated the opposing positions. However, analyzing Ford and Taylor reveals an intersection of the approaches and a similarity of the key elements. Both Ford and Taylor gathered their insights of labor productivity in everyday business operations. Both approaches focused on a specialization of the individual working steps and a preceding education and training of the individual manufacturing processes. Furthermore, both aspects emphasize the need that all works are the individual responsibilities of the respective worker. The development of chances also has a great significance in both of the concepts. Taylor speaks of the cooperation between the management and the workers. 
Ford on the other side speaks of motivation. Whatever name this element is given, the result is the same in both of the approaches. The workers and the management can only be productive together, if both parties are working together and if there are equal opportunities that grant the possibility to contribute to the design process in an active and positive way and therefore to achieve a productive way of working. Frederick W. Taylor does not have a contrary position to Henry Ford. The approach of Taylor can rather be considered to be a proactive development of Ford. If there is a combination of both these approaches, this is a great opportunity to improve labor productivity.

The depicted elements of productivity were used to generate the increase in productivity of the individual companies in the previous years and decades. Of course, the individual elements generated varying manifestations for the individual companies subject to the respective application and industry.

This will become obvious when comparing the increase in productivity with the performance of the previous years. Besides product innovations and the technological progress there is one essential element for long-term success and the development and the survivability of a company: labor productivity. 


\subsection{The development of productivity in comparison with labor wages}

After being able to identify the basic principle of labor productivity of the individual pioneers it is interesting to examine the related development of the employee's wages. For this purpose, the employee's wages shall be compared with the real output per hour (rOPH) to show the respective development of both parameters in direct comparison. To facilitate this comparison, data of the US Bureau of Labor Statistics was used to analyze and subsequently compare the actual employee's wages with the real output per Hour (rOPH). The following diagram is the result of this examination. 
U.S. Output per hour

in manufacturing

1950-2011

$($ Index: 2002 = 100)

\begin{tabular}{l|l} 
& \\
Year & Basis \\
& \\
$\mathbf{1 9 5 0}$ & 19.53 \\
$\mathbf{1 9 5 1}$ & 20.17 \\
$\mathbf{1 9 5 2}$ & 20.55 \\
$\mathbf{1 9 5 3}$ & 20.92 \\
$\mathbf{1 9 5 4}$ & 21.33 \\
$\mathbf{1 9 5 5}$ & 22.29 \\
$\mathbf{1 9 5 6}$ & 21.83 \\
$\mathbf{1 9 5 7}$ & 22.45 \\
$\mathbf{1 9 5 8}$ & 22.52 \\
$\mathbf{1 9 5 9}$ & 23.54 \\
$\mathbf{1 9 6 0}$ & 23.67 \\
$\mathbf{1 9 6 1}$ & 24.33 \\
$\mathbf{1 9 6 2}$ & 25.50 \\
$\mathbf{1 9 6 3}$ & 27.24 \\
$\mathbf{1 9 6 4}$ & 28.55 \\
$\mathbf{1 9 6 5}$ & 29.64 \\
$\mathbf{1 9 6 6}$ & 30.21 \\
$\mathbf{1 9 6 7}$ & 30.22 \\
$\mathbf{1 9 6 8}$ & 31.38 \\
$\mathbf{1 9 6 9}$ & 31.82 \\
$\mathbf{1 9 7 0}$ & 31.92 \\
$\mathbf{1 9 7 1}$ & 33.98 \\
$\mathbf{1 9 7 2}$ & 35.44 \\
$\mathbf{1 9 7 3}$ & 37.20 \\
$\mathbf{1 9 7 4}$ & 36.31 \\
$\mathbf{1 9 7 5}$ & 37.57 \\
$\mathbf{1 9 7 6}$ & 39.61 \\
$\mathbf{1 9 7 7}$ & 41.10 \\
$\mathbf{1 9 7 8}$ & 41.47 \\
$\mathbf{1 9 7 9}$ & 42.03 \\
& \\
\hline
\end{tabular}

\begin{tabular}{cc} 
Development & cumulated \\
& \\
$0.00 \%$ & $0.00 \%$ \\
$3.30 \%$ & $3.30 \%$ \\
$1.89 \%$ & $5.19 \%$ \\
$1.80 \%$ & $6.99 \%$ \\
$1.93 \%$ & $8.92 \%$ \\
$4.52 \%$ & $13.44 \%$ \\
$-2.06 \%$ & $11.38 \%$ \\
$2.82 \%$ & $14.20 \%$ \\
$0.31 \%$ & $14.51 \%$ \\
$4.53 \%$ & $19.04 \%$ \\
$0.59 \%$ & $19.62 \%$ \\
$2.76 \%$ & $22.39 \%$ \\
$4.81 \%$ & $27.20 \%$ \\
$6.85 \%$ & $34.05 \%$ \\
$4.81 \%$ & $38.86 \%$ \\
$3.80 \%$ & $42.66 \%$ \\
$1.92 \%$ & $44.58 \%$ \\
$0.03 \%$ & $44.62 \%$ \\
$3.82 \%$ & $48.44 \%$ \\
$1.42 \%$ & $49.86 \%$ \\
$0.31 \%$ & $50.17 \%$ \\
$6.45 \%$ & $56.62 \%$ \\
$4.29 \%$ & $60.91 \%$ \\
$4.99 \%$ & $65.90 \%$ \\
$-2.40 \%$ & $63.49 \%$ \\
$3.47 \%$ & $66.96 \%$ \\
$5.42 \%$ & $72.38 \%$ \\
$3.77 \%$ & $76.15 \%$ \\
$0.90 \%$ & $77.05 \%$ \\
$1.37 \%$ & $78.41 \%$ \\
& \\
\hline
\end{tabular}

U.S. Real average annual compensation

in manufacturing

1950-2011

(Index: $2002=\mathbf{1 0 0}$ )

Basis

Development

cumulated

$\begin{array}{lll}42.34 & 0.00 \% & 0.00 \%\end{array}$

$\begin{array}{lll}43.25 & 2.15 \% & 2.15 \%\end{array}$

$\begin{array}{lll}45.19 & 4.50 \% & 6.65 \%\end{array}$

$\begin{array}{lll}47.14 & 4.30 \% & 10.95 \%\end{array}$

$\begin{array}{lll}48.08 & 1.99 \% & 12.95 \%\end{array}$

$\begin{array}{lll}51.10 & 6.30 \% & 19.25 \%\end{array}$

$\begin{array}{lll}53.23 & 4.16 \% & 23.40 \%\end{array}$

$\begin{array}{lll}53.95 & 1.35 \% & 24.75 \%\end{array}$

$\begin{array}{lll}54.24 & 0.55 \% & 25.30 \%\end{array}$

$\begin{array}{lll}57.00 & 5.09 \% & 30.39 \%\end{array}$

$\begin{array}{lll}57.75 & 1.31 \% & 31.70 \%\end{array}$

$\begin{array}{lll}58.94 & 2.06 \% & 33.76 \%\end{array}$

$\begin{array}{lll}61.11 & 3.68 \% & 37.44 \%\end{array}$

$\begin{array}{lll}62.22 & 1.82 \% & 39.26 \%\end{array}$

$\begin{array}{lll}64.30 & 3.34 \% & 42.60 \%\end{array}$

$\begin{array}{lll}65.38 & 1.68 \% & 44.28 \%\end{array}$

$\begin{array}{lll}66.53 & 1.76 \% & 46.04 \%\end{array}$

$\begin{array}{lll}66.84 & 0.47 \% & 46.51 \%\end{array}$

$\begin{array}{lll}68.86 & 3.02 \% & 49.53 \%\end{array}$

$69.52 \quad 0.96 \% \quad 50.49 \%$

$\begin{array}{lll}68.95 & -0.82 \% & 49.67 \%\end{array}$

$\begin{array}{lll}70.15 & 1.73 \% & 51.40 \%\end{array}$

$\begin{array}{lll}72.60 & 3.50 \% & 54.90 \%\end{array}$

$\begin{array}{lll}73.49 & 1.23 \% & 56.13 \%\end{array}$

$\begin{array}{lll}72.14 & -1.84 \% & 54.29 \%\end{array}$

$\begin{array}{lll}73.02 & 1.22 \% & 55.51 \%\end{array}$

$\begin{array}{lll}75.64 & 3.59 \% & 59.09 \%\end{array}$

$\begin{array}{lll}77.62 & 2.62 \% & 61.71 \%\end{array}$

$\begin{array}{lll}77.98 & 0.47 \% & 62.18 \%\end{array}$

$\begin{array}{lll}77.64 & -0.43 \% & 61.75 \%\end{array}$

Table 4 Analyze rOPH with rAAC 1950 - 2011 Part I (Index 2002)

(U.S. Bureau of Labor Statistics 2010) 
U.S. Output per hour

in manufacturing

1950-2011

\begin{tabular}{l|l} 
& \\
Year & Basis \\
& \\
$\mathbf{1 9 8 0}$ & 41.71 \\
$\mathbf{1 9 8 1}$ & 43.99 \\
$\mathbf{1 9 8 2}$ & 44.37 \\
$\mathbf{1 9 8 3}$ & 47.51 \\
$\mathbf{1 9 8 4}$ & 48.85 \\
$\mathbf{1 9 8 5}$ & 50.58 \\
$\mathbf{1 9 8 6}$ & 51.40 \\
$\mathbf{1 9 8 7}$ & 54.96 \\
$\mathbf{1 9 8 8}$ & 57.08 \\
$\mathbf{1 9 8 9}$ & 57.38 \\
$\mathbf{1 9 9 0}$ & 58.06 \\
$\mathbf{1 9 9 1}$ & 59.68 \\
$\mathbf{1 9 9 2}$ & 61.98 \\
$\mathbf{1 9 9 3}$ & 63.63 \\
$\mathbf{1 9 9 4}$ & 66.28 \\
$\mathbf{1 9 9 5}$ & 68.54 \\
$\mathbf{1 9 9 6}$ & 70.88 \\
$\mathbf{1 9 9 7}$ & 73.81 \\
$\mathbf{1 9 9 8}$ & 77.69 \\
$\mathbf{1 9 9 9}$ & 82.43 \\
$\mathbf{2 0 0 0}$ & 88.83 \\
$\mathbf{2 0 0 1}$ & 90.66 \\
$\mathbf{2 0 0 2}$ & 100.00 \\
$\mathbf{2 0 0 3}$ & 108.49 \\
$\mathbf{2 0 0 4}$ & 117.97 \\
$\mathbf{2 0 0 5}$ & 123.43 \\
$\mathbf{2 0 0 6}$ & 127.64 \\
$\mathbf{2 0 0 7}$ & 134.39 \\
$\mathbf{2 0 0 8}$ & 131.79 \\
$\mathbf{2 0 0 9}$ & 137.27 \\
$\mathbf{2 0 1 0}$ & 152.68 \\
$\mathbf{2 0 1 1}$ & 155.74 \\
\hline
\end{tabular}

(Index: 2002 = 100)

\begin{tabular}{cc} 
Development & cumulated \\
& \\
$-0.76 \%$ & $77.65 \%$ \\
$5.45 \%$ & $83.11 \%$ \\
$0.86 \%$ & $83.97 \%$ \\
$7.08 \%$ & $91.05 \%$ \\
$2.81 \%$ & $93.86 \%$ \\
$3.56 \%$ & $97.41 \%$ \\
$1.63 \%$ & $99.04 \%$ \\
$6.92 \%$ & $105.96 \%$ \\
$3.86 \%$ & $109.82 \%$ \\
$0.53 \%$ & $110.35 \%$ \\
$1.19 \%$ & $111.53 \%$ \\
$2.78 \%$ & $114.32 \%$ \\
$3.85 \%$ & $118.17 \%$ \\
$2.66 \%$ & $120.83 \%$ \\
$4.16 \%$ & $124.99 \%$ \\
$3.41 \%$ & $128.40 \%$ \\
$3.42 \%$ & $131.82 \%$ \\
$4.13 \%$ & $135.95 \%$ \\
$5.26 \%$ & $141.22 \%$ \\
$6.10 \%$ & $147.31 \%$ \\
$7.77 \%$ & $155.08 \%$ \\
$2.06 \%$ & $157.14 \%$ \\
$10.30 \%$ & $167.44 \%$ \\
$8.49 \%$ & $175.93 \%$ \\
$8.74 \%$ & $184.67 \%$ \\
$4.63 \%$ & $189.30 \%$ \\
$3.41 \%$ & $192.70 \%$ \\
$5.29 \%$ & $198.00 \%$ \\
$-1.94 \%$ & $196.06 \%$ \\
$4.16 \%$ & $200.22 \%$ \\
$11.23 \%$ & $211.45 \%$ \\
$2.00 \%$ & $213.45 \%$ \\
\hline & \\
\hline
\end{tabular}

U.S. Real average annual compensation

in manufacturing

1950-2011

(Index: 2002 = 100)

$\begin{array}{lll}\text { Basis } & \text { Development } & \text { cumulated } \\ & & \\ 77.44 & -0.26 \% & 61.48 \% \\ 77.71 & 0.35 \% & 61.83 \% \\ 78.96 & 1.61 \% & 63.44 \% \\ 80.07 & 1.41 \% & 64.85 \% \\ 80.62 & 0.68 \% & 65.53 \% \\ 82.08 & 1.81 \% & 67.34 \% \\ 84.25 & 2.65 \% & 69.99 \% \\ 84.19 & -0.07 \% & 69.91 \% \\ 85.13 & 1.12 \% & 71.04 \% \\ 84.12 & -1.19 \% & 69.85 \% \\ 83.15 & -1.15 \% & 68.69 \% \\ 84.41 & 1.52 \% & 70.21 \% \\ 87.26 & 3.37 \% & 73.58 \% \\ 88.13 & 1.00 \% & 74.58 \% \\ 89.38 & 1.42 \% & 76.00 \% \\ 88.02 & -1.51 \% & 74.48 \% \\ 87.10 & -1.05 \% & 73.43 \% \\ 88.14 & 1.19 \% & 74.62 \% \\ 91.32 & 3.61 \% & 78.23 \% \\ 94.19 & 3.15 \% & 81.38 \% \\ 97.20 & 3.19 \% & 84.57 \% \\ 96.17 & -1.05 \% & 83.52 \% \\ 100.00 & 3.98 \% & 87.50 \% \\ 105.40 & 5.40 \% & 92.90 \% \\ 104.36 & -0.99 \% & 91.91 \% \\ 103.71 & -0.62 \% & 91.29 \% \\ 103.80 & 0.09 \% & 91.37 \% \\ 104.23 & 0.41 \% & 91.79 \% \\ 104.21 & -0.02 \% & 91.77 \% \\ 106.74 & 2.43 \% & 94.20 \% \\ 109.23 & 2.33 \% & 96.53 \% \\ 109.55 & 0.29 \% & 96.82 \%\end{array}$

Table 5 Analyze rOPH with rAAC 1950 - 2011 Part II (Index 2002)

(U.S. Bureau of Labor Statistics 2010) 
By using a graphical representation - that is shown in the following illustration the development becomes particularly obvious.

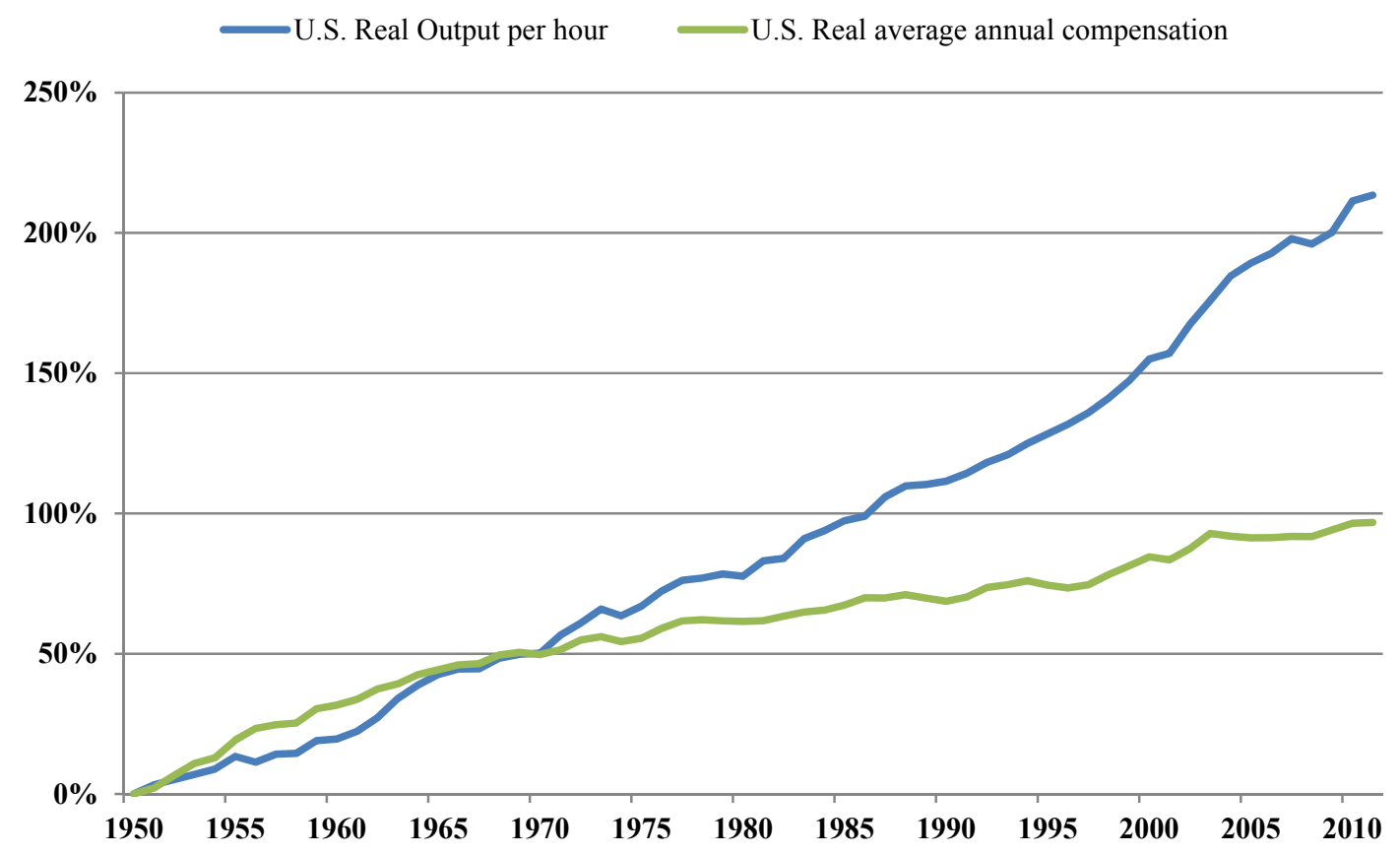

Figure 14 Comparison rOPH and rAAC 1950 - 2011

(U.S. Bureau of Labor Statistics 2010)

Whereas the actual wage increase per year exceeded the increase in productivity per year at the beginning of the 1950s, there was a continually increasing asymmetrical development with the beginning of the 1970s. In addition, this comparison shows that the growing discrepancy between the actual employee's wages and the real output per hour (rOPH) was continually increasing. For the first 20 years the development of the labor productivity (rOPH) and the wages was virtually parallel and was subject to the annual adjustment in this period. From the 1970s onwards these currents drifted apart. 
匹 Spread Real average annual compensation Output per hour

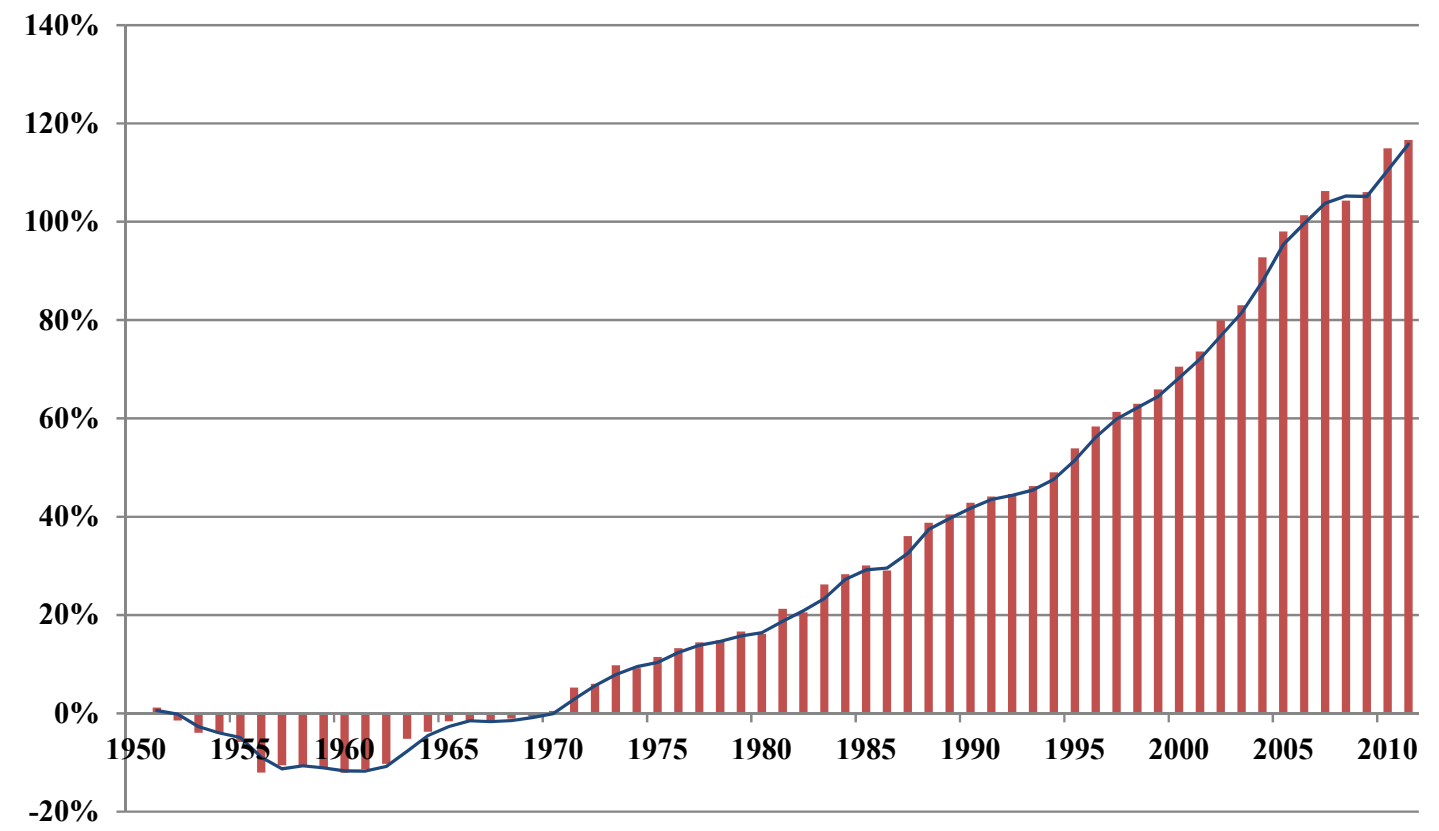

.Figure $15 \Delta$ between Comparison rOPH and rAAC 1950 - 2011

(U.S. Bureau of Labor Statistics 2010) 
Spread Real average annual compensation - Output per hour (1950 - 2011)

\begin{tabular}{|c|c|c|c|c|c|c|c|c|c|}
\hline $\mathbf{1 9 5 0}$ & $\mathbf{1 9 5 1}$ & $\mathbf{1 9 5 2}$ & $\mathbf{1 9 5 3}$ & $\mathbf{1 9 5 4}$ & $\mathbf{1 9 5 5}$ & $\mathbf{1 9 5 6}$ & $\mathbf{1 9 5 7}$ & $\mathbf{1 9 5 8}$ & $\mathbf{1 9 5 9}$ \\
$0.00 \%$ & $1.15 \%$ & $-2.61 \%$ & $-2.51 \%$ & $-0.06 \%$ & $-1.78 \%$ & $-6.21 \%$ & $1.47 \%$ & $-0.24 \%$ & $-0.56 \%$ \\
\hline
\end{tabular}

\begin{tabular}{|c|c|c|c|c|c|c|c|c|c|}
\hline $\mathbf{1 9 6 0}$ & $\mathbf{1 9 6 1}$ & $\mathbf{1 9 6 2}$ & $\mathbf{1 9 6 3}$ & $\mathbf{1 9 6 4}$ & $\mathbf{1 9 6 5}$ & $\mathbf{1 9 6 6}$ & $\mathbf{1 9 6 7}$ & $\mathbf{1 9 6 8}$ & $\mathbf{1 9 6 9}$ \\
$-0.73 \%$ & $0.70 \%$ & $1.13 \%$ & $5.03 \%$ & $1.47 \%$ & $2.12 \%$ & $0.16 \%$ & $-0.43 \%$ & $0.80 \%$ & $0.46 \%$ \\
\hline
\end{tabular}

\begin{tabular}{|c|c|c|c|c|c|c|c|c|c|}
\hline $\mathbf{1 9 7 0}$ & $\mathbf{1 9 7 1}$ & $\mathbf{1 9 7 2}$ & $\mathbf{1 9 7 3}$ & $\mathbf{1 9 7 4}$ & $\mathbf{1 9 7 5}$ & $\mathbf{1 9 7 6}$ & $\mathbf{1 9 7 7}$ & $\mathbf{1 9 7 8}$ & $\mathbf{1 9 7 9}$ \\
$1.13 \%$ & $4.72 \%$ & $0.79 \%$ & $3.76 \%$ & $-0.57 \%$ & $2.25 \%$ & $1.84 \%$ & $1.15 \%$ & $0.43 \%$ & $1.80 \%$ \\
\hline
\end{tabular}

\begin{tabular}{|c|c|c|c|c|c|c|c|c|c|}
\hline $\mathbf{1 9 8 0}$ & $\mathbf{1 9 8 1}$ & $\mathbf{1 9 8 2}$ & $\mathbf{1 9 8 3}$ & $\mathbf{1 9 8 4}$ & $\mathbf{1 9 8 5}$ & $\mathbf{1 9 8 6}$ & $\mathbf{1 9 8 7}$ & $\mathbf{1 9 8 8}$ & $\mathbf{1 9 8 9}$ \\
$-0.50 \%$ & $5.11 \%$ & $-0.75 \%$ & $2.13 \%$ & $-1.02 \%$ & $7.00 \%$ & $-1.02 \%$ & $7.00 \%$ & $2.73 \%$ & $1.72 \%$ \\
\hline
\end{tabular}

\begin{tabular}{|c|c|c|c|c|c|c|c|c|c|}
\hline $\mathbf{1 9 9 0}$ & $\mathbf{1 9 9 1}$ & $\mathbf{1 9 9 2}$ & $\mathbf{1 9 9 3}$ & $\mathbf{1 9 9 4}$ & $\mathbf{1 9 9 5}$ & $\mathbf{1 9 9 6}$ & $\mathbf{1 9 9 7}$ & $\mathbf{1 9 9 8}$ & $\mathbf{1 9 9 9}$ \\
$2.34 \%$ & $1.27 \%$ & $0.48 \%$ & $1.66 \%$ & $2.75 \%$ & $4.92 \%$ & $4.47 \%$ & $2.94 \%$ & $1.65 \%$ & $2.95 \%$ \\
\hline
\end{tabular}

\begin{tabular}{|c|c|c|c|c|c|c|c|c|c|}
\hline $\mathbf{2 0 0 0}$ & $\mathbf{2 0 0 1}$ & $\mathbf{2 0 0 2}$ & $\mathbf{2 0 0 3}$ & $\mathbf{2 0 0 4}$ & $\mathbf{2 0 0 5}$ & $\mathbf{2 0 0 6}$ & $\mathbf{2 0 0 7}$ & $\mathbf{2 0 0 8}$ & $\mathbf{2 0 0 9}$ \\
$4.58 \%$ & $3.11 \%$ & $6.32 \%$ & $3.09 \%$ & $9.72 \%$ & $5.26 \%$ & $3.32 \%$ & $4.88 \%$ & $-1.92 \%$ & $1.73 \%$ \\
\hline
\end{tabular}

\begin{tabular}{|c|c|}
\hline $\mathbf{2 0 1 0}$ & $\mathbf{2 0 1 1}$ \\
$8.90 \%$ & $1.71 \%$ \\
\hline
\end{tabular}

Table 6 Results rOPH and rAAC 1950 - 2011

(U.S. Bureau of Labor Statistics 2010)

When examining these first 20 years it becomes obvious that the cumulative total of the difference between the real average annual compensation (raaC) and the real output per hour (rOPH) are neutralizing each other and result in zero. 
- Spread Real average annual compensation - Output per hour (1950 - 1969)

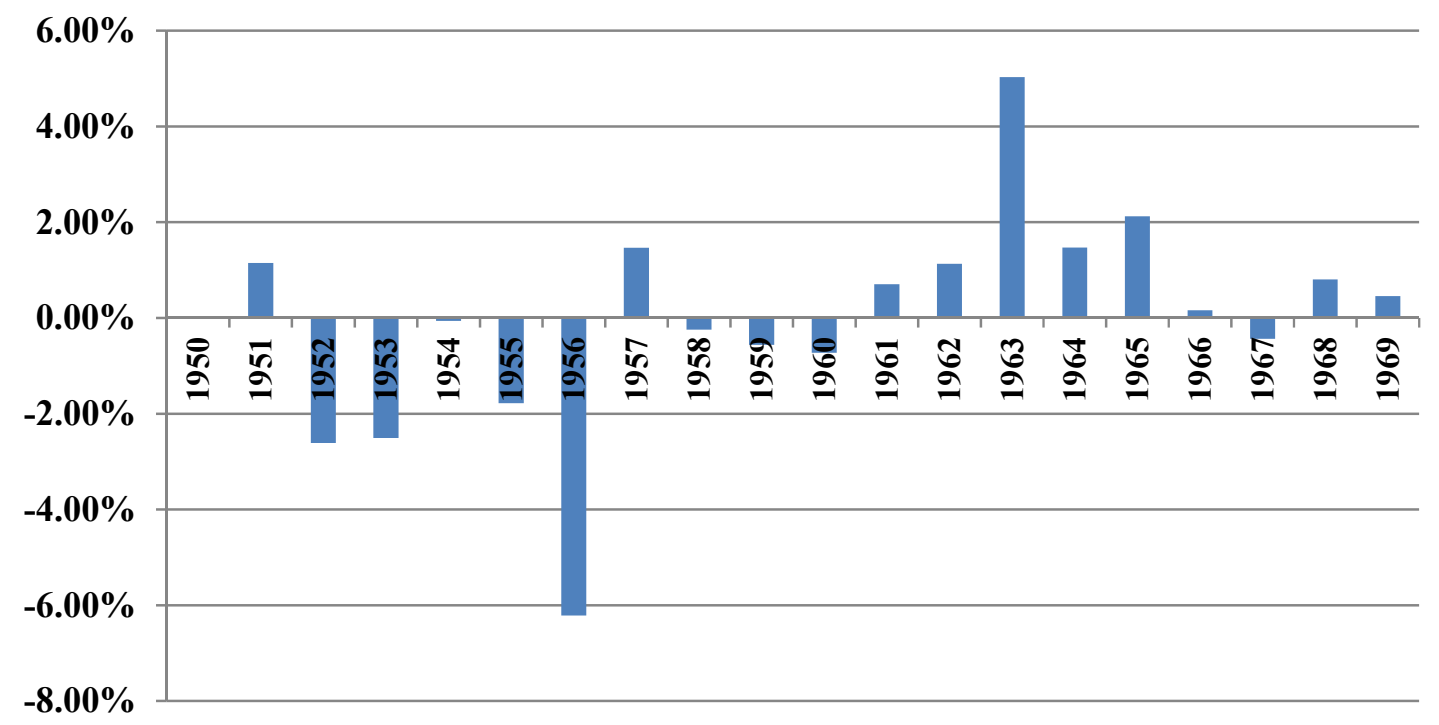

Figure 16 First 20 Years Results rOPH and rAAC 1950 - 1969

(U.S. Bureau of Labor Statistics 2010)

Spread Real average annual compensation - Output per hour (1950 - 1969)

\begin{tabular}{|c|c|c|c|c|c|c|c|c|c|c|c|}
\hline 1950 & 1951 & 1952 & 1953 & 1954 & 1955 & 1956 & 1957 & 1958 & 1959 & \multirow[b]{2}{*}{$-11.35 \%$} & \multirow[b]{2}{*}{$(1950-1959)$} \\
\hline $0.00 \%$ & $1.15 \%$ & $-2.61 \%$ & $-2.51 \%$ & $-0.06 \%$ & $-1.78 \%$ & $-6.21 \%$ & $1.47 \%$ & $-0.24 \%$ & $-0.56 \%$ & & \\
\hline 1960 & 1961 & 1962 & 1963 & 1964 & 1965 & 1966 & 1967 & 1968 & 1969 & \multirow[b]{2}{*}{$10.72 \%$} & \multirow{3}{*}{$(1960-1969)$} \\
\hline$-0.73 \%$ & $0.70 \%$ & $1.13 \%$ & $5.03 \%$ & $1.47 \%$ & $2.12 \%$ & $0.16 \%$ & $-0.43 \%$ & $0.80 \%$ & $0.46 \%$ & & \\
\hline & & & & & & & & & & $-0.63 \%$ & \\
\hline
\end{tabular}

Table 7 Results Analyze rOPH and rAAC 1950 - 1969

(U.S. Bureau of Labor Statistics 2010) 
It is also interesting to examine the subsequent development and the following years. Before it was mentioned that the first 20 years are almost neutralizing each other. However, in the Post-Fordism a steady asymmetry became obvious.

Spread Real average annual compensation - Output per hour (1970 - 2011)

\begin{tabular}{|c|c|c|c|c|c|c|c|c|c|c|c|}
\hline 1970 & 1971 & 1972 & 1973 & 1974 & 1975 & 1976 & 1977 & 1978 & 1979 & & \\
\hline $1.13 \%$ & $4.72 \%$ & $0.79 \%$ & $3.76 \%$ & $-0.57 \%$ & $2.25 \%$ & $1.84 \%$ & $1.15 \%$ & $0.43 \%$ & $1.80 \%$ & $17.29 \%$ & $(1970-1979)$ \\
\hline 1980 & 1981 & 1982 & 1983 & 1984 & 1985 & $\overline{1986}$ & 1987 & 1988 & 1989 & & \\
\hline$-0.50 \%$ & $5.11 \%$ & $-0.75 \%$ & $2.13 \%$ & $-1.02 \%$ & $7.00 \%$ & $-1.02 \%$ & $7.00 \%$ & $2.73 \%$ & $1.72 \%$ & $22.39 \%$ & $(1980-1989)$ \\
\hline 1990 & 1991 & 1992 & 1993 & 1994 & 1995 & 1996 & 1997 & 1998 & 1999 & & \\
\hline$-0.50 \%$ & $5.11 \%$ & $-0.75 \%$ & $2.13 \%$ & $-1.02 \%$ & $7.00 \%$ & $-1.02 \%$ & $7.00 \%$ & $2.73 \%$ & $1.72 \%$ & $22.39 \%$ & $(1990-1999)$ \\
\hline 2000 & 2001 & 2002 & 2003 & 2004 & 2005 & 2006 & 2007 & 2008 & 2009 & & \\
\hline $4.58 \%$ & $3.11 \%$ & $6.32 \%$ & $3.09 \%$ & $9.72 \%$ & $5.26 \%$ & $3.32 \%$ & $4.88 \%$ & $-1.92 \%$ & $1.73 \%$ & $40.09 \%$ & $(2000-2009)$ \\
\hline 2010 & 2011 & & & & & & & & & & \\
\hline $8.90 \%$ & $1.71 \%$ & & & & & & & & & $10.61 \%$ & $(2010-2011)$ \\
\hline
\end{tabular}

Table 8 Results Analyze rOPH and rAAC 1970 - 2011

(U.S. Bureau of Labor Statistics 2010)

In eight subsequent years the growth of productivity was $3 \%$ higher than the actual wage development. In the years 2000-2009, the cumulative asymmetry even reached $40 \%$.

Spread Real average annual compensation - Output per hour (1950 - 1969)

\begin{tabular}{|c|c|c|c|c|c|c|c|c|c|c|}
\hline 2000 & 2001 & 2002 & 2003 & 2004 & 2005 & 2006 & 2007 & 2008 & 2009 & \\
\hline $4.58 \%$ & $3.11 \%$ & $6.32 \%$ & $3.09 \%$ & $9.72 \%$ & $5.26 \%$ & $3.32 \%$ & $4.88 \%$ & $-1.92 \%$ & $1.73 \%$ & $40.09 \%$ \\
\hline
\end{tabular}

(U.S. Bureau of Labor Statistics 2010) 
- Spread Real average annual compensation - Output per hour (1970 - 2011)

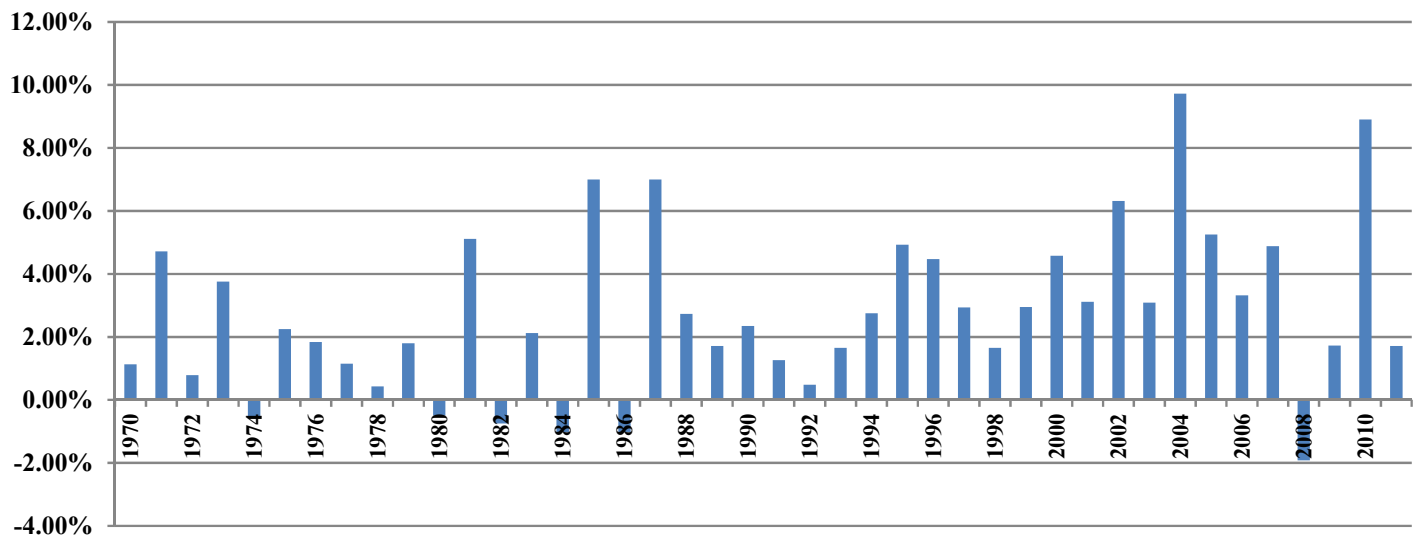

Figure 17 Results rOPH and rAAC 1970 - 2011

(U.S. Bureau of Labor Statistics 2010)

When examined individually, the era of Post-Fordism clearly shows exorbitant increases in productivity when compared with the previous years. Only in six of the 41 years that were analyzed the real earnings were slightly above the increases in productivity and this led to a negative manifestation in such a year. When considering a cumulative total these negative annual developments do not play any key role, because of the massive manifestations of the other years. The overall growth was so massive and the negative annual developments are not worth to be considered when examining the whole observation period. 


\section{INVESTIGATION OF CAUSES FOR THIS ASYMMETRICAL DEVELOPMENT}

The question remains why there was such an asymmetrical development at the beginning of the era of Post-Fordism in the early 1970s. Another extremely significant fact that must be considered is that the employee's wages (rAAC) and the labor productivity (rOPH) were moving in a synchronous way at the beginning. For whatever reasons, the increase of labor productivity that played a big part in the success and the positive company development was not shared with the workers in the form of employee's wages.

To answer this question it is necessary to analyze this development in the historical context. Especially in the 1970s there were various very extensive influences and changes that could have had a direct impact on these manifestations. It is important to note that there is a differentiation between internal and external reasons of influence. 


\subsection{Selected example of a potential internal cause}

One significant internal influence might have been due the fact that with the introduction of the Toyota Production Process (TPS) and the Lean Management there was a fundamental change in the manufacturing processes and the classic industrial production model. Whereas there was a preferably deep and broad configuration in the early production models - think of the extensive supply chain of Ford in the 1940s and 1950s reaching as far as the own production of metal, and this could indeed be considered to be a standard - there was a trimming and reduction of as many processes of the production flow as possible when the change to Lean Management started. This resulted in the outsourcing of individual productions steps or whole production processes. Whereas the approaches of the past did preferably consider all steps and stages in one hand, the new approach primarily focused on key elements.

Inevitably, such a change and reform has consequences for the groups of people of the production flows. In the modern production models there are various suppliers and these suppliers are forced into a competitive situation. This struggle for the market shares in a polypoly market first and foremost has consequences on the costs side. The easiest setscrews in this context are the wages and the pay (the question with respect to the sustainable effectiveness of such measures must be answered elsewhere). The polypoly of the emerging price war and price erosion resulted in an asynchronous development of thereal earnings with respect to the increase in productivity or the productivity growth and this still is the case. 


\subsection{Selected example of an potential external cause}

Besides the above mentioned internal influence the explanation also lies in the external influencing factors that depend on the company itself.

If the economic situation at the beginning of the era of Post-Fordism is considered, the eye is directed to the first oil crisis and the resulting Great Depression. The reduction of the production rates in the OPEC countries resulted in a dramatic increase of the crude oil price. The associated cost explosion resulted in a recession in the western industrialized countries and this recession had far-reaching consequences for the employees and their income situation. Difficult economic times - in the holistic economic context - or a cyclical decline of demand always do have a direct impact and influences on the increase of the pay sector. Caution on the side of the employer is the classic consequence, if there is a general costs increase and / or a difficult situation with respect to assignments or revenue.

It is remarkable in this context that the real wage increases were not only corrected with respect to the oil crises (the first oil crisis was in the year 1973), but also were the starting point for the ongoing and increasing asynchronous development. 


\subsection{Impacts on consequences for development of the wealth}

It does not matter, if there is an internal or external cause: the wealth of the individual and the state requires a certain income. The state must have a genuine interest to achieve an employment rate that is as high as possible and the workers must earn an income that is as high as possible. Each of these aspects in itself results in the income that the state needs so badly. This income of the state consists of direct income in the form of taxes for wages and indirect income in the form of alternative taxation options like excise and consumption tax.

Both of these approaches take a potential competing and opposing position and it is even possible that they block each other. The best option for the fiscal policy of the state would be a full employment with a high income level. Due to the high employment figures the revenue from taxes would increase and simultaneously the government expenditure for welfare programs would be reduced. However, a global world has its own mechanisms and the employment can profit from individual actions - but these individual actions do also influence the overall structure. (Friedmann 2007) 


\title{
6. A PRESCRIPTIVE MODEL FOR PRODUCTIVITY
}

\begin{abstract}
ALLOCATION
Possible causes and reasons for the unbalanced development of labor productivity in comparison to the development of real wages were shortly descripted in the previous section. Important fact is the realization of the distinction between internal and external factors. Of course, a closer examination and analyze will promote additional other aspects.
\end{abstract}

Rather interesting is the consideration of the development of an assumed average growth rate and its effects in an effective and balanced distribution of capital, the workforce and the high of selling prices for products and services.

It is a fact that since 1970 the real average productivity increase was $3.89 \%$ per year. During the same period, wages have risen by an average of $1.20 \%$ per year. The average annual inflation rate surged by more than $4.31 \%$ points. 
U.S. Output per hour in manufacturing

U.S. Real average annual compensation development in manufacturing

U.S. Consumer Price Indexes (CPI) Development

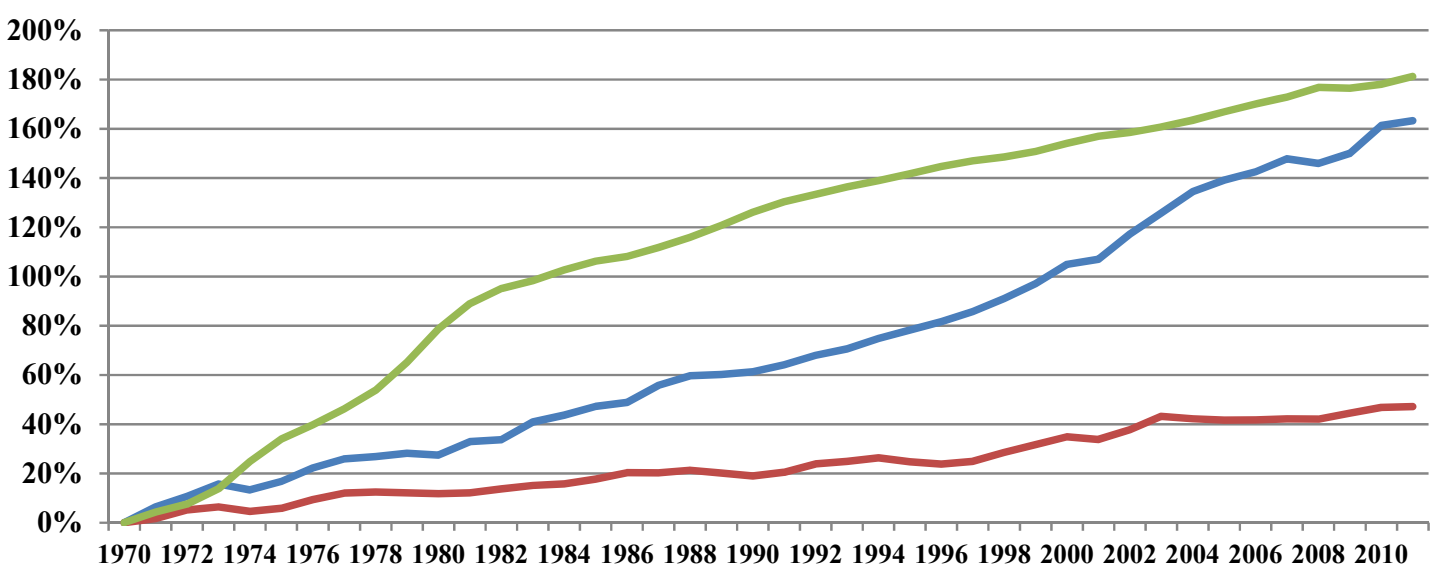

Figure 18 Comparison original rOPH, rAAC and CPI 1970-2011

(U.S. Bureau of Labor Statistics 2010) 


\begin{tabular}{|c|c|c|c|c|c|c|c|c|}
\hline \multicolumn{3}{|c|}{$\begin{array}{l}\text { U.S. Output per hour in manufacturing } \\
\qquad \begin{array}{c}1970-2011 \\
\text { (Index: } 2002=100)\end{array}\end{array}$} & \multicolumn{3}{|c|}{$\begin{array}{l}\text { U.S. Real average annual compensation } \\
\text { development in manufacturing } \\
1970-2011 \\
(\text { Index: } 2002=100)\end{array}$} & \multicolumn{3}{|c|}{$\begin{array}{l}\text { U.S. Consumer Price Indexes (CPI) } \\
\text { Development } \\
\text { 1970-2011 } \\
\text { (Index: } 2002=100)\end{array}$} \\
\hline Bas is & $\begin{array}{l}\text { Development } \\
\text { (ORIGINAL) }\end{array}$ & $\begin{array}{l}\text { cumulated rOPH } \\
\text { (ORIGINAL) }\end{array}$ & Basis & $\begin{array}{l}\text { Development } \\
\text { (ORIGINAL) }\end{array}$ & $\begin{array}{l}\text { cum ulated rAAC } \\
\text { (ORIGINAL) }\end{array}$ & Bas is & $\begin{array}{l}\text { Development } \\
\text { (ORIGINAL) }\end{array}$ & $\begin{array}{l}\text { cumulated CPI } \\
\text { (ORIGINAL) }\end{array}$ \\
\hline 31.92 & $0.00 \%$ & $0.00 \%$ & 68.95 & $0.00 \%$ & $0.00 \%$ & 21.6 & $0.00 \%$ & $0.00 \%$ \\
\hline 33.98 & $6.45 \%$ & $6.45 \%$ & 70.15 & $1.73 \%$ & $1.73 \%$ & 22.5 & $4.38 \%$ & $4.38 \%$ \\
\hline 35.44 & $4.29 \%$ & $10.74 \%$ & 72.60 & $3.50 \%$ & $5.23 \%$ & 23.2 & $3.21 \%$ & $7.59 \%$ \\
\hline 37.20 & $4.99 \%$ & $15.73 \%$ & 73.49 & $1.23 \%$ & $6.46 \%$ & 24.7 & $6.22 \%$ & $13.81 \%$ \\
\hline 36.31 & $-2.40 \%$ & $13.32 \%$ & 72.14 & $-1.84 \%$ & $4.62 \%$ & 27.4 & $11.04 \%$ & $24.85 \%$ \\
\hline 37.57 & $3.47 \%$ & $16.79 \%$ & 73.02 & $1.22 \%$ & $5.84 \%$ & 29.9 & $9.13 \%$ & $33.98 \%$ \\
\hline 39.61 & $5.42 \%$ & $22.21 \%$ & 75.64 & $3.59 \%$ & $9.43 \%$ & 31.6 & $5.76 \%$ & $39.74 \%$ \\
\hline 41.10 & $3.77 \%$ & $25.98 \%$ & 77.62 & $2.62 \%$ & $12.04 \%$ & 33.7 & $6.50 \%$ & $46.24 \%$ \\
\hline 41.47 & $0.90 \%$ & $26.88 \%$ & 77.98 & $0.47 \%$ & $12.51 \%$ & 36.2 & $7.59 \%$ & $53.83 \%$ \\
\hline 42.03 & $1.37 \%$ & $28.24 \%$ & 77.64 & $-0.43 \%$ & $12.08 \%$ & 40.4 & $11.35 \%$ & $65.18 \%$ \\
\hline 41.71 & $-0.76 \%$ & $27.48 \%$ & 77.44 & $-0.26 \%$ & $11.81 \%$ & 45.8 & $13.50 \%$ & $78.68 \%$ \\
\hline 43.99 & $5.45 \%$ & $32.94 \%$ & 77.71 & $0.35 \%$ & $12.16 \%$ & 50.5 & $10.32 \%$ & $88.99 \%$ \\
\hline 44.37 & $0.86 \%$ & $33.80 \%$ & 78.96 & $1.61 \%$ & $13.77 \%$ & 53.6 & $6.16 \%$ & $95.16 \%$ \\
\hline 47.51 & $7.08 \%$ & $40.88 \%$ & 80.07 & $1.41 \%$ & $15.18 \%$ & 55.4 & $3.21 \%$ & $98.37 \%$ \\
\hline 48.85 & $2.81 \%$ & $43.69 \%$ & 80.62 & $0.68 \%$ & $15.86 \%$ & 57.8 & $4.32 \%$ & $102.68 \%$ \\
\hline 50.58 & $3.56 \%$ & $47.25 \%$ & 82.08 & $1.81 \%$ & $17.68 \%$ & 59.8 & $3.56 \%$ & $106.25 \%$ \\
\hline 51.40 & $1.63 \%$ & $48.87 \%$ & 84.25 & $2.65 \%$ & $20.32 \%$ & 60.9 & $1.86 \%$ & $108.10 \%$ \\
\hline 54.96 & $6.92 \%$ & $55.79 \%$ & 84.19 & $-0.07 \%$ & $20.25 \%$ & 63.1 & $3.65 \%$ & $111.75 \%$ \\
\hline 57.08 & $3.86 \%$ & $59.65 \%$ & 85.13 & $1.12 \%$ & $21.37 \%$ & 65.8 & $4.14 \%$ & $115.89 \%$ \\
\hline 57.38 & $0.53 \%$ & $60.18 \%$ & 84.12 & $-1.19 \%$ & $20.18 \%$ & 68.9 & $4.82 \%$ & $120.71 \%$ \\
\hline 58.06 & $1.19 \%$ & $61.36 \%$ & 83.15 & $-1.15 \%$ & $19.03 \%$ & 72.7 & $5.40 \%$ & $126.11 \%$ \\
\hline 59.68 & $2.78 \%$ & $64.15 \%$ & 84.41 & $1.52 \%$ & $20.54 \%$ & 75.7 & $4.21 \%$ & $130.32 \%$ \\
\hline 61.98 & $3.85 \%$ & $68.00 \%$ & 87.26 & $3.37 \%$ & $23.91 \%$ & 78.0 & $3.01 \%$ & $133.33 \%$ \\
\hline 63.63 & $2.66 \%$ & $70.66 \%$ & 88.13 & $1.00 \%$ & $24.91 \%$ & 80.3 & $2.99 \%$ & $136.33 \%$ \\
\hline 66.28 & $4.16 \%$ & $74.82 \%$ & 89.38 & $1.42 \%$ & $26.33 \%$ & 82.4 & $2.56 \%$ & 138.89\% \\
\hline 68.54 & $3.41 \%$ & $78.23 \%$ & 88.02 & $-1.51 \%$ & $24.82 \%$ & 84.7 & $2.83 \%$ & $141.72 \%$ \\
\hline 70.88 & $3.42 \%$ & $81.65 \%$ & 87.10 & $-1.05 \%$ & $23.76 \%$ & 87.2 & $2.95 \%$ & $144.67 \%$ \\
\hline 73.81 & $4.13 \%$ & $85.78 \%$ & 88.14 & $1.19 \%$ & $24.96 \%$ & 89.2 & $2.29 \%$ & $146.97 \%$ \\
\hline 77.69 & $5.26 \%$ & $91.05 \%$ & 91.32 & $3.61 \%$ & $28.56 \%$ & 90.6 & $1.56 \%$ & $148.52 \%$ \\
\hline 82.43 & $6.10 \%$ & $97.14 \%$ & 94.19 & $3.15 \%$ & $31.71 \%$ & 92.6 & $2.21 \%$ & $150.73 \%$ \\
\hline 88.83 & $7.77 \%$ & $104.91 \%$ & 97.20 & $3.19 \%$ & $34.90 \%$ & 95.7 & $3.36 \%$ & $154.09 \%$ \\
\hline 90.66 & $2.06 \%$ & $106.97 \%$ & 96.17 & $-1.05 \%$ & $33.85 \%$ & 98.4 & $2.85 \%$ & $156.94 \%$ \\
\hline 100.00 & $10.30 \%$ & $117.27 \%$ & 100.00 & $3.98 \%$ & $37.83 \%$ & 100.0 & $1.58 \%$ & $158.52 \%$ \\
\hline 108.49 & $8.49 \%$ & $125.76 \%$ & 105.40 & $5.40 \%$ & $43.23 \%$ & 102.3 & $2.28 \%$ & $160.80 \%$ \\
\hline 117.97 & $8.74 \%$ & $134.50 \%$ & 104.36 & $-0.99 \%$ & $42.24 \%$ & 105.0 & $2.66 \%$ & $163.46 \%$ \\
\hline 123.43 & $4.63 \%$ & $139.13 \%$ & 103.71 & $-0.62 \%$ & $41.62 \%$ & 108.6 & $3.39 \%$ & $166.85 \%$ \\
\hline 127.64 & $3.41 \%$ & $142.53 \%$ & 103.80 & $0.09 \%$ & $41.71 \%$ & 112.1 & $3.23 \%$ & $170.08 \%$ \\
\hline 134.39 & $5.29 \%$ & $147.83 \%$ & 104.23 & $0.41 \%$ & $42.12 \%$ & 115.3 & $2.85 \%$ & $172.93 \%$ \\
\hline 131.79 & $-1.94 \%$ & $145.89 \%$ & 104.21 & $-0.02 \%$ & $42.10 \%$ & 119.7 & $3.84 \%$ & $176.76 \%$ \\
\hline 137.27 & $4.16 \%$ & $150.05 \%$ & 106.74 & $2.43 \%$ & $44.53 \%$ & 119.3 & $-0.36 \%$ & $176.41 \%$ \\
\hline 152.68 & $11.23 \%$ & $161.28 \%$ & 109.23 & $2.33 \%$ & $46.86 \%$ & 121.2 & $1.64 \%$ & $178.05 \%$ \\
\hline 155.74 & $2.00 \%$ & $163.28 \%$ & 109.55 & $0.29 \%$ & $47.15 \%$ & 125.0 & $3.16 \%$ & $181.21 \%$ \\
\hline
\end{tabular}

Table 10 Original Data rOPH, rAAC and CPI 1970 - 2011

(U.S. Bureau of Labor Statistics 2010) 
Assuming an annual average productivity growth rate of $3.89 \%$ since 1970 per year.

What development for the capital, wages and prices would have occurred if this rate would have been evenly distributed on these three factors? The result would be that wages would have risen by $1.29667 \%$ annually, the equity ratio would have increased by $1.29667 \%$, or companies could use this content for potential investments by simultaneously falling product prices and service to also $1.29667 \%$. Where would the economy stand today if such an allocation had been made?

Using annual average increase of productivity of $3.89 \%$ will be distributed equally among the three elements of capital, wages and prices.

The annual average productivity rate of $3.89 \%$ will distributed and effect to

- An increase $1 / 3$ for Capital expansion $(+1.29667 \%)$

- An increase $1 / 3$ for Wages $(+1.29667 \%)$

- A reduction $1 / 3$ for Prices (- $1.29667 \%)$

This redistribution would mean that following development would have been realized over the last 40 years. 


\begin{tabular}{|c|c|c|c|c|c|c|c|c|c|}
\hline \multirow[b]{2}{*}{ Year } & \multicolumn{3}{|c|}{$\begin{array}{l}\text { U.S. Output per hour in manufacturing } \\
\qquad \begin{array}{c}1970-2011 \\
\text { (Index: } 2002=100)\end{array}\end{array}$} & \multicolumn{3}{|c|}{$\begin{array}{l}\text { U.S. Real average annual compensation } \\
\text { development in manufacturing } \\
\qquad 1970-2011 \\
\text { (Index: } 2002=100)\end{array}$} & \multicolumn{3}{|c|}{\begin{tabular}{|} 
U.S. Consumer Price Indexes (CPI) \\
Development \\
$1970-2011$ \\
(Index: $2002=100)$
\end{tabular}} \\
\hline & Bas is & $\begin{array}{l}\text { Development } \\
\text { (ORIGINAL) }\end{array}$ & $\begin{array}{c}\text { cumulated rOPH } \\
\text { (ORIGINAL) }\end{array}$ & Basis & $\begin{array}{c}\text { Development } \\
(1 / 3=+1.29667 \% \\
\text { ALLOCATION })\end{array}$ & $\begin{array}{c}\text { cumulated } \\
\text { rAAC }(1 / 3= \\
+1.29667 \% \\
\text { ALLOCATION })\end{array}$ & Bas is & $\begin{array}{c}\text { Development } \\
(1 / 3=+1.29667 \% \\
\text { ALLOCATION })\end{array}$ & $\begin{array}{c}\text { cumulated } \\
\text { CPI }(1 / 3= \\
+1.29667 \% \\
\text { ALLOCA AION })\end{array}$ \\
\hline 1970 & 31.92 & $0.00 \%$ & $0.00 \%$ & 68.95 & $0.00 \%$ & $0.00 \%$ & 21.6 & $0.00 \%$ & $0.00 \%$ \\
\hline 1971 & 33.98 & $6.45 \%$ & $6.45 \%$ & 70.15 & $3.03 \%$ & $3.03 \%$ & 22.5 & $3.08 \%$ & $3.08 \%$ \\
\hline 1972 & 35.44 & $4.29 \%$ & $10.74 \%$ & 72.60 & $4.80 \%$ & $7.82 \%$ & 23.2 & $1.91 \%$ & $5.00 \%$ \\
\hline 1973 & 37.20 & $4.99 \%$ & $15.73 \%$ & 73.49 & $2.52 \%$ & $10.35 \%$ & 24.7 & $4.92 \%$ & $9.92 \%$ \\
\hline 1974 & 36.31 & $-2.40 \%$ & $13.32 \%$ & 72.14 & $-0.54 \%$ & $9.81 \%$ & 27.4 & $9.74 \%$ & $19.66 \%$ \\
\hline 1975 & 37.57 & $3.47 \%$ & $16.79 \%$ & 73.02 & $2.51 \%$ & $12.32 \%$ & 29.9 & $7.83 \%$ & $27.49 \%$ \\
\hline 1976 & 39.61 & $5.42 \%$ & $22.21 \%$ & 75.64 & $4.88 \%$ & $17.21 \%$ & 31.6 & $4.47 \%$ & $31.96 \%$ \\
\hline 1977 & 41.10 & $3.77 \%$ & $25.98 \%$ & 77.62 & $3.91 \%$ & $21.12 \%$ & 33.7 & $5.21 \%$ & $37.16 \%$ \\
\hline 1978 & 41.47 & $0.90 \%$ & $26.88 \%$ & 77.98 & $1.76 \%$ & $22.89 \%$ & 36.2 & $6.29 \%$ & $43.46 \%$ \\
\hline 1979 & 42.03 & $1.37 \%$ & $28.24 \%$ & 77.64 & $0.86 \%$ & $23.75 \%$ & 40.4 & $10.05 \%$ & $53.51 \%$ \\
\hline 1980 & 41.71 & $-0.76 \%$ & $27.48 \%$ & 77.44 & $1.03 \%$ & $24.78 \%$ & 45.8 & $12.20 \%$ & $65.71 \%$ \\
\hline 1981 & 43.99 & $5.45 \%$ & $32.94 \%$ & 77.71 & $1.64 \%$ & $26.42 \%$ & 50.5 & $9.02 \%$ & $74.73 \%$ \\
\hline 1982 & 44.37 & $0.86 \%$ & $33.80 \%$ & 78.96 & $2.91 \%$ & $29.33 \%$ & 53.6 & $4.86 \%$ & $79.60 \%$ \\
\hline 1983 & 47.51 & $7.08 \%$ & $40.88 \%$ & 80.07 & $2.70 \%$ & $32.03 \%$ & 55.4 & $1.92 \%$ & $81.51 \%$ \\
\hline 1984 & 48.85 & $2.81 \%$ & $43.69 \%$ & 80.62 & $1.98 \%$ & $34.02 \%$ & 57.8 & $3.02 \%$ & $84.53 \%$ \\
\hline 1985 & 50.58 & $3.56 \%$ & $47.25 \%$ & 82.08 & $3.11 \%$ & $37.13 \%$ & 59.8 & $2.26 \%$ & $86.80 \%$ \\
\hline 1986 & 51.40 & $1.63 \%$ & $48.87 \%$ & 84.25 & $3.94 \%$ & $41.07 \%$ & 60.9 & $0.56 \%$ & $87.36 \%$ \\
\hline 1987 & 54.96 & $6.92 \%$ & $55.79 \%$ & 84.19 & $1.22 \%$ & $42.29 \%$ & 63.1 & $2.35 \%$ & $89.71 \%$ \\
\hline 1988 & 57.08 & $3.86 \%$ & $59.65 \%$ & 85.13 & $2.42 \%$ & $44.71 \%$ & 65.8 & $2.84 \%$ & $92.55 \%$ \\
\hline 1989 & 57.38 & $0.53 \%$ & $60.18 \%$ & 84.12 & $0.11 \%$ & $44.82 \%$ & 68.9 & $3.52 \%$ & $96.07 \%$ \\
\hline 1990 & 58.06 & $1.19 \%$ & $61.36 \%$ & 83.15 & $0.14 \%$ & $44.96 \%$ & 72.7 & $4.11 \%$ & $100.18 \%$ \\
\hline 1991 & 59.68 & $2.78 \%$ & $64.15 \%$ & 84.41 & $2.81 \%$ & $47.77 \%$ & 75.7 & $2.91 \%$ & $103.09 \%$ \\
\hline 1992 & 61.98 & $3.85 \%$ & $68.00 \%$ & 87.26 & $4.67 \%$ & $52.44 \%$ & 78.0 & $1.71 \%$ & $104.80 \%$ \\
\hline 1993 & 63.63 & $2.66 \%$ & $70.66 \%$ & 88.13 & $2.30 \%$ & $54.74 \%$ & 80.3 & $1.70 \%$ & $106.50 \%$ \\
\hline 1994 & 66.28 & $4.16 \%$ & $74.82 \%$ & 89.38 & $2.71 \%$ & $57.45 \%$ & 82.4 & $1.26 \%$ & $107.77 \%$ \\
\hline 1995 & 68.54 & $3.41 \%$ & $78.23 \%$ & 88.02 & $-0.22 \%$ & $57.23 \%$ & 84.7 & $1.54 \%$ & $109.30 \%$ \\
\hline 1996 & 70.88 & $3.42 \%$ & $81.65 \%$ & 87.10 & $0.25 \%$ & $57.48 \%$ & 87.2 & $1.66 \%$ & $110.96 \%$ \\
\hline 1997 & 73.81 & $4.13 \%$ & $85.78 \%$ & 88.14 & $2.49 \%$ & $59.97 \%$ & 89.2 & $1.00 \%$ & $111.96 \%$ \\
\hline 1998 & 77.69 & $5.26 \%$ & $91.05 \%$ & 91.32 & $4.91 \%$ & $64.87 \%$ & 90.6 & $0.26 \%$ & $112.22 \%$ \\
\hline 1999 & 82.43 & $6.10 \%$ & $97.14 \%$ & 94.19 & $4.44 \%$ & $69.32 \%$ & 92.6 & $0.91 \%$ & $113.13 \%$ \\
\hline 2000 & 88.83 & $7.77 \%$ & $104.91 \%$ & 97.20 & $4.49 \%$ & $73.80 \%$ & 95.7 & $2.06 \%$ & $115.19 \%$ \\
\hline 2001 & 90.66 & $2.06 \%$ & $106.97 \%$ & 96.17 & $0.24 \%$ & $74.05 \%$ & 98.4 & $1.55 \%$ & $116.74 \%$ \\
\hline 2002 & 100.00 & $10.30 \%$ & $117.27 \%$ & 100.00 & $5.28 \%$ & $79.32 \%$ & 100.0 & $0.28 \%$ & $117.03 \%$ \\
\hline 2003 & 108.49 & $8.49 \%$ & $125.76 \%$ & 105.40 & $6.70 \%$ & $86.02 \%$ & 102.3 & $0.98 \%$ & $118.01 \%$ \\
\hline 2004 & 117.97 & $8.74 \%$ & $134.50 \%$ & 104.36 & $0.31 \%$ & $86.33 \%$ & 105.0 & $1.37 \%$ & $119.38 \%$ \\
\hline 2005 & 123.43 & $4.63 \%$ & $139.13 \%$ & 103.71 & $0.67 \%$ & $87.00 \%$ & 108.6 & $2.09 \%$ & $121.47 \%$ \\
\hline 2006 & 127.64 & $3.41 \%$ & $142.53 \%$ & 103.80 & $1.38 \%$ & $88.39 \%$ & 112.1 & $1.93 \%$ & $123.40 \%$ \\
\hline 2007 & 134.39 & $5.29 \%$ & $147.83 \%$ & 104.23 & $1.71 \%$ & $90.10 \%$ & 115.3 & $1.55 \%$ & $124.95 \%$ \\
\hline 2008 & 131.79 & $-1.94 \%$ & $145.89 \%$ & 104.21 & $1.28 \%$ & $91.37 \%$ & 119.7 & $2.54 \%$ & $127.49 \%$ \\
\hline 2009 & 137.27 & $4.16 \%$ & $150.05 \%$ & 106.74 & $3.73 \%$ & $95.10 \%$ & 119.3 & $-1.65 \%$ & $125.84 \%$ \\
\hline 2010 & 152.68 & $11.23 \%$ & $161.28 \%$ & 109.23 & $3.63 \%$ & $98.73 \%$ & 121.2 & $0.34 \%$ & $126.18 \%$ \\
\hline 2011 & 155.74 & $2.00 \%$ & $163.28 \%$ & 109.55 & $1.59 \%$ & $100.32 \%$ & 125.0 & $1.86 \%$ & $128.04 \%$ \\
\hline
\end{tabular}

Table 11 Allocated Data 1/3 Participation: OPH, rAAC and CPI 1970 - 2011

(U.S. Bureau of Labor Statistics 2010) 


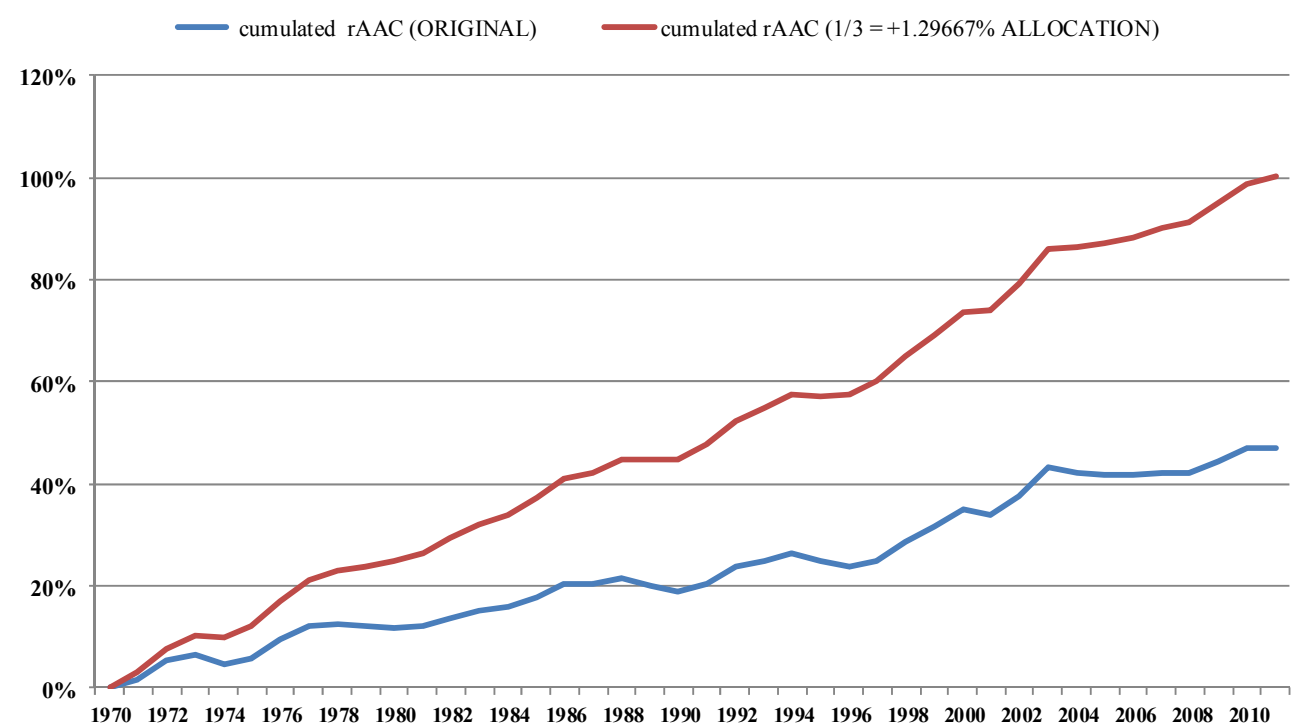

Figure 19 Development rAAC (1/3 allocation) 1970-2011

(U.S. Bureau of Labor Statistics 2010)

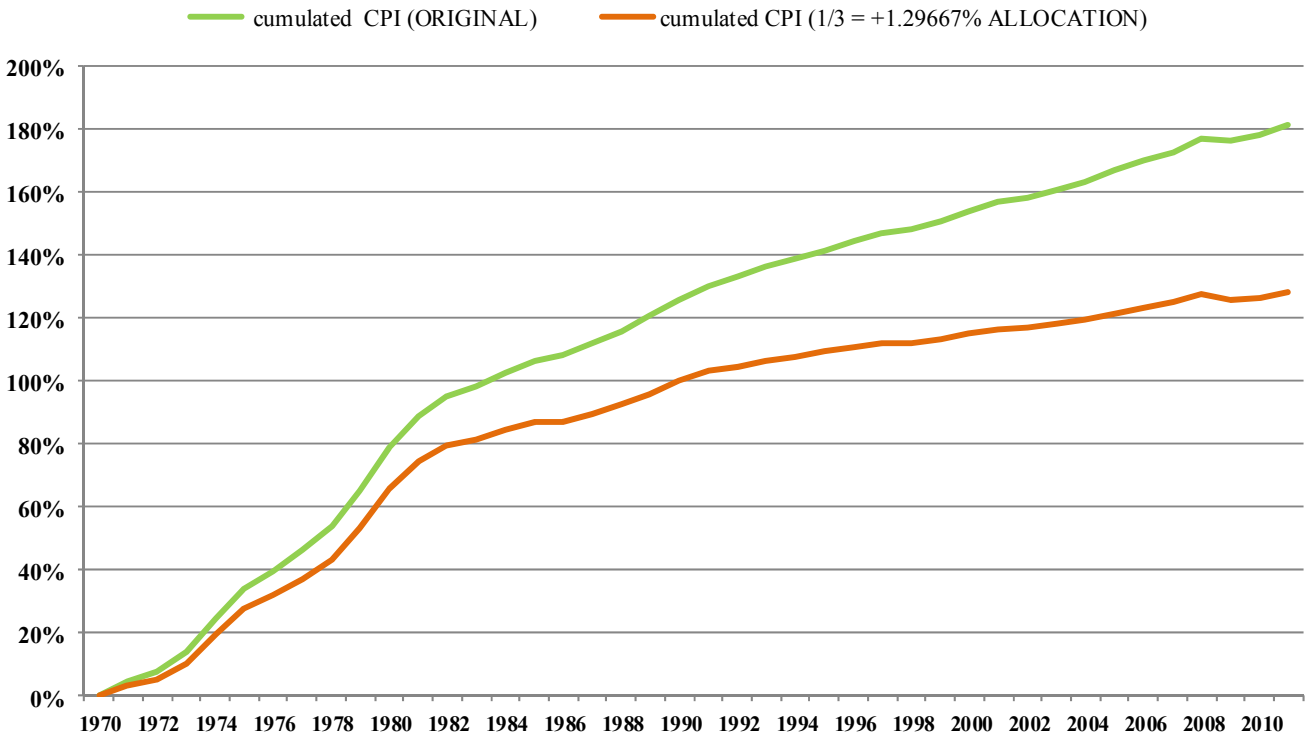

Figure 20 Development CPI (1/3 allocation) 1970-2011

(U.S. Bureau of Labor Statistics 2010) 


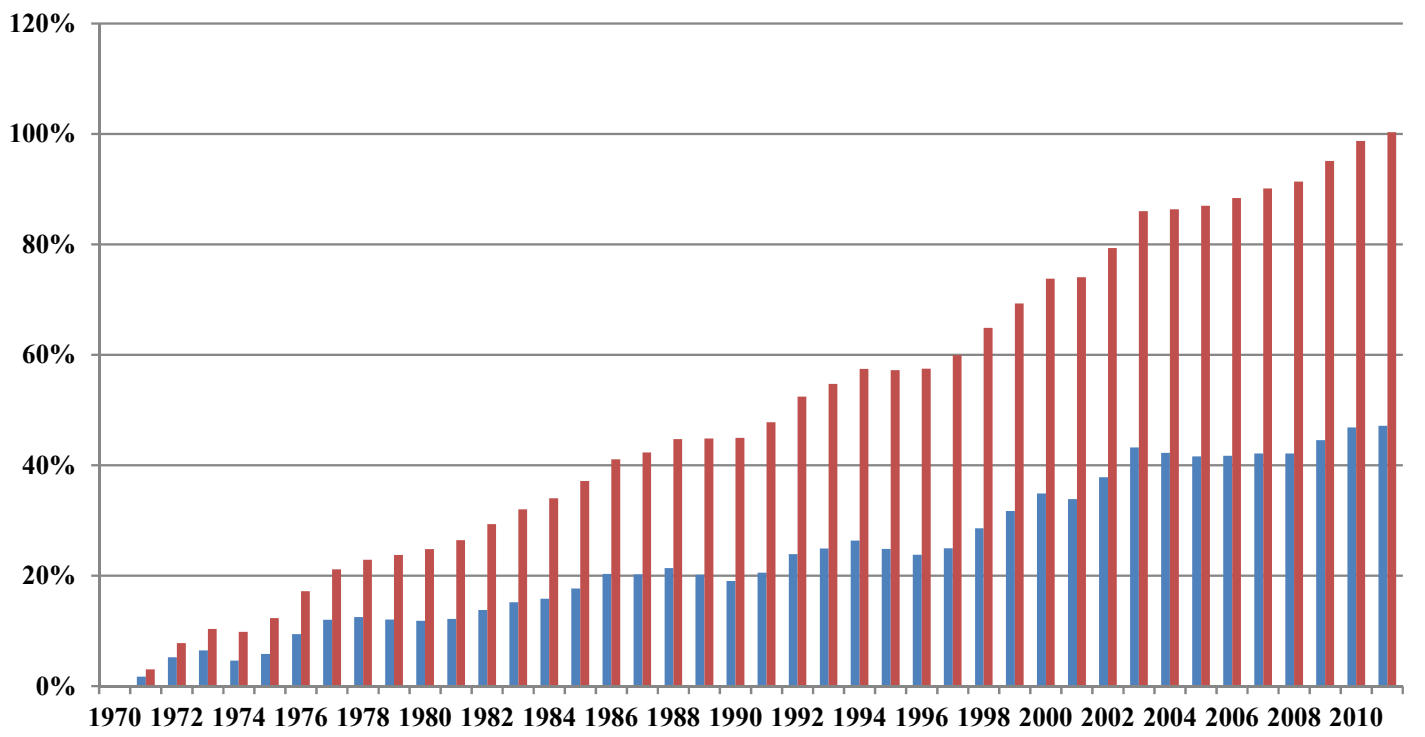

Figure 21 Comparison Original and Allocated Data rAAC 1970-2011, (Index: $2002=100)$

(U.S. Bureau of Labor Statistics 2010)

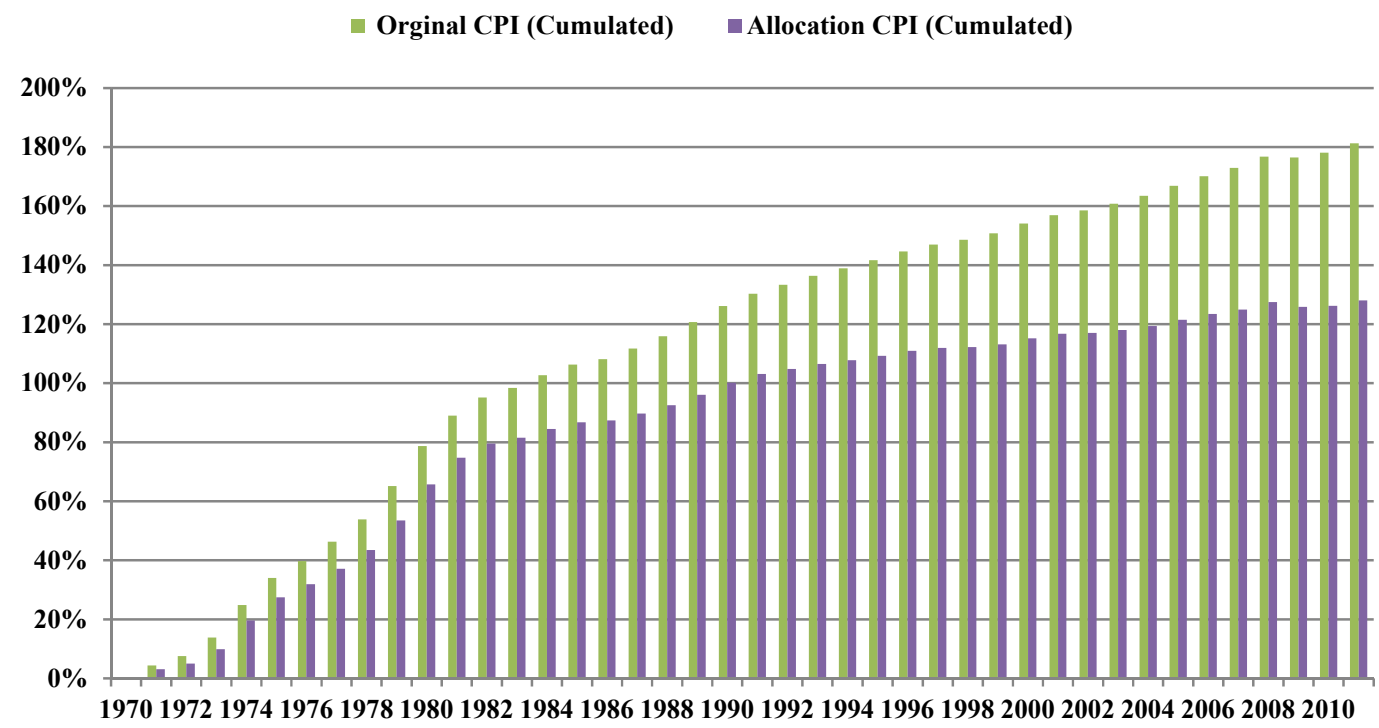

Figure 22 Comparison Original and Allocated Data CPI 1970-2011, (Index: $2002=100)$

(U.S. Bureau of Labor Statistics 2010) 
For a deeper clarification of this effect a second development shall support the sensitivity analyze. The annual average increase of productivity of $3.89 \%$ will be distributed for this allocation in the following distribution to the three elements of capital, wages and prices.

- An increase $1 / 2$ for Capital expansion $(+1.94500 \%)$

- An increase $1 / 4$ for Wages $(+0.97250 \%)$

- A reduction $1 / 4$ for Prices $(-0.97250 \%)$

This second allocated redistribution would mean that following development would have been realized over the last 40 years. 


\begin{tabular}{|c|c|c|c|c|c|c|c|c|c|}
\hline \multirow[b]{2}{*}{ Year } & \multicolumn{3}{|c|}{$\begin{array}{l}\text { U.S. Output per hour in manufacturing } \\
1970-2011 \\
\text { (Index: } 2002=100)\end{array}$} & \multicolumn{3}{|c|}{$\begin{array}{l}\text { U.S. Real average annual } \\
\text { compensation development in } \\
\text { 1970-2011 } \\
\text { (Index: } 2002=100 \text { ) }\end{array}$} & \multicolumn{3}{|c|}{$\begin{array}{l}\text { U.S. Consumer Price Indexes (CPI) } \\
\text { Development } \\
1970-2011 \\
\text { (Index: } 2002=100)\end{array}$} \\
\hline & Bas is & $\begin{array}{l}\text { Development } \\
\text { (ORIGINAL) }\end{array}$ & $\begin{array}{c}\text { cumulated rOPH } \\
\text { (ORIGINAL) }\end{array}$ & Bas is & $\begin{array}{l}\text { Development } \\
(1 / 4=0.9725 \% \\
\text { ALLOCATION) }\end{array}$ & $\begin{array}{c}\text { cumulated } \\
\text { rAAC }(1 / 4= \\
0.9725 \% \\
\text { ALLOCATION })\end{array}$ & Bas is & $\begin{array}{l}\text { Development } \\
(1 / 4=0.9725 \% \\
\text { ALLOCATION) }\end{array}$ & $\begin{array}{l}\text { cum ulated CPI } \\
(1 / 4=0.9725 \% \\
\text { ALLOCATION })\end{array}$ \\
\hline 1970 & 31.92 & $0.00 \%$ & $0.00 \%$ & 68.95 & $0.00 \%$ & $0.00 \%$ & 21.6 & $0.00 \%$ & $0.00 \%$ \\
\hline 1971 & 33.98 & $6.45 \%$ & $6.45 \%$ & 70.15 & $2.71 \%$ & $2.71 \%$ & 22.5 & $3.41 \%$ & $3.41 \%$ \\
\hline 1972 & 35.44 & $4.29 \%$ & $10.74 \%$ & 72.60 & $4.47 \%$ & $7.18 \%$ & 23.2 & $2.24 \%$ & $5.65 \%$ \\
\hline 1973 & 37.20 & $4.99 \%$ & $15.73 \%$ & 73.49 & $2.20 \%$ & $9.38 \%$ & 24.7 & $5.25 \%$ & $10.89 \%$ \\
\hline 1974 & 36.31 & $-2.40 \%$ & $13.32 \%$ & 72.14 & $-0.86 \%$ & $8.51 \%$ & 27.4 & $10.06 \%$ & $20.96 \%$ \\
\hline 1975 & 37.57 & $3.47 \%$ & $16.79 \%$ & 73.02 & $2.19 \%$ & $10.70 \%$ & 29.9 & $8.16 \%$ & $29.11 \%$ \\
\hline 1976 & 39.61 & $5.42 \%$ & $22.21 \%$ & 75.64 & $4.56 \%$ & $15.26 \%$ & 31.6 & $4.79 \%$ & $33.90 \%$ \\
\hline 1977 & 41.10 & $3.77 \%$ & $25.98 \%$ & 77.62 & $3.59 \%$ & $18.85 \%$ & 33.7 & $5.53 \%$ & $39.43 \%$ \\
\hline 1978 & 41.47 & $0.90 \%$ & $26.88 \%$ & 77.98 & $1.44 \%$ & $20.29 \%$ & 36.2 & $6.62 \%$ & $46.05 \%$ \\
\hline 1979 & 42.03 & $1.37 \%$ & $28.24 \%$ & 77.64 & $0.54 \%$ & $20.83 \%$ & 40.4 & $10.38 \%$ & $56.43 \%$ \\
\hline 1980 & 41.71 & $-0.76 \%$ & $27.48 \%$ & 77.44 & $0.71 \%$ & $21.54 \%$ & 45.8 & $12.53 \%$ & $68.95 \%$ \\
\hline 1981 & 43.99 & $5.45 \%$ & $32.94 \%$ & 77.71 & $1.32 \%$ & $22.86 \%$ & 50.5 & $9.34 \%$ & $78.30 \%$ \\
\hline 1982 & 44.37 & $0.86 \%$ & $33.80 \%$ & 78.96 & $2.58 \%$ & $25.44 \%$ & 53.6 & $5.19 \%$ & $83.49 \%$ \\
\hline 1983 & 47.51 & $7.08 \%$ & $40.88 \%$ & 80.07 & $2.38 \%$ & $27.82 \%$ & 55.4 & $2.24 \%$ & $85.73 \%$ \\
\hline 1984 & 48.85 & $2.81 \%$ & $43.69 \%$ & 80.62 & $1.66 \%$ & $29.48 \%$ & 57.8 & $3.34 \%$ & $89.07 \%$ \\
\hline 1985 & 50.58 & $3.56 \%$ & $47.25 \%$ & 82.08 & $2.79 \%$ & $32.26 \%$ & 59.8 & $2.59 \%$ & $91.66 \%$ \\
\hline 1986 & 51.40 & $1.63 \%$ & $48.87 \%$ & 84.25 & $3.62 \%$ & $35.88 \%$ & 60.9 & $0.89 \%$ & $92.54 \%$ \\
\hline 1987 & 54.96 & $6.92 \%$ & $55.79 \%$ & 84.19 & $0.90 \%$ & $36.78 \%$ & 63.1 & $2.68 \%$ & $95.22 \%$ \\
\hline 1988 & 57.08 & $3.86 \%$ & $59.65 \%$ & 85.13 & $2.10 \%$ & $38.88 \%$ & 65.8 & $3.16 \%$ & $98.39 \%$ \\
\hline 1989 & 57.38 & $0.53 \%$ & $60.18 \%$ & 84.12 & $-0.22 \%$ & $38.66 \%$ & 68.9 & $3.85 \%$ & $102.23 \%$ \\
\hline 1990 & 58.06 & $1.19 \%$ & $61.36 \%$ & 83.15 & $-0.18 \%$ & $38.48 \%$ & 72.7 & $4.43 \%$ & $106.66 \%$ \\
\hline 1991 & 59.68 & $2.78 \%$ & $64.15 \%$ & 84.41 & $2.49 \%$ & $40.97 \%$ & 75.7 & $3.24 \%$ & $109.90 \%$ \\
\hline 1992 & 61.98 & $3.85 \%$ & $68.00 \%$ & 87.26 & $4.34 \%$ & $45.31 \%$ & 78.0 & $2.04 \%$ & $111.94 \%$ \\
\hline 1993 & 63.63 & $2.66 \%$ & $70.66 \%$ & 88.13 & $1.97 \%$ & $47.28 \%$ & 80.3 & $2.02 \%$ & $113.96 \%$ \\
\hline 1994 & 66.28 & $4.16 \%$ & $74.82 \%$ & 89.38 & $2.39 \%$ & $49.67 \%$ & 82.4 & $1.59 \%$ & $115.55 \%$ \\
\hline 1995 & 68.54 & $3.41 \%$ & $78.23 \%$ & 88.02 & $-0.54 \%$ & $49.13 \%$ & 84.7 & $1.86 \%$ & $117.41 \%$ \\
\hline 1996 & 70.88 & $3.42 \%$ & $81.65 \%$ & 87.10 & $-0.08 \%$ & $49.05 \%$ & 87.2 & $1.98 \%$ & $119.39 \%$ \\
\hline 1997 & 73.81 & $4.13 \%$ & $85.78 \%$ & 88.14 & $2.16 \%$ & $51.21 \%$ & 89.2 & $1.32 \%$ & $120.71 \%$ \\
\hline 1998 & 77.69 & $5.26 \%$ & $91.05 \%$ & 91.32 & $4.58 \%$ & $55.79 \%$ & 90.6 & $0.59 \%$ & $121.29 \%$ \\
\hline 1999 & 82.43 & $6.10 \%$ & $97.14 \%$ & 94.19 & $4.12 \%$ & $59.91 \%$ & 92.6 & $1.24 \%$ & $122.53 \%$ \\
\hline 2000 & 88.83 & $7.77 \%$ & $104.91 \%$ & 97.20 & $4.16 \%$ & $64.08 \%$ & 95.7 & $2.39 \%$ & $124.92 \%$ \\
\hline 2001 & 90.66 & $2.06 \%$ & $106.97 \%$ & 96.17 & $-0.08 \%$ & $64.00 \%$ & 98.4 & $1.87 \%$ & $126.79 \%$ \\
\hline 2002 & 100.00 & $10.30 \%$ & $117.27 \%$ & 100.00 & $4.95 \%$ & $68.95 \%$ & 100.0 & $0.61 \%$ & $127.40 \%$ \\
\hline 2003 & 108.49 & $8.49 \%$ & $125.76 \%$ & 105.40 & $6.37 \%$ & $75.32 \%$ & 102.3 & $1.31 \%$ & $128.71 \%$ \\
\hline 2004 & 117.97 & $8.74 \%$ & $134.50 \%$ & 104.36 & $-0.01 \%$ & $75.31 \%$ & 105.0 & $1.69 \%$ & $130.40 \%$ \\
\hline 2005 & 123.43 & $4.63 \%$ & $139.13 \%$ & 103.71 & $0.35 \%$ & $75.66 \%$ & 108.6 & $2.42 \%$ & $132.81 \%$ \\
\hline 2006 & 127.64 & $3.41 \%$ & $142.53 \%$ & 103.80 & $1.06 \%$ & $76.72 \%$ & 112.1 & $2.25 \%$ & $135.07 \%$ \\
\hline 2007 & 134.39 & $5.29 \%$ & $147.83 \%$ & 104.23 & $1.39 \%$ & $78.10 \%$ & 115.3 & $1.88 \%$ & $136.94 \%$ \\
\hline 2008 & 131.79 & $-1.94 \%$ & $145.89 \%$ & 104.21 & $0.95 \%$ & $79.05 \%$ & 119.7 & $2.87 \%$ & $139.81 \%$ \\
\hline 2009 & 137.27 & $4.16 \%$ & $150.05 \%$ & 106.74 & $3.40 \%$ & $82.46 \%$ & 119.3 & $-1.33 \%$ & $138.48 \%$ \\
\hline 2010 & 152.68 & $11.23 \%$ & $161.28 \%$ & 109.23 & $3.31 \%$ & $85.76 \%$ & 121.2 & $0.67 \%$ & $139.15 \%$ \\
\hline 2011 & 155.74 & $2.00 \%$ & $163.28 \%$ & 109.55 & $1.26 \%$ & $87.02 \%$ & 125.0 & $2.18 \%$ & $141.33 \%$ \\
\hline
\end{tabular}

Table 12 Allocated Data 1/4 Participation: OPH, rAAC and CPI 1970 - 2011

(U.S. Bureau of Labor Statistics 2010) 


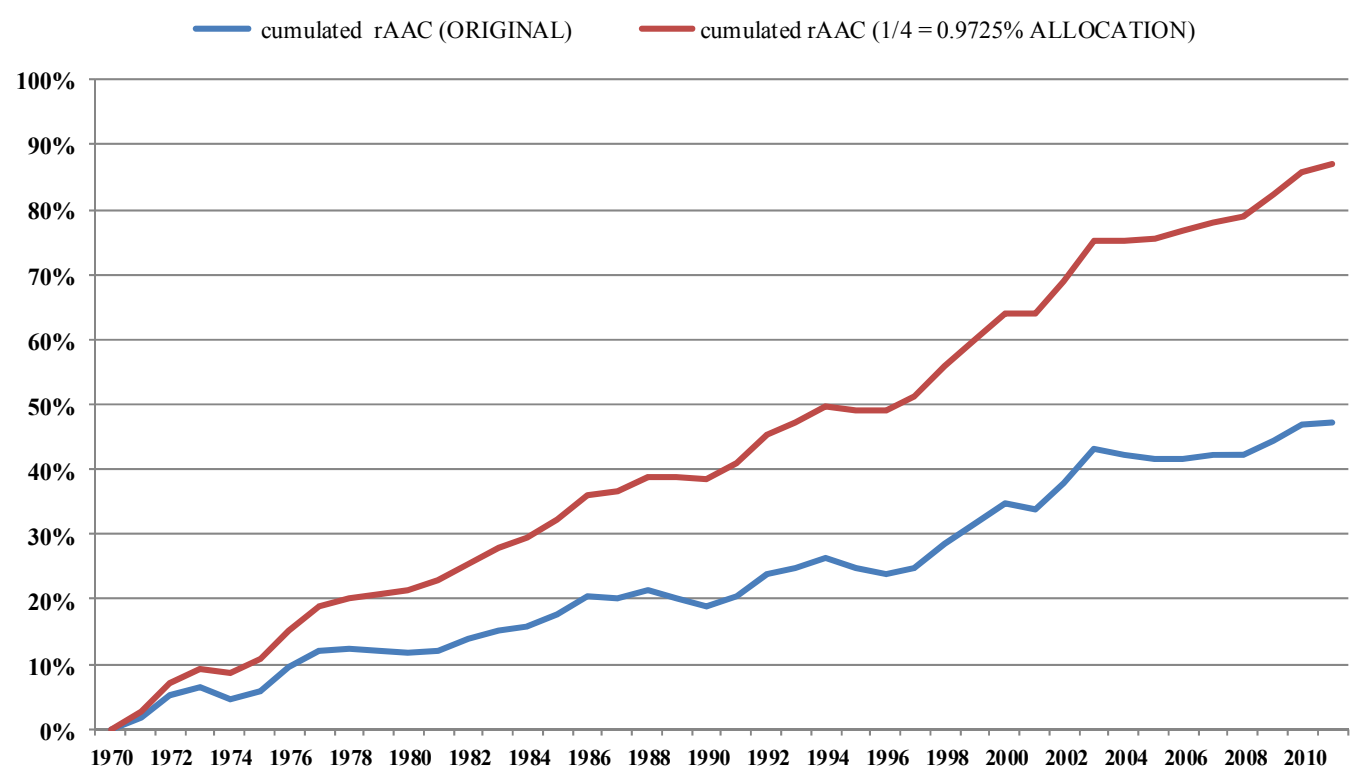

Figure 23 Development rAAC (1/4 allocation) 1970-2011

(U.S. Bureau of Labor Statistics 2010)

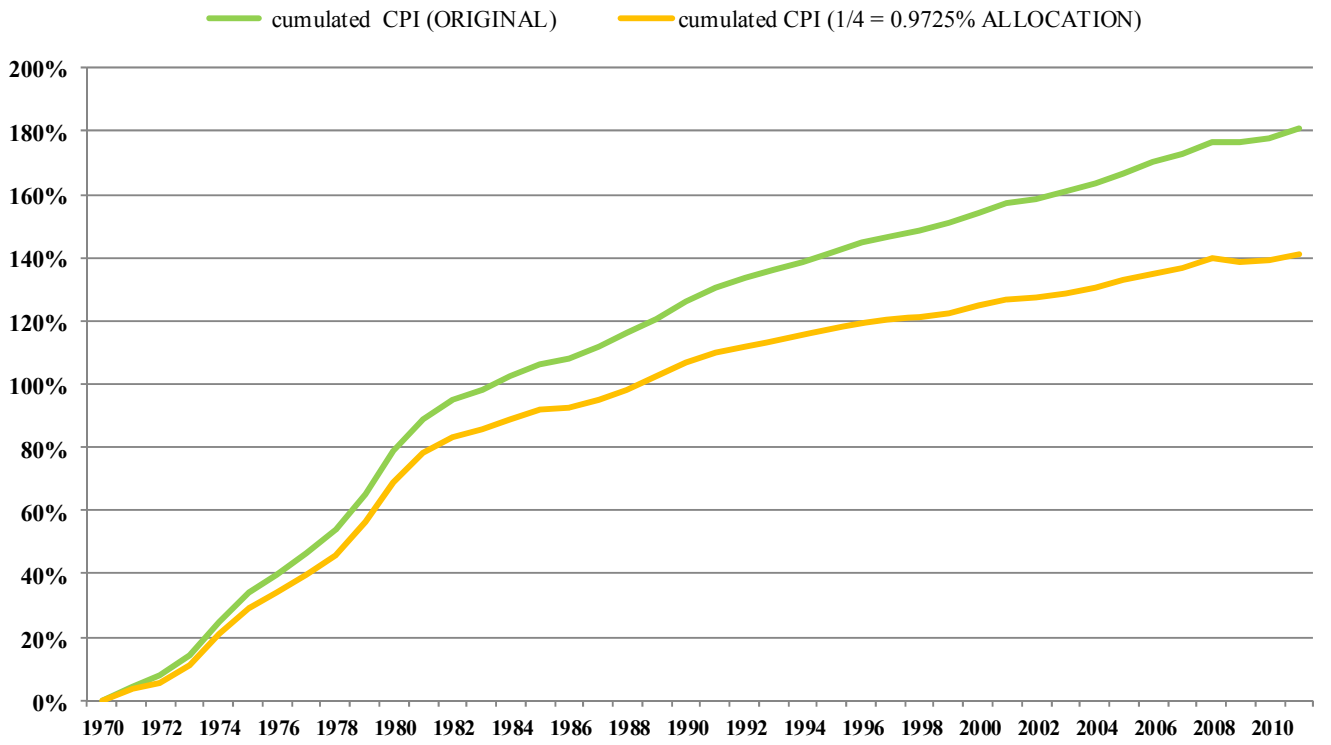

Figure 24 Development CPI (1/4 allocation) 1970-2011

(U.S. Bureau of Labor Statistics 2010) 
A direct comparison shall show the sensitivity analyze in a more detailed view.

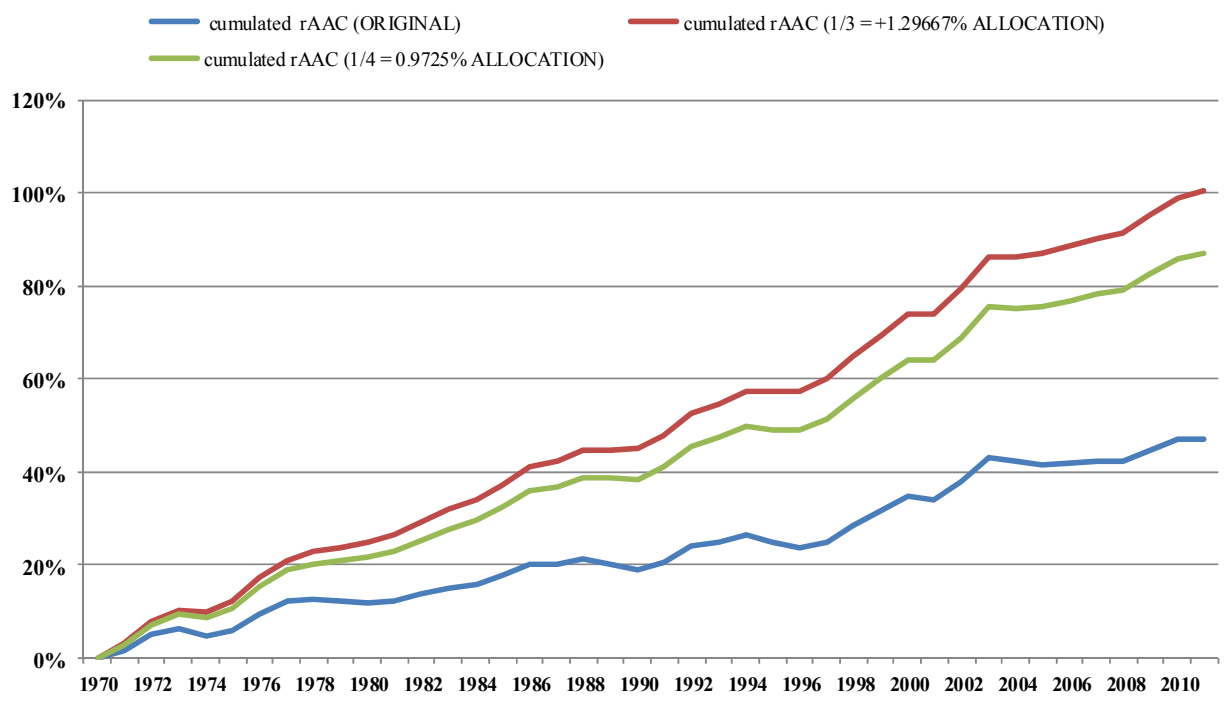

Figure 25 Comparison Original, 1/3 Allocated and 1/4 Allocated rAAC 1970 - 2011

(U.S. Bureau of Labor Statistics 2010)

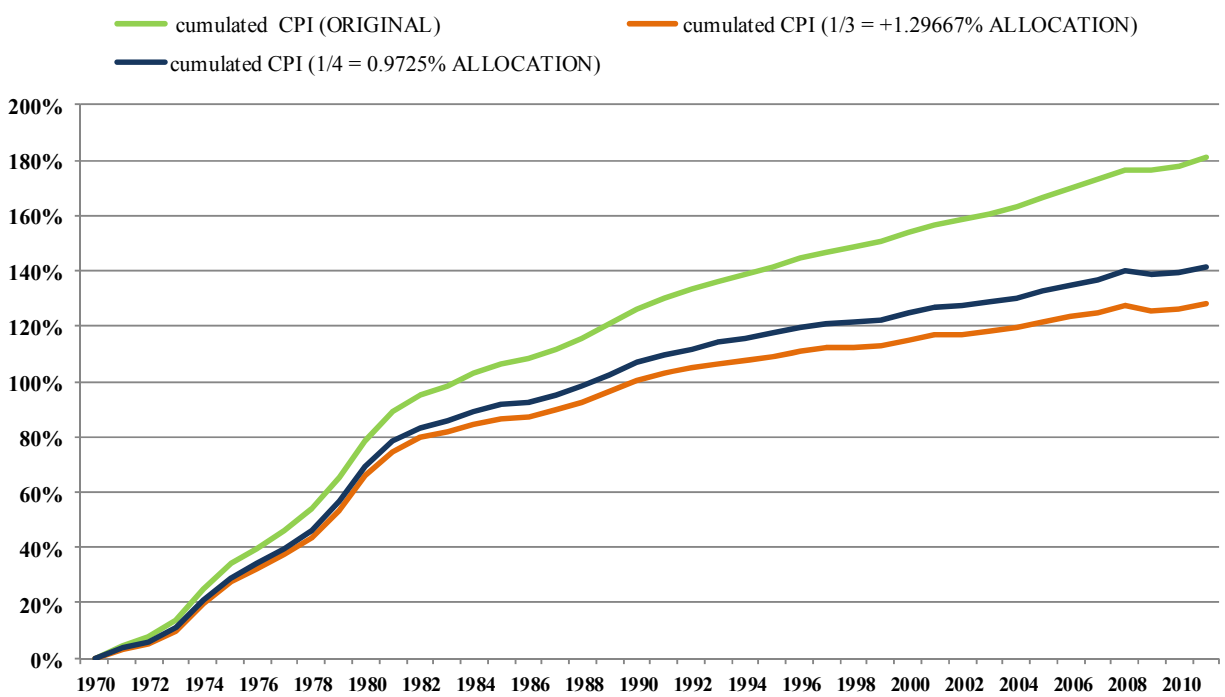

Figure 26 Comparison Original, 1/3 Allocated and 1/4 Allocated CPI 1970 - 2011

(U.S. Bureau of Labor Statistics 2010) 
It is show above that each kind of share distribution will affect the rAAC and CPI. The quantity of each single allocation has direct influence on the effect. Nevertheless, each allocation contributes to achieve benefit in this illustrated model. The sensitivity analyze shows convincingly how the allocations process behaves in the development and contributions the share participation.

It is immediately clear how wages and price index equalize in such a model. The massive asymmetrical development of real wages to labor productivity would be prevented. The additional benefit of the declining prices would result in a double effect. At the same time lower prices and higher real income, leads to an effect of an increased demand and will turn the strengthening of the production and distribution channels. Possible initial disadvantages incurred due to reduction of capital expansion side can thus compensated medium and long term.

The direct comparison of the models shows that a steady balanced distribution of additional productivity clearly leads to an increase and positive sustainable development for the economic sector - over a longer period.

Individual successes of such effects can be shown to find already at Henry Ford. Through successful growth of productivity the company the increase the labor wages in a second step. Would now the model be consistent optimization in the third element by lowering the prices the model would have had already sustained successful implemented at Ford. 


\section{CONCLUSIONS}

Productivity probably already existed since the beginning of mankind. It is clear, that the major and most influential development that was happening in the past 250 years in the area of labor productivity is the foundation of today's wealth and standard of living. Without any labor productivity and the associated economic growth it is not possible to have any increase or to meet the challenges in the international context.

The examination of the productivity approaches of the outstanding pioneers has shown that there are both individual and common influencing factors that are forming a basis. In addition to that the subsequent analyze of the development of the increase in productivity clearly showed in comparison to the growth rates of the actual wage increase that there are influencing factors that allow an increase in productivity, but this increase in productivity is an asymmetrical increase when compared with the wage development.

The basis for growth and each and every increase of the productivity can always be traced back on the human element. It is the human being - the worker or the employee - that introduces or implements the necessary steps for any improvement and optimization of working steps or working processes. Therefore it is no wonder, that all the key elements of the examined personalities can be traced back on the human element.

It is a fact that there was an asymmetrical development of the actual employee's wages (rAAC) since the beginning of the era of Post-Fordism in the early 1970s when compared with the increases in productivity (rOPH). The results of this gap for the asset 
situation and the distribution of wealth were already examined in various other studies. Building a Better America - this study that was published in the year 2011 clearly shows the imbalance of the distribution of wealth. (Norton and Ariely 2011)However, it might be the wrong action to introduce redistribution by burden the rich part of the population. Already at the beginning of the 20th Century William J. H. Boetcker warned not to burden the rich for the benefit of the poor - "You cannot help the poor by destroying the rich”. (Lader 2009)

The analyze of the key elements showed that the human element always plays the decisive role both for the productivity and the increase in productivity. All factors can be traced back to the human being.

The further analyze of the productivity growth rates in relation to the real wage increases since Post-Fordism shows - and this is even more astounding - that the modern development of the increase in productivity gaps in such a great way with respect to the growth rates of the real earnings. Bearing in mind the influences of this development on the debt ratio of the individual economies, it would be interesting to carry out another study to examine the interactions and correlations of the debt ratio of the individual nations and the development of the real earnings and the productivity growth rates.

At this point, the question must be asked: what will labor productivity look like in the future? What are the approaches to the challenges of modern times, the changed internal and external requirements, and the continually evolving framework conditions and how are these factors dealt with to be able to act in efficient, economic and - above all - productive ways in the future, both in the national and international context. For this 
high priority challenge there are three parties with corresponding responsibility for this task.

(1) The Industrial Engineer,

(2) the Industrial Manager and

(3) the Society.

The role of the Industrial Engineer in future productivity gains will be the same as it has been for the last century; namely, in the design of safe, efficient, effective and productive work. This role was established by none other than Frederick W. Taylor himself when, in 1908 at the behest of the then governor of Pennsylvania, General Beaver, Taylor recommended that an academic department of Industrial Engineering be formed at The Pennsylvania State College. That department was formed in 1909 and remains the oldest continually operating department of Industrial Engineering in the US.

Recent studies have shown that the area of work design remains the single most important area of work activity for the Industrial Engineer. Although such areas as operations research, manufacturing systems, statistical analyze, and logistics systems have emerged as perhaps more quantitatively challenging areas of IE work activity, work design and by its other names work measurement and methods and human factors engineering remain as the classical areas of IE activity. So the IE's role is to ensure the continuation of a healthy and robust growth in productivity gains in the workplace.

Furthermore if the role of the Industrial Engineer remains a staunch continuation of the philosophy of Frederick W. Taylor, the role of the Industrial Manager becomes that 
of Henry Ford. That is, the industrial worker should participate in the financial gains that derive from his (her) productivity gains in order to better participate in the economy. Both Taylor's developments (Taylorism) and Ford's (Fordism) were marked by the parallel growth of productivity gains and increases in labor wages that persisted for most of the $20^{\text {th }}$ century.

While Barnard was not nearly as forceful as Taylor and Ford in this parallel development, his company AT\&T was. The Hawthorne studies at the Western Electric facility of AT\&T were hugely successful in advancing the science of motivation, in which workers were motivated to improve their productivity. Barnard stressed motivation as a means of having workers become willing to accept the goals of the organization, among them productivity improvement, with the obvious implication that all employees would benefit from such improvement.

Also the society should explicitly expect the participation of industrial workers in the fruits of their labors. This can only be managed in a democratic society through representative government; that is, citizens must make the worker's role in the free enterprise marketplace a priority. This can only be managed through "getting the message out" in free elections. The public has to be made to see that productivity gains benefit all. 


\section{REFERENCES}

Balkhausen, D. (1984). Die dritte industrielle Revolution. Wie die Mikroelektronik unser Leben verändert. München, Econ Verlag.

Barnard, C. I. (1968). The Functions of the Executive. Cambridge Massachusetts, London England, Harvard Univeersity Press.

Becker, H. (2006). Phänomen Toyota Berlin, Springer.

Blanchard, O. and G. Illing (2009). Makroökonomie München, Pearson Studium.

Brynjolfsson, E. and S. Yang (1996). "Information Technology and Productivity: A Review of the Literature." Advances in Computers 43: 179-214.

Burt, D. S. (2001). The Biography Book: A Reader's Guide to Nonfiction, Fictional, and Film Biographies of More Than 500 of the Most Fascinating Individuals Oryx Press.

Butler, E. (2001). The Condensed Wealth of Nations and The Incredibly Condensed Theory of Moral Sentiments. London, Adam Smith Research Trust.

Cobet, A. E. and G. A. Wilson (2002). "U.S. and Foreign Labor Productivity Comparing 50 years of labor productivity in U.S. and foreign manufacturing." International Labor Comparisons (ILC) program June 2002: 65. 
Copley, F. B. (1923). Frederick Winslow Taylor: Father of Scientific Management New York and London, Harper and Brothers.

Czernich, N., O. Falck, et al. (2009) Broadband Infrastructure and Economic Growth. CESIFO WORKING PAPER 2861,

Drew, J., B. McCallum, et al. (2005). Unternehmen Lean: Schritte zu einer neuen Organisation München, Campus Verlag.

EUKLEMS (2011). Growth and Productivity Accounts, European Commission, Research 6th Framework Programme, Priority 8, "Policy Support and Anticipating Scientific and Technological Needs" and as part of the 7th Framework Programme, Theme 8: Socio-Economic Sciences and Humanities, Grant Agreement no: 225281 .

Fayol, H. (1969). Gemeral and Industrial Management. London, Sir Isaac Pitman and Sons.

Ford, B. R. (2002). Friends, Families \& Forays: Scenes from the Life and Times of Henry Ford. Detroit, Wayne State University Press.

Ford, H. (2006). My Life and Work, Filiquarian Publishing.

Friedmann, G. (1959). Grenzen der Arbeitsteilung. Frankfurth Main, Europäische Verlagsanstalt

Friedmann, T. L. (2007). The World is Flat: The Globalized World in the Twenty-first Century: A Brief History of the Globalized World in the Twenty-First Century Penguin Books Limited

Friedrich, A. (1924). Henry Ford der König der Autos und der Herrscher über die Seelen. Berlin, Neuer Deutscher Verlag. 
Gargallo-Castel, A. and C. Galve-Górriz (2007). "Information Technology, Complementarities and Three Measures of Organizational Performance: Empirical Evidence from Spain." Journal of Information Technology Impact 7(1): 43-58.

Gienke, H. and R. Kämpf (2007). Produktionsmanagement: Organisation, Konzepte, Controlling. München, Carl Hanser Verlag

Handelsblatt (2005). Die bedeutendesten Management Vordenker. Frankfurt/Main, Campus Verlag.

Hebeisen, W. (1999). F.W. Taylor und der Taylorismus. Über das Wirken und die Lehre Taylors und die Kritik am Taylorismus. Zürich, vdf Hochschulverlag

Henry-Ford-Heritage-Association (2012). " "The Ford Story." from http://hfha.org/HenryFord.htm

Héron, A. (1976). Der Taylorismus: Grundsätze, Methoden, Doktirn. Berlin, Rotbuch.

Hirsch, J. (1995). Der nationale Wettbewerbsstaat. Staat, Demokratie und Politik im globalen Kapitalismus. Berlin, Id-Verlag.

Hirsch, J. (2005). Materialistische Staatstheorie: Transformationsprozesse des kapitalistischen Staatensystems. Hamburg, VSA Verlag.

Hughes, T. P. (1991). Die Erfindung Amerikas: Der technologische Aufstieg der USA seit 1870. München, Beck.

Kennedy, C. (1998). Management Gurus 40 Vordenker und ihre Ideen. Wiesbaden, Gabler Verlag. 
Kieser, A. (2006). Organisationstheorien Stuttgart, Mark Ebers.

Kirchler, E. (2008). Arbeits- und Organisationspsychologie Wien, Facultas Verlag.

Kosak, F. (2006). Eckpunkte der Verwaltungstheorie nach Fayol in kritischer Diskussion. Potsdam, Universität Potsdam: 17.

Krause, W., K.-H. Graupner, et al. (1989). Ökonomenlexikon. Berlin, Dietz Verlag.

Kretschmer, T., M. Cardona, et al. (2012). IKT und Produktivität: Fahrplan durch die empirische Forschung.

Kretschmer, T. and T. Strobel (2012) IKT und Produktivität: Identifikation und Beitrag des IKT-Effekts in der empirischen Forschung. 65, 17

Kurz, H.-D. (1990). Adam Smith(1723-1790): Ein Werk und seine Wirkungsgeschichte. Marburg, Metropolis.

Kurz, H. D. (2008). Klassiker des ökonomischen Denkens 01: Von Adam Smith bis Alfred Marshall München, Beck Verlag.

Lader, C. (2009). Painless American History. New York, Barrons Educational Series Inc.

Liker, J. (2004). The Toyota Way: Fourteen Management Principles from the World's Greatest Manufacturer New York, Mcgraw-Hill Professional.

Lüchinger, R. (2009). Die zwölf wichtigsten Ökonomen der Welt: Von Smith bis Stiglitz Zürich, Orell Fuessli Verlag.

Marx-Engels-Lenin-Institut (1971). Karl Marx Chronik seines Lebens in Einzeldaten Frankfurt am Main, makol Verlag. 
Marx, K. (1867). Das Kapital. Köln, Anaconda Verlag.

Mehta, P. (1989). "MIT releases study on productivity." The Tech 109(22): 1.

Miller, J. (1922). The Amazing Story of Henry Ford: The Ideal American and the World's Most Famous Private Citizen; a Complete and Authentic Account of His Life and Surpassing Achievements, M. A. Donohue \& Company.

Miner, J. B. (2006). Organizational Behavior 3: Historical Origins, Theoretical Foundations, and the Future New York, Sharpe Inc.

Morgan, R. (2008). The German Social Democrats and the First International: 1864-1872 London, Cambridge University Press.

Norton, M. I. and D. Ariely (2011). "Building a Better America--One Wealth Quintile at a Time." Perspectives on Psychological Science 6: 9.

Norton, M. I. and D. Ariely (2011). Building a Better America--One Wealth Quintile at a Time, Sage Publications.

Ohno, T. (1998). Toyota Production System: Beyond Large-Scale Production. New York, Productivity Press.

Picot, A. (1986). Das Bildungswesen in der dritten industriellen Revolution München, Ehrenwirth Verlag.

Piller, F. T. (1998). "Das Produktivitätsparadoxon der Informationstechnologie." WiSt 27 257-262.

Potthoff, H. and S. Miller (2002). Kleine Geschichte der SPD. Bonn, Dietz Verlag. 
Raff, D. M. G. and L. H. Summers (1987). "Did Henry Ford Pay Efficiency Wages?" Journal of Economics 5: 57-86.

Sapru, R. K. (2006). Administrative Theories And Management Thought. New Delhi, PHI Learning Pvt.

Schachter, H. L. (1989). Frederick Taylor and the Public Administration Community: A

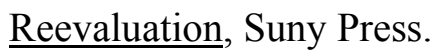

Scott, W. G. (1992). Chester I. Barnard and the guardians of the managerial state. Kansas, University Press of Kansas.

Shores, E. L. (2003). Henry Ford: A Photo-Illustrated Biography Minesota, Bridgestone Books.

Skousen, M. (2007). The Big Three in Economics: Adam Smith, Karl Marx, and John Maynard Keynes. New York, M E Sharpe Inc

Smith, A. (2009). Der Wohlstand der Nation. München, Deutscher Taschenbuch Verlag.

Steinkühler, M. (1995). Lean Production - Das Ende der Arbeitsteilung?. München, Rainer Hampp Verlag.

Taylor, F. W. (1998). The Principles of Scientific Management. New York, Institute of Industrial Engineers

Taylor, F. W. (2004). Die Grundsätze wissenschaftlicher Betriebsführung: The Principles

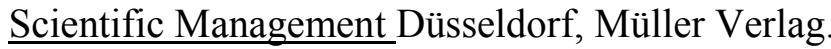

The Conference Board (2011). Total Economy Database. 
Timmer, M. P., R. Inklaar, et al. (2012). Economic Growth in Europe - A Comparative Industry Perspective. Cambridge Cambridge University Press.

Toyota (2010). Toyota Production System and what it means for business, Toyota.

Trahair, R. C. S. (1994). From Aristotelian to Reaganomics: A Dictionary of Eponyms with Biographies in the Social Sciences Westport, Greenwood Press.

U.S. Bureau of Labor Statistics (2010). International Comparison of Labor Productivity and Unit Labor Cost Trends. Washington, D.C., Bureau of Labor Statistics.

Volker (1996). „Wirtschaftswunder“ - Weltmarkt - westdeutscher Fordismus. Der Fall Volkswagen. Münster, Westfälisches Dampfboot

Walton, M. (1988). The Deming Management Method Berley Publishing Group

Watts, S. (2006). The People's Tycoon: Henry Ford And the American Century. New York, Vintage Books.

Weitz, B. O. (2008). Bedeutende Ökonomen Oldenburg, Oldenbourg Wissenschaftsverlag

Witzel, M. (2003). Fifty Key Figures in Management. New York, Routledge Chapman \& Hall

Wolf, W. B. (1961). "Chester I. Barnard (1886-1961)." Academy of Management Journal 4: $167-173$.

Wolf, W. B. (1973). Conversations with Chester I. Barnard. New Yord, School of Industrial and Labor Relations, Cornell University Press. 
Womack, J. P., D. T. Jones, et al. (1991). The Machine That Changed the World: The Story of Lean Production Ney York, Simon \& Schuster

Womack, J. P., D. T. Jones, et al. (1997). Die zweite Revolution in der Autoindustrie München, Heyne

Wren, D. A., A. G. Bedeian, et al. (2002). "The foundations of Henri Fayol's administrative theory." Management Decision 40/9: 912.

Znoj, P. D. H. (2007). Anthropologie der Arbeit: Taylorismus, Fordismus und PostFordismus. Bern. 


\section{APPENDIX}

Appendix A Short biography Adam Smith $1723-1790$

Appendix B $\quad$ Short biography Karl Marx 1818 - 1883

Appendix C Short biography Frederick W. Taylor 1856-1915

Appendix D Short biography Henri Fayol 1841 - 1925

Appendix E Short biography Chester I Barnard 1886 - 1961

Appendix F Short biography Henry Ford $1863-1947$

Appendix G List of Abbreviations 


\section{APPENDIX A}

\section{Short biography Adam Smith 1723 - 1790}

Adam Smith was a Scottish philosopher of the Enlightenment. He was born at the beginning of the 18th century in 1723 in Kirkcaldy (Scotland). The exact date of birth is still unknown. His father of the same name was lawyer and customs official in Kirkcaldy. His mother was the daughter of a wealthy landowner. His father died before he was born and Adam Smith grew up alone with his mother Margret Douglas. (Lüchinger 2009)

Due to his family environment and his ancestry he was able to begin his studies at Glasgow University at the early age of 14 . This was nothing unusual in the 18th century. During 1737-1740 he was taught Greek, Math, Latin and Moral Philosophy. (Weitz 2008) Especially the lectures in moral philosophy held by Francis Hutcheson 1694-1746 the most well-known representative of the Scottish Enlightenment of his time - should have influenced young Smith early in his youth. Hutcheson was said to be one of the greatest masterminds in the areas of ethics and economics of this time. (Weitz 2008) Subsequently, Adam Smith continued his studies in 1740 in the field of philosophy at Balliol College in Oxford, graduating in the year of 1746. After returning to Kirkcaldy he was appointed professor for moral philosophy at Glasgow University at the age of 28 years. He retired in 1763. (Weitz 2008) After his teaching Adam Smith went on educational travels in the same year. Till 1766 he visited France and Switzerland. During 
these travels he met Jacques Turgot and François Quesnay. Their theories of Enlightenment and physiocracy certainly also influenced Adam Smith. (Lüchinger 2009) After his return he became customs commissioner in the year 1778. (Kurz 1990) In addition to his work he spent his time on the study of philosophy. (Krause, Graupner et al. 1989)

His whole life Adam Smith had a very deep relationship with his mother, since he grew up without a fatherly attachment figure and next to his career he mainly devoted his life to the studying and teaching of ethics and moral philosophy. (Kurz 1990) Adam Smith died on the 17th of July 1790 at the age of 67 in Edinburgh. (Lüchinger 2009)

Adam Smith already got famous with his first publication "Theory of Moral Sentiments" dating 1759. It brought him to international attention and reinforced his reputation as a moral philosopher. He also was incorporated in the Royal Society of London for Improving Natural Knowledge in 1773. The Royal Society of London is known as the oldest society that is dedicated to science and research and it was founded already in 1660 by King Charles II. (Krause, Graupner et al. 1989)

His main work up to this day is An Inquiry into the Nature and Causes of the Wealth of Nations that was recognized to be a basic work in economics and that was published in 1776. (Skousen 2007) His paper on the national economy mainly describes cause and distribution of wealth of his time and it changed the point of view of his contemporaries that were heavily influenced by mercantilism back then. Smith was a representative of free competition and he created an economic model based on selfinterest and free trade. (Lüchinger 2009) Smith's work marks the beginning of the classical national economy and the economic liberalism. 


\section{APPENDIX B}

\section{Short biography Karl Marx 1818 - 1883}

Karl Marx as well as Adam Smith were sons of well-respected and important families of their time. Karl Marx was born in 1818 in Trier (Germany) and his father was a lawyer and interpreter. (Kurz 2008)

Because of this family background young Marx was able to visit secondary school from 1830 to 1835. (Marx-Engels-Lenin-Institut 1971) After his education in school he enrolled at Trier University to study law. He soon changed university and went to the faculty of law at Berlin University where his interest in philosophy and history was aroused and he joined the Young Hegelian Movement. (Marx-Engels-Lenin-Institut 1971) The biggest influence on Karl Marx most likely have been this period of time and the encounter with other philosophers critical of religion and the system. The important topics for the so-called "Club of Doctors" was the observation and the solving of the current and prevailing problems such as poverty and social injustice. In 1841 Marx obtained his PhD with his paper Differenz der demokritischen und epikureischen Naturphilosophie at Jena University. (Kurz 2008) Just like many of his fellow activists he was not able to accomplish an academical career due to his participation in the Young Hegelian Movement. Subsequently, Karl Marx caused a sensation with his work as an editor at the "Rheinische Zeitung" until the newspaper was censored by the politics in 
1843. (Marx-Engels-Lenin-Institut 1971) In the same year, Marx married his fiancée Jenny von Westphalen. This marriage resulted in seven children. (Marx-Engels-LeninInstitut 1971)

It was in the same year of 1843 that Marx moved to Paris (France) together with his family to further his career and to publish his writings. (Marx-Engels-Lenin-Institut 1971) His greatest hope was to be supported by the French Socialist Group. In Paris he began to develop his early ideas and steps with respect to the prevailing political economy. His point of view was reinforced by the fact that he met new people like Heinrich Heine and Friedrich Engels; both were politically active critics of this time. After another critical writing about the prevailing political social structure Prussia forced Marx to leave France and he had to go to Brussels in 1845. This, however, did not prevent him from working as a publicist. (Kurz 2008) Due to the political changes in France and Germany at that time, Marx finally was forced to go into exile to London in 1849. Besides his journalistic work Marx spent his time to criticize capitalism as well as the development and distribution of his socio-political point of view. Starting 1852, Karl Marx worked as a correspondent for the New York Tribune for almost ten years. (Krause, Graupner et al. 1989)

Marx died in London in 1883. His whole life - as well as the whole life of his family - was devoted to the ideas and the distribution of his theories that were critical of market and society. (Marx-Engels-Lenin-Institut 1971)

His published works attracted great and sometimes critical attention already during his lifetime. Especially after 1843 he wrote many theories on religion, society and the philosophy of economics. These works were published by Marx alone or in 
collaboration with other authors - e.g. Friedrich Engels. During this time, most likely one important idea has developed: the social and economic theory that is better known as Marxism. Without a doubt, the biggest influence that is highly controversially discussed up to the present time is his paper "The Capital - Volume 1" of 1867. It was a further development of his critique on political economy written in 1859. Already the first edition was printed 1000 times. (Marx-Engels-Lenin-Institut 1971)

During his whole life Karl Marx was active in creating his theory and the actual practice of his theory. In co-operation with Engels he founded the "Communist Correspondence Committee“ (Kommunistische Korrespondenz-Komitee) in 1846. The aim was to promote the revolutionary movement of the proletariat. (Krause, Graupner et al. 1989) One year later, the "Communist League" (Bund der Kommunisten) was founded and it resulted in the famous "The Communist Manifesto" (Das Kommunistische Manifest) at the end of 1847/beginning of 1848. (Marx-Engels-Lenin-Institut 1971) In 1864 Marx was actively involved in the foundation of the "International Workingmen's Association" (Internationale Arbeiterassoziation) in London. (Morgan 2008)

In 1869, the predecessor of the present day "Social Democratic Party of Germany" (SPD - Sozialdemokratische Partei Deutschlands) was founded: the "Social-Democratic Labor Party" (Sozialdemokratische Arbeiterpartei). (Potthoff and Miller 2002) 


\begin{abstract}
APPENDIX C
Short biography Frederick W. Taylor 1856-1915

Frederick Winslow Taylor as well as Adam Smith and Karl Marx were sons of wealthy families. Frederick Winslow Taylor was born in 1856 in Germantown, USA. His father (Franklin Taylor) was a rich lawyer. (Hebeisen 1999) Already as a pupil young Taylor got into contact with "little time studies". His math teacher at that time analyzed the duration of time the pupils needed to complete individual math calculations and used his results to derive the homework of the pupils. (Hebeisen 1999)
\end{abstract}

To get the admission to study at Harvard University, F. W. Taylor daily went to the Phillips Exeter Academy in New Hampshire in 1872. Despite his successful graduation with honors he was never able to study law in Harvard, because he got ill. (Copley 1923) That was why his first contact with the industrial environment was an apprenticeship as pattern maker and machinist at Enterprise Hydraulic Worcs in Philadelphia. In 1878 he changed career to Midvale Steel and quickly made a name for himself. In 1884 he was promoted to the position of chief engineer. Due to his talent and intelligence he managed to complete his engineering studies at the Stevens Institute of Technology (1880-1883) while simultaneously working at Midvale Steel. He graduated as mechanical engineer. (Copley 1923) 
In 1890 he changed career again to work at Manufacturing Investment Company. In 1893 there was one of his most interesting steps in his career. His employment contract was not renewed. Frederick W. Taylor decided to work independently as managementconsultant. He was one of the first persons in history who did this. (Handelsblatt 2005)

Due to his success and because he was wildly known at that time, the Bethlehem Steel Company hired him to help them solve the machine shop capacity problems. It was during this period of time that he was able to realize his theories in various time studies. An example is the famous Taylor-Shovel-Study where he observed individual workers shoveling material and recorded the duration of time they needed for this task.(Taylor 2004)

Because of his theory and the respective basic rules and aspects with respect to productive work soon there were intolerable conflicts with the management of Bethlehem Steel Co. resulting in Taylor's dismissal in 1901. (Hebeisen 1999)

Subsequently, Taylor's professional main emphasis was on his theory and publications. Besides lectures and several publications Frederick W. Taylor finally got to Harvard University. From 1909 to 1914 he taught scientific management in Harvard. (Copley 1923) In 1906 he was awarded the honorary doctorate of the University of Pennsylvania and in 1912 he was awarded the honorary doctorate of the Hobart College. (Copley 1923) He refused to accept presidency of the famous Massachusetts Institute of Technology MIT to be able to work on his theories and papers full-time. (Hebeisen 1999)

Frederick W. Taylor died in 1915 in Pennsylvania at the early age of 59 years. (Copley 1923) Besides his $\mathrm{PhD}$, Taylor already was brought to international attention in 
the year 1900 at the world exhibition in Paris presenting his Taylor-White-Processes for the hardening of steel. (Hebeisen 1999) He got internationally recognized not only in his own professional field by publishing his studies and first of foremost by his publication "Shop Management" of 1903 and "The Principles of Scientific Management" of 1911. (Hebeisen 1999) 


\section{APPENDIX D}

\section{Short biography Henri Fayol 1841 - 1925}

Henri Fayol, son of French parents, was born in 1841 in the nowadays Istanbul area. His father was an engineer and after he had completed his bridge building project he returned back to France in 1847. (Witzel 2003)

Young Fayol enrolled at the famous École National Supérieure des Mines in Saint-Étienne and graduated as mining engineer in 1860 at the age of 19.(Miner 2006)

After completing his studies be began working at the mining company Compagnie de Commentry Fouchambeau Dacazeville and he quickly made a career. In the year 1888 he became general manager and worked in this position until he went into retirement in 1918. (Handelsblatt 2005)

In 1925 Henri Fayol died at the age of 84 years. (Witzel 2003) Henri Fayol received great attention in 1916 when he published his knowledge and observations made during his professional career in his paper Administration Industrielle et Generale. Like F. W. Taylor it was the aim of Fayol's considerations to increase productivity and efficiency in the working environment. His approaches were rather aimed at the administration and organization in itself, whereas Taylor wanted to optimize the work to achieve as much output as possible. (Kirchler 2008) (Sapru 2006) 


\begin{abstract}
APPENDIX E
Short biography Chester I Barnard 1886 - 1961

Chester Irving Barnard was born on the 17th of November 1886 in a rural area in New England and is known as an outstanding personality in the field of management and organization theory up to the present day. (Trahair 1994)

Barnard studied economics at the University of Harvard. He quit university without graduating in 1909. (Wolf 1961) His professional career began at American Telephone and Telegraph, AT\&T where he spent a total of 39 years until he went into retirement. (Scott 1992) Chester I. Barnard died at the age of 76 in 1961. (Wolf 1973)

During his career at American Telephone and Telegraph - where he initially worked as a statistical clerk and finally was promoted to president of New Jersey Bell Telephone - he wrote many of his famous publications. (Wolf 1961)

- The Functions of the Executive (1938), Cambridge, Massachusetts:

(Harvard University Press)

- Organization and Management (1948), Cambridge, Massachusetts:

(Harvard University Press)
\end{abstract}




\section{APPENDIX F}

\section{Short biography Henry Ford 1863 - 1947}

Henry Ford was the son of a farmer and he was born in 1863 close by the town of Detroit, USA in Michigan. During his childhood he visited elementary school, which was common back then. It was already during these years that he discovered his interest in mechanics. (Shores 2003)

He was the oldest son of his parents' six children and since he had no interest whatsoever to work at his parents' farm he decided to get trained as a machinist in 1879 at F. Flower \& Brows and Detroit Dry Doch Company. After his apprenticeship he went on working at the Westinghouse Electric Corporation. During this time Ford also visited the Goldsmith, Bryant \& Stratton Business College in Detroit where he studied accounting. (Watts 2006)

Starting 1891 he worked as an engineer at the Edison Illuminating Company and was promoted to chief engineer only 2 years later. His occupational career and the rapid ascent enabled Henry Ford to mainly concentrate on combustion engines. (Henry-FordHeritage-Association 2012) This period of time in combination with his technical and

mechanical interests that became apparent in his childhood may be seen to be cornerstones for his subsequent successful career in the automotive industry. 
In 1896 his passion for technology and his experiments resulted in the development of a self-propelled vehicle called "Quadircycle". (Henry-Ford-HeritageAssociation 2012)

He was encouraged by this development and so he quit his job at Edison Illuminating Company and together with several partners he founded the Detroit Automobile Company in 1899. But Ford was not able to manufacture products that succeeded on the market. The reasons for this failure most likely were bad quality and prices that were too high. Therefore, the Detroit Automobile Company was forced to stop all entrepreneurial activities in 1901 - after less than three years after its foundation. (Henry-Ford-Heritage-Association 2012)

Henry Ford was not discouraged because of this failure and already two years later - in 1903 - with the help of investors and US\$28,000 in cash he founded the Ford Motor Company. In this company he worked as vice president and chief engineer. (Miller 1922) (Ford 2006)

With the development of the Ford T Model in 1908 and the implementation of the conveyor-belt for the manufacturing processes in 1913 Henry Ford laid the foundations for his entrepreneurial success and reinforced his significance for the industrial development. (Friedrich 1924)

Henry Ford died in 1947 at the age of 83, married and father of a son. (Ford 2002) 


\section{APPENDIX G}

\section{List of Abbreviations}

$\begin{array}{ll}\text { AT\&T } & \text { American Telephone \& Telegraph } \\ \text { GDP } & \text { Gross Domestic Product } \\ \text { ICT } & \text { Information and Communication Technology } \\ \text { JIT } & \text { Just-in-Time } \\ \text { MIT } & \text { Massachusetts Institute of Technology } \\ \text { OPEC } & \text { Organization of the Petroleum Exporting Countries } \\ \text { rAAC } & \text { real Average Annual Compensation } \\ \text { rOPH } & \text { real Output per Hour } \\ \text { SPD } & \text { Sozialdemokratische Partei Deutschland } \\ \text { TPS } & \text { Toyota Production System } \\ \text { US } & \text { United States }\end{array}$




\section{CURRICULUM VITAE}

\section{PERSONAL}

$\begin{array}{ll}\text { NAME: } & \text { Peter Brem } \\ \text { ADDRESS: } & \text { Rua Sansão Alves dos Santos, 343 / Brooklin } \\ & \text { CEP 04571-090 - São Paulo (SP) / Brazil } \\ \text { DOB: } & \text { Hirschau, Germany - March 14, 1979 }\end{array}$

\section{EDUCATION}

- Ph.D. Industrial Engineering, University of Louisville, 2013

"An Historical Perspective on Labor Productivity in the Modern Era"

Dissertation Director: Dr. William E. Biles

- Master of Science Industrial Engineering, University of Louisville, 2010

"Facility Layout - For a new production and warehouse area"

- Diplom Kaufmann, HFH Hamburg Germany, 2007

"Corporate Succession - Starting up Your Own Business" 